Western University

Scholarship@Western

Digitized Theses

Digitized Special Collections

1971

\title{
A Long Term Econometric Model Of The Canadian Economy With Emphasis On The Financial Sector: A Simulation Study Of Some Alternative Policy Rules
}

Michael Angus Walker

Follow this and additional works at: https://ir.lib.uwo.ca/digitizedtheses

\section{Recommended Citation}

Walker, Michael Angus, "A Long Term Econometric Model Of The Canadian Economy With Emphasis On The Financial Sector: A Simulation Study Of Some Alternative Policy Rules" (1971). Digitized Theses. 501.

https://ir.lib.uwo.ca/digitizedtheses/501 
The author of this thesis has granted The University of Western Ontario a non-exclusive license to reproduce and distribute copies of this thesis to users of Western Libraries. Copyright remains with the author.

Electronic theses and dissertations available in The University of Western Ontario's institutional repository (Scholarship@Western) are solely for the purpose of private study and research. They may not be copied or reproduced, except as permitted by copyright laws, without written authority of the copyright owner. Any commercial use or publication is strictly prohibited.

The original copyright license attesting to these terms and signed by the author of this thesis may be found in the original print version of the thesis, held by Western Libraries.

The thesis approval page signed by the examining committee may also be found in the original print version of the thesis held in Western Libraries.

Please contact Western Libraries for further information:

E-mail: libadmin@uwo.ca

Telephone: (519) 661-2111 Ext. 84796

Web site: http://www.lib.uwo.ca/ 


\title{
A LONG T ERM ECONOMET RIC MODEL OF THE
}

CANADIAN ECONOMY WITH EMPHASIS ON THE FINANCIAL SECTOR; A SIMULATION STUDY OF SOME ALT ERNATIVE POLICY RULES

\author{
by \\ Michael Angus Walker \\ Department of Econornics
}

\author{
Submitted in partial fulfillment \\ of the requirements for the degree of \\ Doctor of Philosophy \\ l.
}

Faculty of Graduate Studies

The University of Western Ontario

London, Canada

August 1970

(C) Michael Angus Walker 1971 


\section{ABST RACT}

The purpose of this study was to build a long-term econometric model of the Canadian economy and to use the model to simulate the effects on the economy of various monetary-policy rules.

The model consists of a financial sector and a real sector and totals 46 equations of which 26 are stochastic. The model differs from other long-term models of the Canadian economy in that the financial sector is endogenous. Limited-information estimation procedures of various sorts were used to obtain consistent estimates of the structural parameters. The model is a simultaneous system and utilizes market clearing conditions to determine some of the endogenous variables.

The model was tested for dynamic accuracy by a multi-period simulation run over the fitting period and for structural stability by a single-period forecast bey ond the fitting period. Extensive simulation and structural modification was carried out before the reported structure was arrived at. The final control solution and the final forecast are both reported.

Use of the model to simulate various policy rules indicated that although it is possible to achieve better performance under regimes of money-supply rules, interest-rate rules or a combination of the two the outcome is very sensitive to the rule chosen. An attempt is made to rank policy rules according to the effect which they had on the averige 
level, growth rate and stability of the simulated growth path of the Canadian economy over the period 1951-1966. The ranking obtained was found to be invariant with respect to random stocks imposed on the path of a principal exogenous variable. 


\section{ACKNOW LEDGMENT}

I would like to acknowledge and express my appreciation for the innumerable contributions which were made to this work by my parents and by my wife, Janet.

I would also like to thank Professor A. J. Wintermans and Professor T.J. Courchene for the guidance and assistance which they have provided at various stages in my training.

Appreciation must also be expressed to Professors T. M. Brown and T.J. Courchene who so conscientiously culled the small amounts of wheat from the vast amounts of chaff which my first efforts produced and to Professors T. R. Robinson, C. D. Hodgins, P. Kirkham and Professor E. Tanner who read the manuscript at various stages.

Financial support for the work which underlies the study was provided by the Woodrow Wilson Foundation, the Canada Council and the Ontario Government. The final drafts of the study were prepared while I was employed by the Research Department of the Bank of Canada which bears no responsibility for the views expressed.

The various drafts of the work were cheerfully and expertly typed by Miss B.J. MacAllister while Mrs. Margaret Gower provided able assistance in proofreading. 
TABLE OF CONT ENTS

page

Certificate of Examination ....................... ii

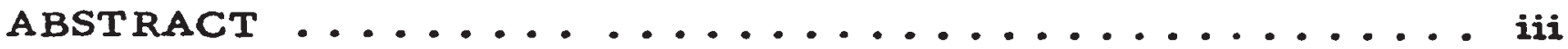

ACKNOWLEDG MENT ......................... v

TABLE OF CONTENTS ...................... vi

LIST OF TABLES .......................

CHAPTER I - AN OV ERVIEW ..................... 1

Introduction ........................ 1

Previous work ....................... 1

Design of the Model.................... 2

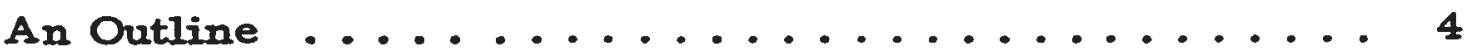

A Flow Chart of the Model ................. 4

CHAPTER II - THE FINANCIAL SUB-MODEL ........... 6

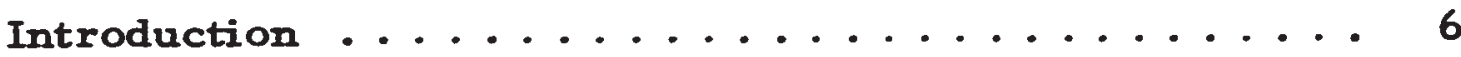

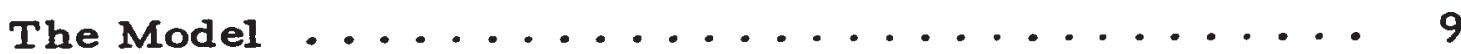

(i) Block One - High Powered Money ........ 9

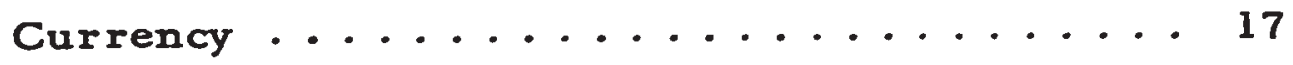

(ii) Block Two - Chartered-Bank Deposits...... 19

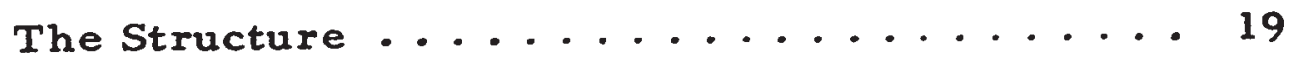

Personal Savings Deposits........... 23

Non-personal Term and Notice Deposits ... 25 
page

The Supply of Notice Deposits . . . . . . . . 28

The Demand for Demand Deposits ....... 30

The Supply of Demand Deposits ......... 32

(iii) Block Three - Bonds; the Term Structure .... 34

The Corporate Rate............. 34

The Government Rate ............ 39

(iv) Consumer Credit .............. 43

A PP ENDIX A CHAPTER II - DATA ............ 45

Units of Measure................... 45

A PPENDIX B CHAPTER II - DATA ............. 46

Sources and Procedures ................ 46

Expenditure and Income $\ldots \ldots \ldots \ldots . \ldots . \ldots 4$

Population, Employment, Wages ......... 51

Capital Stock ....................... 52

Monetary Series ................... 53

APPENDIX C CHAPTER II - METHODS OF ESTIMATION .... \$ 56

Parameter Estimation .................. 56

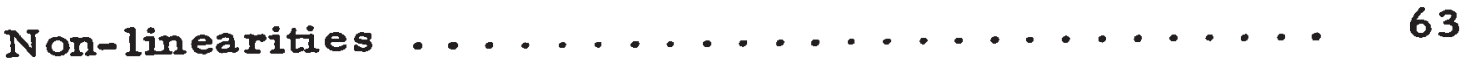

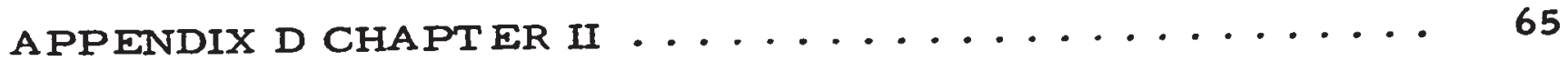

Lagged Variables and Structural Hypotheses ..... 65

APPENDIX E CHAPTER II ................. 67

Taylor Series Approximation ........... 67 
CHAPTER III - THE REAL SECTOR .............. 70

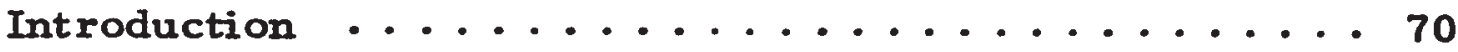

Private Sector Demand ............... 70

Consumption Expenditures .............. 71

Investment Expenditures .............. 72

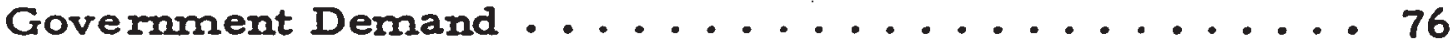

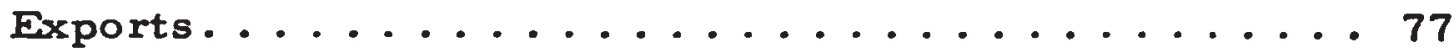

Aggregate Supply .................. 77

Prices and Miscellaneous Equations .......... 84

APPENDIX A CHAPTER III - PRODUCTION FUNCTIONS . . . . 86

CHAPTER IV - ASSEMBLING THE MODEL. ............90

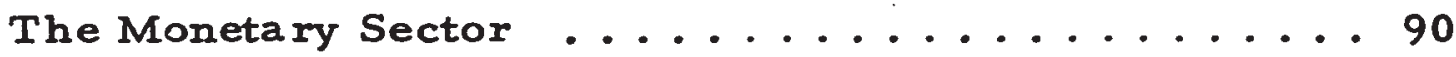

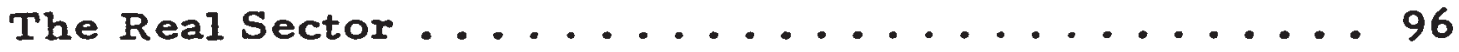

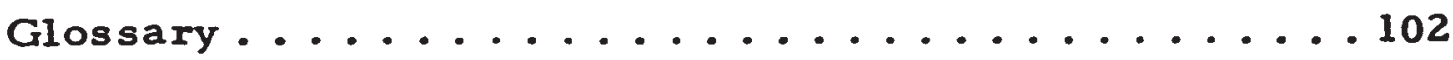

CHAPTER V - PRELIMINARY SIMULATIONS AND ST RUCTURAL

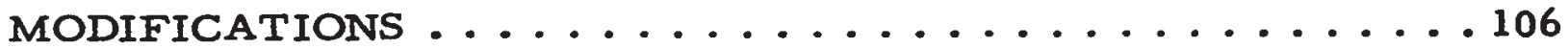

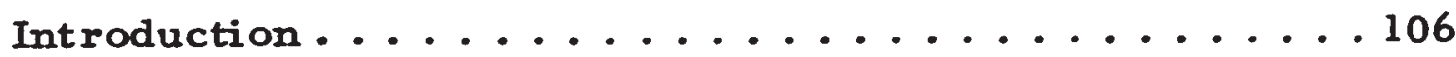

Monetary Dynamics ......................... 106

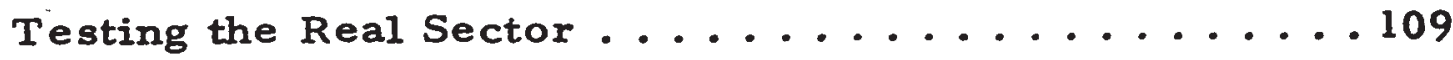

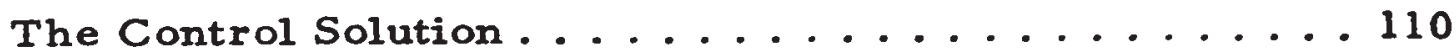

Predicting Beyond the Sample ........... 116

CHAPTER VI - POLICY SIMULATIONS . . . . . . . . . . 119

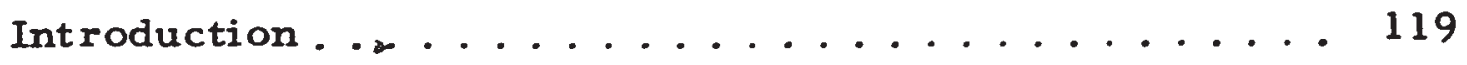


Some Technical Consideration ........... 119

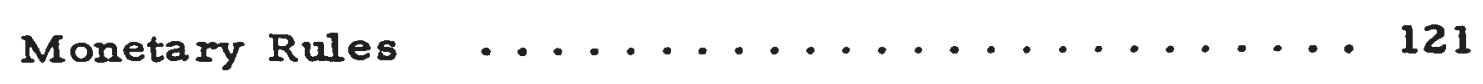

A Degression on the Neutrality of Money ........ 130

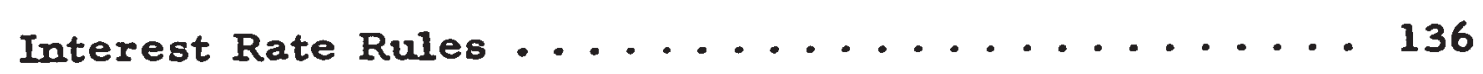

Compound Rules ...................... 140

Policy Response to Random Shocks . . . . . . . . . . . 143

Summary and Conclusions on Monetary Rules...... 145

APP ENDIX A CHAPT ER VI - A TABULAR SUMMARY OF THE

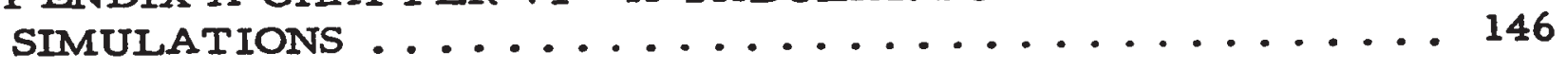

CHAPTER VII - SUGGESTIONS FOR FUTURE RESEARCH . . . . 169

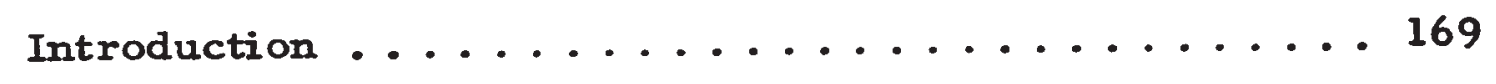

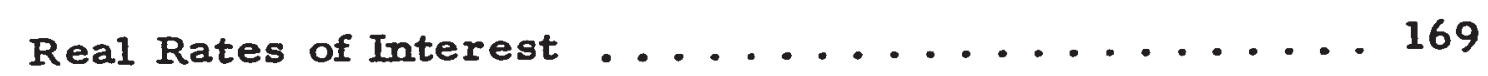

Prices and the Money Supply ............... 173

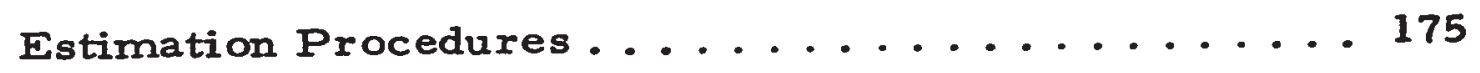

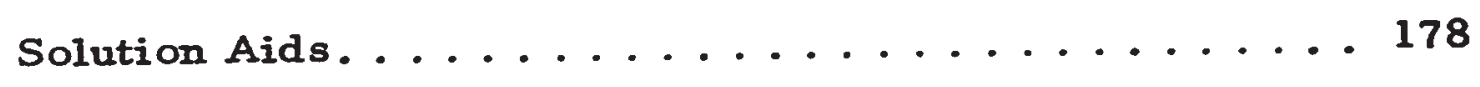




\section{LIST OF TABLES}

TABLE

page

V-1 Simulating the Fitting Period - Actual

Versus predicted values for $1967 \ldots$. . . . . . 117-118

VI- 1 Total Money Supply Including Government

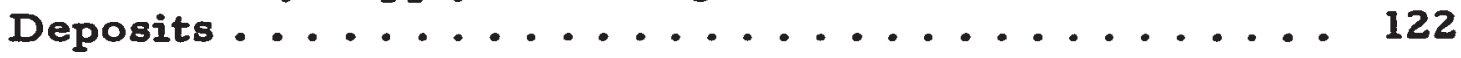

VI-2 Deviations of Test GDP From Control GDP....... 123

VI-3 Deviations of Test GDP From Control GDP

for Various Growth Rates in MS. . . . . . . . . . . 129

VI-3A Neutrality Results for Various Growth Rates

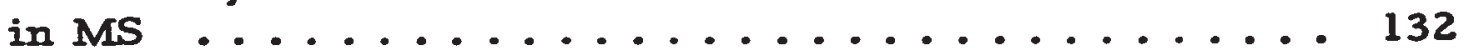

VI-4 Deviations from Control .............. 136

VI-5 Stability, Average Level, Growth ........... 138

VI-6 Stability, Average Level, Growth ............ 140

VI-7 Summary of Policy Results . . . . . . . . . . . . . 142

VI-8 Shocked Paths ..................... 144 


\section{CHAPTER ONE}

\section{AN OV ERVIEW}

Section A - Introduction

This study investigates long term monetary behaviour in the

Canadian Economy and contributes in two respects to the existing lowowedge of the subject. First, we construct an annual econometric model describing both the monetary and real sectors of the economy. (At the time of this writing it remains the only long term model of the Canadian Economy which contains a monetary sector.) Secondly, we use the model to simulate the effects of monetary policy rules of the sort proposed by the "Chicago School". Section B - Previous Work

The model which is developed in the following chapters relies to a great extent on the work which others have done in the area. To that extent, it is the progeny of many marriages and of an ancestral tree that spans many years and many ideas. While we can acknowledge this legacy we would be hard pressed to recount it. The most direct influences on the current form of the model came from the works of T.J. Courchene and T.M. Brown (1) Courchene's work forms the basis for the monetary sector while Brown's work provides the spirit of the real sector.

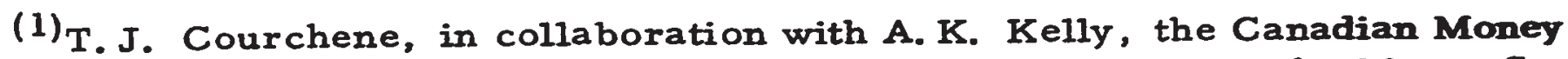
Supply: An Econometric Analysis with Special Emphasis on the Money Supply Multiplier, Paper prepared for the meetings of the Canadian Economics Association, Calgary, June, 1968.

T. M. B rown, Canadian Economic Growth, The Queen's Printer, Ottawa 1965, Chapter 9. 
Section C - Design of the model

A realistic model should reflect the apposition of the two major elements in the economic system - aggregate supply and aggregate demand and how they are related via the income distribution mechanism of the factor market. One can visualize the economic process in this sense as a circular flow - the expectation that products can be sold generating output, the production of output generating demand for factors, the purchase of factors creating an income flow and the basic needs and wants of the owners of the factors generating supplies of factors and demands for the output of the production process. It is clear that for meaningful long-term analysis of this process it simply will not do to treat demand or supply to the exclusion of the other. This is so because it is demand which is ultimately responsible for supply and the generation of income; on the other hand the complex pattern of demand is due in large measure to the income flows associated with the production of output.

The method of capturing these relationships adopted here is to determine the major components of demand endogenously and to equate this demand to an aggregate production function. This intersection serves to determine the level of employment (which may be less than the supply of labour) and, via an hours-oi-work and wage block, the civilian wage bill. Other income variables are generated by the inclusion of identities. Provision is made for the degree of capital utilization by adjusting the capital stock for the proportion of the labour force employed. 
A complete model of course contains many stocks as well as flows - the labour force, stocks of physical capital and stocks of money and of other financial variables; a distinguishing feature of our model is the inclusion of a financial sector.

The method of incorporating financial instruments into the circular flow relies on the assumption that real behaviour in each period is in fact influenced by monetary phenomena. The specific way in which this behaviour is influenced is set out in the behavioural hypotheses of the model. The inclusion of these monetary influences in the real sector does not, however, close the issue because just as there is a circular interaction in the real sector there is a financial market mechanism with which we must deal.

The addition of a financial sector is intended to provide for the endogenous determination of some of the more important financial variables which influence the behaviour of individuals toward the supply and demand of final goods. Treatment of these variables as exogenous would ignore the important interactive effects of real and monetary variables in the determination of movements in the latter.

A serious deficiency of the model is that it is for all practical purposes "closed." The omission of a full-blown international sector was motivated by resource constraints and the fact that for much of the period under consideration Canada was on a flexible exchange rate. 
Section D - An outline

Chapter two presents the structure of the financial sector and briefly discusses the theoretical and institutional framework within which the various hypothesis are tested. The empirical results for the monetary sector and the procedures used to arrive at them are also included in (or appended to) chapter two.

Chapter three is devoted to the reworking of Brown's madel, to which substantial modifications have been made. Commentary on the real sector is limited to indications of where and why these changes were made.

Chapter four serves the mechanical function of presenting in one place all the equations of the model together with a glossary of the variables used.

Chapter five presents the structural changes which a series of preliminary simulations showed to be necessary. Also contained in chapter five is a graphical comparison of actual and simulated paths for some of the endogenous variables over the fitting period and a prediction of the endogenous variables for a year outside the fitting period.

Chapter six summarizes the results of simulation experiments which were performed under various assumptions as to the course of monetary policy. Some of the results obtained a re compared to the results of similar tests which have recently been made on a model of U. S. economy.

Chapter seven outlines a few areas for future research. Section E-A Flow Chart of the Model. 


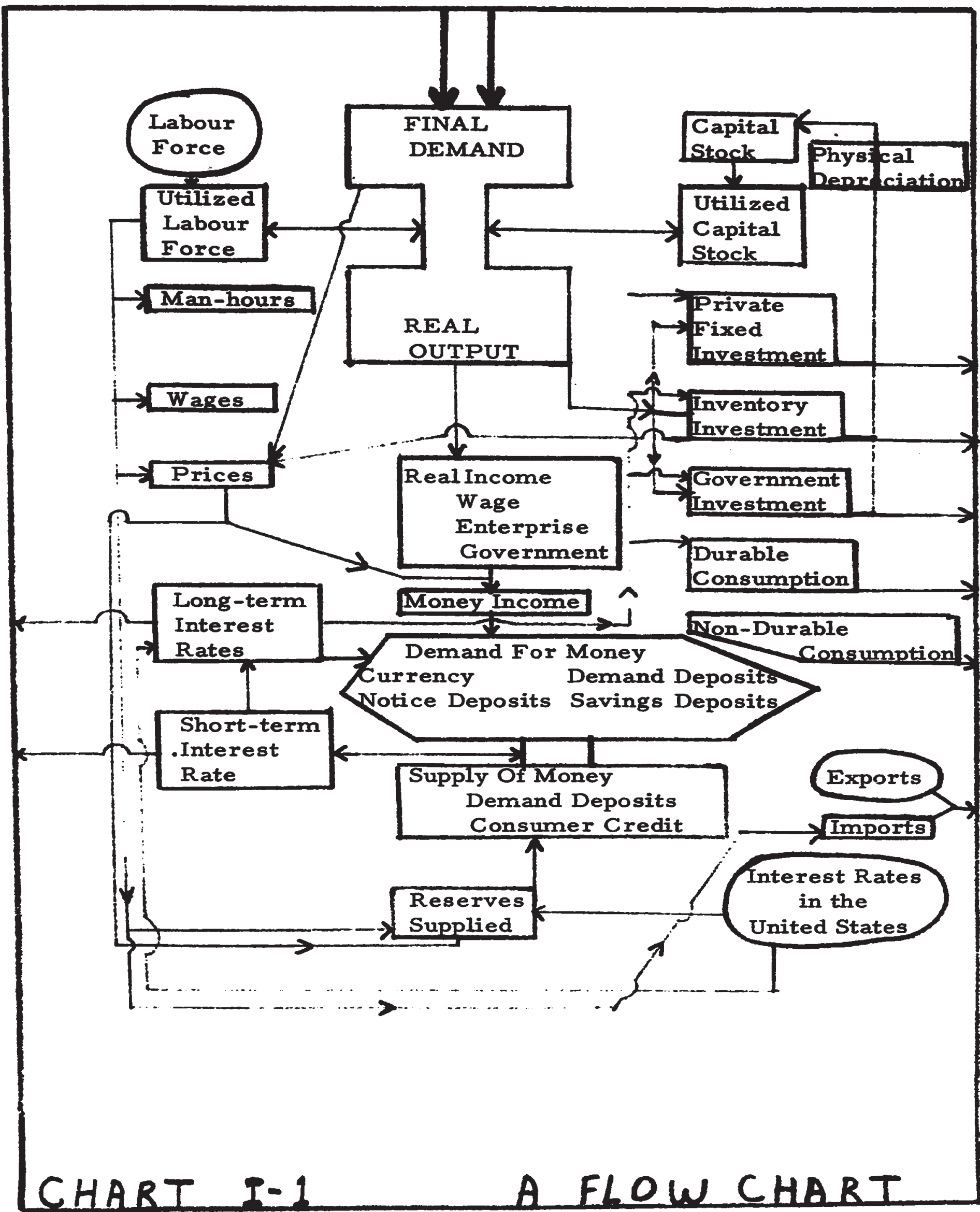




\section{THE FINANCIAL SUB-MODEL}

\section{Section A - Introduction}

The purpose of this chapter is to develop a long-term model of financial behaviour which describes the basic structure of the Canadian monetary sector. It is not meant to be an exhaustive treatment but rather a preliminary effort to describe empirically monetary behaviour in Canada.

In general terms, financial behaviour may be described as the behaviour of economic units with respect to the supply and demand of financial goods. Accordingly, a model of financial behaviour concerns itself with the range of financial instruments which are supplied and demanded in a modern monetary economy. The size and complexity of such a model is governed principally by the number of such instruments which it attempts to explain. In view of the resource and manpower constraints on this effort, only four types of instruments will be dealt with, namely: Bank-of-Canada notes and deposits, chartered-bank deposits, bonds, and consumer debt.

The principal forces which determine the quantity of each of these instruments outstanding can be distinguished conceptually and arranged in relations or equations. For the purposes of this paper, the convention we adopt is to arrange causal variables and dependent variables respectively on the right and left hand side of a full colon. Furthermore, 
the relation or set of relations pertaining to the determination of the quantity or volume of each of the instruments is arranged in a block or set of equations, each block being designated according to the instrument which it explains. Each variable used in the development of the model will be defined on the occasion of its first appearance. A complete glossary of terms is included at the end of chapter four (page 102). Individual relations of the sub-model are constructed to reflect the forces of demand or of supply commonly accepted in economic theory. as well as the institutional and structural framework of the Canadian economy.

From a theoretical point of view the relations of the model reflect the generalized portfolio theory of asset choice developed from the work of Keynes(1) by, James Tobin and others(2). Because this is an exercise in applied economics the relations as specified conform to the spirit and not to the detail of the theoretical literature. In particular, the present work makes use of the practical reduction of the theory as suggested by Goldfeld, De Leeuw, Courchene and others. (3)

(1) J. M. Keynes, The General Theory of Employment, Interest and Money, Macmillan \& Co., First edition, London, 1964.

(2) See H. G. J ohnson, Monetary Theory and Policy, The American Economic Review, Vol, LII, No. 3, (June 1962), Pp. 335-84. (3) S. M. Goldfeld, Commercial Bank Behavioux and Economic Activity, North Holland, Amsterdam, 1966. 
In empirical research it is also necessary to temper theoretical constructs with the peculiarities of specific institutional patterns. Accordingly, at several points, a rguments which theory (in a general sense) may suggest are revised or abandoned on the basis of institutional or historical facts.

In order to compress the presentation of the model and to avoid needless repetition, the empirical results and any remarks periairing to them will be presented immediately after the theoretical-institutional specification of each equation. In this regard, the reader should consult Appendix A of this chapter for a resume of the units of measure used in the equations.

The equations were fitted to a sample of data for the period 1947 to $1966^{(4)}$. Initial hypothesis testing was done with Ordinary Least Squares and consistent estimates were obtained with instrumental variables (TSLS) and principal component two stage least squares (PC - TSLS)(5). The statistical package used for the fitting chores was written by Dr. P. A. Tinsley of the Board of Governors of the Federal Reserve System and adapted to IBM 7040 Fortran IV by T.J. Courchene. The Tinsley package, "Boris", provided $t$ ratios (which are reported in brackets beneath the parameter to which they refer), the

(4) Notes on sources and methods used to obtain the data series in Appendix $B$.

(5) For a description of the estimation procedures, see Appendix C of this chapter. 
correlation coefficient adjusted for degrees of freedom (denoted as $\bar{R}$ ), the coefficient of variation (SU / $\bar{Y}$, which we report as a percentage) and the Durbin-Watson and F statistics. The final selection of equations was based on the best combination of consistency, economic meaningfulness, goodness of fit and performance in simulation. Section B - The Model

(i) Block One - High Powered Money.

The purpose of this block is to determine the total volume of

Bank of Canada notes and deposits made available by the Bank of Canada. Accordingly, it is to a large extent a description of the behaviour pattern of the monetary authority.

The preamble to the Bank Act outlines the duties of the Bank of

Canada as follows:

to regulate credit and currency in the best interests of the economic life of the nation, to control and protect the external value of the national monetary unit and to mitigate by its influence fluctuations in the general level of production, trade, prices and employment so far as may be possible within the scope of monetary action and generally to promote the economic and financial welfare of the Dominion. (6)

Thus, the Bank is charged with the maintenance of a policy which is optimal from the viewpoint of general economic well-being. The way in which the Bank ultimately influences the economy is through the effect which it has on the money supply and general credit availability. Apart

(6) Evidence of the Governor before the Royal Commission on Banking and Finance, Bank of Canada, Ottawa, May 1964, pp. 113-114. 
from using signals and persuasion, the Bank exerts its control of the monetary environment in the long run through being able to change the reserves (the sum of notes in till and deposits at the Bank of Canada) of the chartered-banking system. Accordingly, the supply of high-powered money (the total of reserves of the banking system and currency in the hands of the public) which the monetary authority provides at a given time is presumably motivated by the movements in economic variables which are indicative of "economic and financial welfare".

The observation that the monetary authority probably behaves in this way has led researchers $(7)$ to formulate a relation called a reaction function, the arguments of which are economic indicators and the dependent variable of which is the stock of high-powered money outstanding. Relying on the research cited, we hypothesize the following relation as a description of the reaction properties of the monetary authority in its capacity as controller of the supply of high-powered money. 1. HPM: $P \times$ GDF, $P *$ (USCBR $\left.-\mathrm{RC}_{15}\right), \mathrm{N}_{\mathrm{upc}}, \mathrm{u}_{1}$
HPM
the stock of high-powered money a the sum of reserves of the chartered banks and currency holdings of the non-bank public minus coin.
GDF Gross Domestic Flow of trade $=$ GDP $+F_{1}$
GDP Gross Domestic Product in real terms

(7) See, for example, Courchene and Kelly, op. cit. , and works cited, p. 30 . 
$F_{1}$

$\mathbf{P}$

P*

$\mathrm{RC}_{15}$

USCBR

$\mathbf{N}_{\text {upc }}$

$\mathbf{u}_{1}$ imports, excluding payments of interest and dividends, in real terms

implicit price deflator of Net National Product $\left(\left(\frac{\Delta P}{P_{-1}} \times 100\right)-2 \%\right) ; \Delta P_{t}=P_{t}-P_{t-1}$

Canadian high-grade corporate-bond yield

United States high-grade corporate-bond yield

Unemployment as a percent of the labour force

a portmanteau variable meant to capture the influence of small omitted variables both systematic and non-systematic (or random). In other words we hypothesize that all major influences have been accounted for in the other variables but that there are a host of minor influences which may or may not exert a net influence on HPM. The central limit theorem allows us to assume that $u$ is a random variable, approximately normally distributed.

The stock of high-powered money is assumed to exhibit a rate of growth over time determined by the needs of trade ( $P$ X GDF) and the goals of a high level of employment and price stability. The presence of United States interest rates in the function is a reflection of the fact that once the government adopts a fixed exchange rate, it implicitly agrees to adjust its domestic monetary policy to be compatible with international phenomena.

The volume of gross domestic flow adjusted for price movements is used as an indicator of the total requirement of trade for means of payment. The price deflator of net national product (rather than the GDF 
index) is used because PGDF is not explained elsewhere in the model.

PINP also enters as a separate variable to reflect the monetary authority's goal of price stability. Following Courchene, (8) we have opted for a "deviation from target" formulation of the price variable.

The international capital-account requirements and the manner in which they impinge on the monetary policy of a government under a system of fixed exchange rates are represented by the difference between the long-term average yield on corporate securities prevailing in the U. S. and that prevailing in Canada. A tendency for this differential to rise would cause the Canadian monetary authorities to tighten the Canadian monetary environment (and hence raise domestic rates) to prevent excessive outflows of capital and the corresponding pressures on

The use of $P$ in this regard constitutes an approximation--but not an unreasonable one. Since $P$ is used throughout the model to reflect price movements, a few words of justification are in order.

The deflator of the $i^{\text {th }}$ component of Gross National. Expenditure may be written as $P_{i}=a+B P_{N N P}+u_{i}$--that is, any component index is a linear stochastic function of PNNP. Estimation of this relationship would yield $P_{i}=a+B$ PNN. Inflating the $i$ th component of GNP, $\left(C_{i}\right)$ would yield:

$$
C_{m}=C_{i}\left(a+B P_{N N P}\right)
$$

or

$$
C_{m}=C_{i} a+B P_{\text {NNP }}
$$

Hence, our use of PNNP where it is used as an approximation ignores the constant term $\mathrm{aC}_{i}$, however, since we are only interested in price movements and since PNNP enters as a separate variable whenever it is used in this approximate way, the usage is justified. (8) T. J. Courchene, op. cit. and works cited. 
the exchange rate which would ensue.

In principle, world interest rates should enter because the same situation can arise if interest rates anywhere in the world should rise sufficiently high, e. g. the Euro-dollar rate. However, because of its proximity to the U.S. and the degree to which thc economies are interrelated, Canada's capital market seems most sensitive to U.S. rates; hence the U.S. rate was chosen.

Since fixed rates were in effect for only part of the period studied, (1947-1950 and 1962-1966) the differential is "dummied in" with a rtifical variables only for the relevant period.

In order to complete the specification of the high-powered money function we must introduce two shift variables to cover, respectively, the downshift of 1954 associated with the establishment of the Canadian money market and the lowering of the reserve requirement, (9) and the market support tendered during the coversion loan of 1958.

The function as presented fitted well in spite of the multicollinearity which one might expect of such an equation. However, since a stable, correctly signed parameter estimate for the price variable could not be obtained it was dropped--to yield as our final equation:

(9) Before the 1954 revisions of the Bank Act, the reserve requirement had been 5 per cent on daily averages--because of the difficulties associated with the daily average requirement a ratio of approximately 10 per cent was held. See, H. H. Binhammer, Money, Banking and the Canadian Financial System, Methuen, Toronto, 1968., p. 223. 
1. $\mathrm{HPM}=.03286 \mathrm{GDF} * \mathrm{P}-135.8\left(\mathrm{USCBR}-\mathrm{RC}_{15}\right) \mathrm{x}_{1}+35.61$

$$
\begin{aligned}
& \begin{array}{lll}
(19.526) & (3.016) & (3.230)
\end{array} \\
& \mathrm{N}_{\text {upc }}-92.14 \mathrm{X}_{2}+1002.0+45.48 \mathrm{X}_{3} \\
& \text { (1.879) (21.15035) (.79858) } \\
& R=.9 .9605 \quad \text { D. W. }=1.84357 \text { Su } / \bar{y}=1.891 \neq \\
& \begin{array}{rll}
X_{1}^{*}=1 & t= & 1947-1950 \\
0 & t= & 1951-1961 \\
1 & t= & 1962-1966
\end{array} \\
& \begin{array}{lll}
x_{2}^{t}=0 & t= & 1947-1953 \\
1 & t= & 1954-1966
\end{array} \\
& x_{3}=1 \text { in 1958, } 0 \text { elsewhere }
\end{aligned}
$$

Equation 1. as it stands would suggest that the monetary authority controls only the total of HPM which in turn implies that the behaviour of the public casi strongly affect the level of bank reserves. Such is not the case. The Bank of Canada pointed out in its submission to the Royal Commission on Banking and Finance that ...

The Bank does not control the amount of the note circulation. It is able to influence only the combined total of currency and chartered bank deposits and does not determine the proportion which the public holds in the form of Bank of Canada notes. (10)

This essentially means that the supply of Bank of Canada notes is demand determined. In order to allow for this behaviour and its influence on the level of HPM we must somehow "correct" HPM for currency holdings of the general public. Three possibilities suggest themselves. (10) Evidence of the Governor before the Royal Commission on Banking and Finance op. cit., p 148. Also, see Courchene and Kelly, op. cit., P. 32, for empirical evidence on the matter.

\# It should be noted that in some of the equations which follow, the statistics used to describe goodness of fit include the coefficient of determination corrected for degrees of freedom instead of the correlation coefficient. This change was necessitated by the use of the Massager System, developed by Mr. M. C. McCracken and the Bank of Canada, while I was working on this study at the Bank of Canada. 
We could introduce a currency demand argument into 1. which would explicitly account for the changing level of the general public's holdings of Bank of Canada notes and subsequently determine that variable and subtract it from HPM to arrive at the actual level of reserves of the banking system. Alternatively, we could assume that GDF*P picks up the transactions requirements of the public and hence accounts for most of the variance of note holdings by the public. If the latter assumption is correct, no additional information would be provided by the introduction of a note holdings variable into equation 1. and our only remaining task would be to determine note holdings and subtract it from HPM to get the reserves (RS) of the banking system.

An entirely different tack would involve the separate estimation of RS and note holdings of the public equations without constraining the total. For the purposes of predicting RS in the simulations this approach has the advantage of being less subject to errors than either of the first two approaches since it does not involve the errors generated by the note holdings equation.

A test was made of each of the alternative specifications and the results appear below:

$$
\begin{aligned}
& 1.1 \text { HPM }=1.430009(\text { Cur-Coin- } \bar{C})-43.095\left(\text { USCBR }-R_{15}\right) x_{1} \\
& \text { (5.57994) (1.92919) } \\
& +.0082 \text { GDF*P }-124.816 \mathrm{x}_{2}-8.79956 \mathbf{N}_{\mathbf{u p c}} \\
& \text { (1.7533) (5.78952) (-.979048) } \\
& +12.384 X_{3}+124.913 \\
& (.48958) \quad(.787902) \\
& \bar{R}^{2}=.998321 \mathrm{Su} / \bar{y}=.91011 \quad \text { D. } \mathrm{W} .=2.19334
\end{aligned}
$$




$\begin{array}{ll}\mathrm{X}_{3} & \begin{array}{l}\text { one in } 1958 \text { for the } \\ \text { conversion loan }\end{array} \\ \text { Coin } & \begin{array}{l}\text { Coin holdings of the } \\ \text { general public }\end{array} \\ \overline{\mathrm{C}} & \begin{array}{l}\text { difference between } \\ \text { average of Wednesdays } \\ \text { and month-end currency } \\ \text { holdings of the general } \\ \text { public. }\end{array}\end{array}$

1.1 confirms our suspicion that (Cur-Coin- $\bar{C})$ and GDF*P contain essentially the same currency drain information. The fact that we forced both into the equation caused an arbitrary allocation of the variance between them - hence the ridiculously high parameter on (Cur-Coin- $\bar{C}$ ) and the low one on GDF*P. To confirm further the high degree of co-variation between GDF*P and (Cur-Coin-C) the partial correlation between them was calculated - the result was . 9917.

Hence, if it is decided to use an equation for HPM, we can use 1. with the assurance that no information is lost in excluding a currency drain a rgument.

As suggested, we can also short circuit this whole procedure and use the fact that (Cur-Coin- $\vec{C})$ is demand determined to generate a Reserves Supply equation.

1.2 RS $=.0186134$ GNP*P -65.57453 (USCBR $-R_{15}$ ) $x_{1}$

$$
\begin{aligned}
& (19.67772) \quad(-3.5979) \\
& -138.51442 x_{2}+32.07 * x_{3}+393.750 \\
& \begin{array}{lll}
(6.88636) & (1.36573) \quad(21.4263)
\end{array} \\
& \bar{R}=.98584 \quad \mathrm{Su} / \bar{y}=2.60188 \quad \text { D. } w .=2.40073
\end{aligned}
$$


In 1.2 a 1 ess general income variable is used because the intent is to account only for growth over time, the transactions requirement having been accounted for by the subtraction of (Cur-Coin). In this formulation, neither unemployment (in many different formulations) nor price stability was found to have a significant influence. Part of the difficulty with fitting this equation arose from the steplike behaviour of the monetary authority during the period around 1954 when the reserve requirement was changed. The choice between 1.2 and 1. will depend on their behaviour in simulation.

\section{Currency}

The second equation in the high-powered money block is the Currency demand equation. It is included because if 1 . is used to determine HPM we require (Cur-Coin) to determine RS. On the other hand Cur is a component of the money supply and it is our intention to determine endogenously the behaviour of the money supply.

The basic specification of the currency demand equation, should, like that for any asset, include a scale variable, own rate of return and rates of return on substitutes. The selection of which variables enter with zero coefficients is then left to the empirical tests. Accordingly, extensive testing was done with various specifications. The equation presented below was the best obtained.

$$
\mathrm{Cur}^{\mathrm{d}}=.01018 \mathrm{GNP} * \mathrm{P}+.00707\left(\mathrm{GNP} * \mathrm{P}_{L_{1}}+.00452 \text { GNP * } \text { I }_{-2}\right.
$$

$$
\text { (4. 93354) }
$$

$$
\text { (4. 93354) }
$$


$+.00254\left(\mathrm{GNP} * \mathrm{PL}_{3}+.00113\left(\mathrm{GNP} * \mathrm{PL}_{4}+.00028\left(\mathrm{GNP} * \mathrm{PL}_{5}\right.\right.\right.$

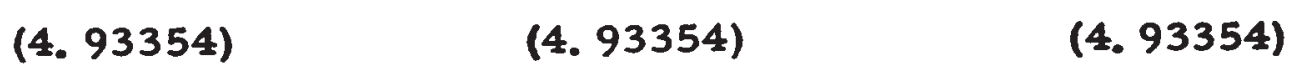

+.350096 Cur $_{-1}+11.5578$ ATM -23.5075 RC $_{15}+356.5568$
(2. 17337)
(2. 07749)
(1. 439602)
(4. 57755)

ATM = Average term to maturity of the public debt.

$$
\overline{\mathrm{R}}^{2}=.997884 \mathrm{Su} / \mathrm{y}=1.0910 \text { D. W. }=1.34890
$$

The distributed lag on GNP * $P$ is meant to be a proxy for wealth and is used in all of the asset demand equations for that reason. It was obtained by fitting a second degree Almon variable constrained to be zero (and have zero slope) at $t-6$. Lagged currency holdings enter to reflect the fact that there is a degree of habitual behaviour(11) involved in currency holdings. Essentially the same specification arises from a stock adjustment model, but the adjustment information implied in the parameter on $\mathrm{Cur}_{-1}$ would make that hypothesis untenable in the face of recent studies. (12), (13)

The own rate of return on currency (the rate of deflation) did not enter the equation with the expected sign when other rate variables were included. When only a transactions variable was included the

(11) T. M. Brown, "Habit Persistence and Lags in Consumer Behaviour," Econometrica, Vol. 20 (1952), p. 355.

(12) See for example, T. J. Courchene, op. cit. , p. 21.

(13) For a note on the use of lagged dependent variables and the hypothesis implied, see appendix $D$ to this chapter. 
variable was correctly signed but not statistically significant.

The average term to maturity of the public debt and the corporate bond rate both enter with the expected sign (although the latter is not significant at the $5 \%$ level) and reflect the effects which portfolio allocation has on the stock of currency held.

Block one can be completed by the inclusion of identities. The number of these required depends on which of 1. or 1.2 is selected. If it is decided to determine HPM via 1. then we must include. 3.

$$
\mathrm{RS}=\mathrm{HPM}-(\text { Cur-Coin) }
$$

The adjustment to Cur is necessary because Cur includes coin holdings of the public and these cannot be held as reserves by the banking system. To reflect the behaviour of the Bank of Canada with regard to currency, we also require:

$$
\text { 4. } \operatorname{Cur}^{s}=\operatorname{Cur}^{d}
$$

In the event that 1,2 is chosen 1. and 3. will be replaced by 1.2. (ii) Block Two - Chartered-Bank Deposits.

\section{A. The Structure}

The second block to be considered describes the forces which, given the supply of the reserve base, generate the non-currency components of the money supply. Several simplifying assumptions are adopted and we now make these explicit.

In the first place the banking system is assumed to accept the supply of reserves determined by the operations of the monetary 
authority as a fact of its economic life. Adjustments to this reserve base are made via changes in the total volume of deposits outstanding. This adjustment process is assumed to determine the supply of demand deposits which when equated to the demand for demand deposits determines the short-term money-market rate of interest. Implicitly assumed in this mechanism is that the volume of non-demand deposits outstanding is demand determined. $(14)+$ In fact these assumptions, restrictive though they may seem, are fairly close descriptions of economic reality, as the following paragraphs demonstrate.

One way to see how the economic structure actually works is to shock it into an adjustment process and to then observe how it reaches a new state of rest. Assume, for example, that the Bank of Canada contracts the supply of the reserve base by one of the methods at its disposal. This contraction causes a shortage in a) the reserves held for the current averaging period if it affects chartered-bank deposits at the Bank of Canada and b) the reserves held for the subsequent averaging period if it affects cash-in-till held by the banks. This distinction,

(14) A bank's demand deposits include personal chequing accounts, current accounts of businesses and individuals and items in transit. They bear a negative yield in the form of service charges. Non-demand deposits are deposits on which interest is paid and on which cheques can be drawn only if prior notice is given (this restriction is seldom enforced). Deposits of the Federal government are treated as non-demand in this sense and Provincial government deposits are treated as demand deposits. * A procedure adapted from Goldfeld op. cit. and used by Courchene and Kelly, op. cit. 
caused by the lagged calculation of the reserve requirement, is crucial for the study of short-term monetary dynamics but washes out at the level of average annual data such as we are using. The options open to the banks are well known--the most-often chosen one is the recall of the day-to-day loans made to investment jobbers on the collateral of their securities inventories. If the reserve contraction affects all banks symmetrically, then the jobbers have no effective recourse but to enter into a purchase-and-resale agreement (PRA) with the Bank of Canada. The Bank's money market rate, which is the rate charged on PRA's is at a level higher than the average rate on treasury bills--the usual instrument involved in the agreements and the principal instrument of trade in the money market--which means that the jobbers pay a penalty for the advance which they receive from the Bank.

Having gained temporary relief from their illiquidity, the jobbers then divest themselves gradually (on maturity) of the securities which they have accumulated and prepare to repurchase the Treasury bills which they have been forced to sell to the Bank. In subsequent dealings, the jobbers will be less eager and able to acquire additions to their inventories and will in any event seek a higher return on instruments traded--this, as well as the banks tighter cash position, will be reflected in the lower average successful bid at the following treasury bill auctions.

In a general sense, then, the contraction of the reserve base 
has decreased the supply of demand deposits and via the mechanism described pushed up the treasury bill rate. The significant point is that during all these manipulations, other deposit supplies could have remained, (and in most cases do remain) unchanged.

In the period after the initial adjustments have occurred the banks gradually adjust to the tighter money environment by doing such things as imposing minimum deposit requirements on the larger loans which they make, and eventually adjusting collateral and "credit worthyness" requirements on personal loans or stopping loan growth entirely. This sort of practice has the effect of contracting further the supply of demand deposits and pushing up the effective prime rate. These Inaneuvers are also reflected in the bill rate and in the short-term money market generally as reaction to the persistence of the tight money environment becomes general.

Hence, our assumption that the "demand-deposits market" bears most of the brunt of adjustments to changes in the reserve base is perhaps a very good approximation to reality. (16) We now proceed to explain the demand for the various kinds of deposits.

(15) Evidence of the Governor before the Royal Commission in Banking and Finance, Op. Cit., Page 126.

T6) Actually the process described is only applicable to the post 1954 period because the Canadian money market as it now exists did not begin to function until then. Before that time the banks were the principal short-term lenders and they then had to bear the brunt of the adjustment process; a process which worked essentially the same but less efficiently. This in part explains the $10 \%$ reserve ratio which the banks felt compelled to maintain. 
B. Personal Savings Deposits

Personal term or time deposits are deposits held by the noncorporate public. They vary in term and pay varying rates of interest. In general, time deposits are not used as transaction medium and appear to be regarded as liquid investments rather than a less liquid form of money. A comparison of the velocities of turnover of time and demand deposits quickly points up the rationale behind these remarks. Historically, the velocity of time deposits has been about 2 , while demand deposits have displayed an increase in velocity over the 1955-1965 period, from 35 to 96. (17) Nevertheless, savings deposits are "counted in" the money supply and in Canada a large proportion of them are chequable and used as a means of payment.

Because of their dual role, the primary direct influences included in the demand for savings deposits are the level of wealth, interest rates, and the level of transactions.

Wealth enters the equation as the scale variable. Interest rates a re included to provide for the allocative effects which own yield-substitute yield differentials have on the stock of a particular asset held. With a given level of wealth, the stock of savings deposits held will fluctuate with the fluctuations in these yield differentials. Because of our use of lagged income to represent wealth, inclusion of a transaction variable

(17) For an illuminating discussion of these matters, the reader is referred to T.J. Courchene, op. cit., p. 22. 
would be redundant. This also means that we are unable to distinguish between the wealth and transactions effects determining the demand for savings deposits.

Collecting these major influences, we have:

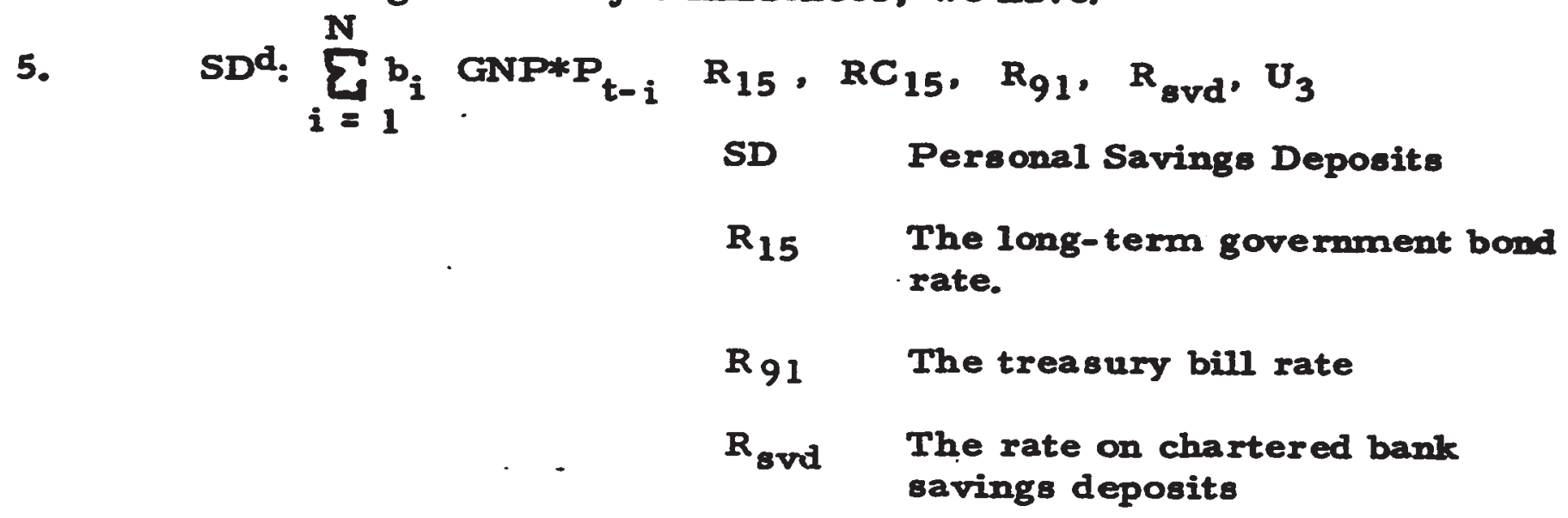

Various forms of this basic hypothesis were tested, including some which assumed that 5. was a Cobb-Douglas-type non-linear function, following Teigen and Goldfeld. (18) Linear forms produced uniformly better equations, however, and the one chosen is linear except for the price variable.

5.

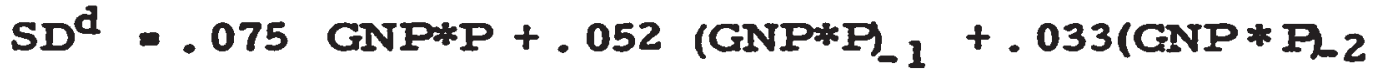

$$
\begin{aligned}
& \begin{array}{lll}
(15.47477) & (15.47477) & (15.47477)
\end{array} \\
& +.019\left(\mathrm{GNP} * \mathrm{P}_{-3}+.008\left(\mathrm{GNP} * \mathrm{P}_{-4}+.002(\mathrm{GNP} * \mathrm{P})_{-5}\right.\right. \\
& \text { (15.47477) (15.47477) (15.47477) } \\
& +161.7684 R_{8 v d}-254.77616 R_{15}+108.4739 A T M \\
& \text { (1.080769) (2.08578) (3.135024) } \\
& +713.94162 \\
& \text { (2. 69648) } \\
& \bar{R}^{2}=.99535 \mathrm{Su} / \bar{y}=2.22913 \quad \text { D. W. }=1.39560
\end{aligned}
$$

(18) Goldfeld, op. cit., p. 76. For a generalization of his result see Appendix $\mathbf{E}$. 
The weak parameter estimate for the own rate ( $\left.R_{\text {gvd }}\right)$ is undoubtedly due to the fact that it does not vary very much over the sample period. In spite of the fact that it is not significant it is left in because it does improvs the equation slightly.

Experimentation with the rate on Canada Savings Bonds and other rates and a dummy for the conversion loan did not improve the equation. The CSB rate was highly correlated with $R_{8 v d}, R_{15}$, and $R_{91}$ and the gain in information from including it was not sufficient to overcome these inter-correlations. (19) A similar relationship between ATM and the conversion dummy made the latter's inclusion redundant.

C. Non-personal Term and Notice Deposits

Non-personal term and notice deposits (ND) consist of chequable and non-chequable notice deposits of corporations and deposit receipts (or certificates of deposit). The latter are deposits with a fixed term to maturity and bear interest at rates competitive with short-term money market instruments. Most of these certificates contain pre-encashment clauses and some are negotiable.

(19) This interpretation of the effects of collinea rity relies on the intuitively appealing analogy of collinea rity to the attempt to fit a hyperplane in $\mathrm{N}$ dimensions to a scatter which only varies in $\mathrm{N}-1$ dimensions. The addition of CSB is thus formally equivalent to increasing the dimensions of the hyperplane without increasing the dimensions of the scatter. 
Prior to 1960, the bulk of ND were of the chequable and nonchequable variety. Since 1960, however, chartered banks have been aggressively bidding for short-term funds by offering competitive shortterm rates on the deposit certificates. Because of these efforts on the part of the banks and the sensitivity of short-term money to interest rate differentials, the behaviour of ND changed markedly in 1961.

Another institutional change which occurred around the same time was the introduction of "swapped" foreign currency deposits. These deposits are denominated in foreign currency and bear interest which is competitive with that available on other short-term instruments; account being taken of the spot-forward exchange differential - the cost of which is imputed by the banks. These deposits are less liquid than ND's because they are not normally pre-encashable (owing to the fact that the bank has undertaken a forward contract in the foreign currencyan obligation which is not usually defaulted).

Nevertheless, "swaps" do provide a source of competition for ND's, the strength of which would depend at any time on the swaps - ND rate differential.

These institutional characteristics suggest the following specification of the notice deposit demand equation:

6. $\quad N D^{d}: \sum_{i=1}^{N} b_{i}((P E Y+D) * P)_{t-i}, R_{s w p}, R_{\text {ond }}, R_{91}, A T M, U_{4}$ 


$\begin{array}{ll}\text { PEY } & \begin{array}{l}\text { Property and enterprise } \\ \text { income }\end{array} \\ \text { D } & \begin{array}{l}\text { Capital consumption } \\ \text { allowances }\end{array} \\ \mathbf{R}_{\text {swp }} & \text { rate on swap deposits } \\ \mathbf{R}_{\text {ond }} & \text { rate on notice deposits }\end{array}$

Attempts to fit 6. in various linear forms were unsuccessful. Very early in the experimentation it became evident that our corporate wealth proxy was not appropriate. After much experimentation it was found that current GNP worked better than either distributed lags on any of the other income aggregates or the current level of (PEY $+D)$. The success of current income over wealth-type configurations is perhaps explained by the pre-encashment option on the ND's - this feature makes them equivalent to interest bearing demand deposits and they are thus used extensively to employ short-term operating surpluses. Since these surpluses are more related to current income than to wealth as such, our result is reasonable.

The yield variables worked fairly well with the exception of $\mathrm{R}_{91}$ which invariably had the wrong sign. The own rate worked best in a cubic formulation - reflecting the highly aggressive behaviour of the banks from 1960 on. For the same reason, a reasonable, significant constant term could not be obtained.

The final regression was: 
6. $\quad \mathrm{ND}^{\mathrm{d}}=.00769112 \mathrm{GNP} * \mathrm{P}+16.4467\left(\mathrm{R}_{\text {ond }}\right)^{3}-66.17586 \mathrm{R}_{\text {swp }}$ (2.7311309) (9.3771271) (2.45320)

+22.3263 ATM

(2. 39355)

$\bar{R}^{2}=.984135 \quad S u / \bar{y}=9.84096 \quad$ D. $w .=1.90662$

It should be noted that $R_{8 w p}$ is relevant only from 1961-1966 and is zero before that period.

D. The Supply of Notice Deposits

In the discussion of the determinants of $\mathrm{ND}^{\mathrm{d}}$ it was indicated that $R_{\text {ond }}$ was a principal causal influence. In fact, 6 . suggests that $R_{\text {ond }}$ is the major influence affecting the demand for ND. Hence, it was decided to include a "supply" equation for ND. Because the banks seem to behave in that way we have above assumed that they respond passively to the demands for non-demand deposits. This is the same as saying that they set the rates and supply the demand at those rates. Accordingly, the supply of ND equation is a rate equation - normalized on R ond.

For much of the period under consideration, the rate on ND was set to vary with the rate on savings deposits. Hence, one of the

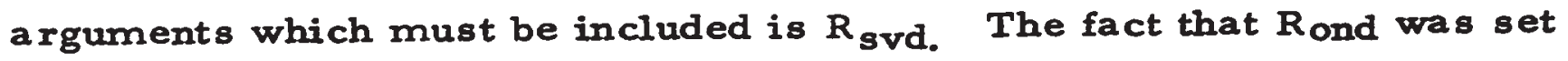
to be competitive after 1961 suggests that from 1961 - 1966 an indicator of short-term rates be included.

$¥$ Peter Miles in his work at the Bank of Canada has also taken this approach. See Miles; Assets and Liabilities of Chartered Banks: An Econometric Analysis, Unpublished $\mathrm{Ph}$. D. thesis, McGill University, 1968. 
Relying on the more general conditions of profit maximizing we have also included indicators of the yield on banks assets. 7. $\mathbf{R}_{\text {ond }} \mathbf{R}_{\text {ovd }} \mathbf{R}_{91}, \mathbf{R}_{\text {tcd }} \cdot \mathbf{i}_{\mathrm{cbpl}} \cdot \mathbf{u}_{5}$

$$
\begin{aligned}
& \text { icbpl chartered bank prime loan } \\
& \text { rate } \\
& R_{\text {tcd }} \quad \text { Truet company deposit rate }
\end{aligned}
$$

$R_{91}$ and $R_{t c d}$ are included to reflect the competitive element in the setting of $R_{\text {ond. Unfortumately. }} \mathbf{R}_{91}$ is also an indicator of the yield on bank assets since a considerable portion of more liquid assets are held in the form of treasury bills. Hence, any estimate of the influence of $\mathrm{R}_{91}$ would reflect both influences.

The chartered bank prime loan rate ( $i_{\text {cbpl }}$ ) enters to reflect the average yield on the banks' portfolios of less liquid assets. It should have a positive influence.

The best equation obtained was:

$$
\begin{aligned}
& \text { 7. } R_{\text {ond }}=.1605882 \mathrm{i}_{\text {cbpl }}+.317499 \mathrm{R}_{\text {svd }}+.5703442 \mathrm{R}_{91} \\
& \begin{array}{lll}
(5.33901) \quad(5.59728) \quad(18.473)
\end{array} \\
& \bar{R}^{2}=.979668 \quad S u / \bar{y}=10.6392 \quad \text { D. W. }=.80108 \\
& \text { R91 enters from } 1961 \text { - } 1966 \text { only }
\end{aligned}
$$

The Durbin-Watson statistic was improved by the addition of a shift dummy for 1961-1966. The dummy $\left(X_{5}\right)$ entered with a negative sign and left the other coeffleiente unchanged with the exception of R91. The amount of unexplained variation in $R_{\text {ond }}$ was reduced and the equation 
generally was improved.

7. 1

$$
\begin{aligned}
& R_{\text {ond }}=.164062 i_{\text {cbpl }}+.320523 R_{\text {avd }}+.872106 R_{91}-1.2265 x_{5} \\
& \begin{array}{lll}
\text { (6. 40562) (6.64231) } & \text { (7. 70069) }
\end{array} \\
& \bar{R}^{2}=.98529 \mathrm{Su} / \bar{y}=9.04843 \quad \text { D. W. }=1.5388
\end{aligned}
$$

The negative sign on the dummy is explained by the radical acceleration of $R_{\text {ond }}$ in 1961 . E. The Demand for Demand Deposits

Demand deposits (DD) include all personal and non-personal chequing accounts which do not bear interest, inclusive (here) of deposits of the Provincial Governments. Also included in DD is the "float" or items in transit aggregate. During the sample period used here, "flost" is a good measure of the degree to which people "'kited"(20) and hence ought to be included. In the more recent period, many banks have begun to "back-date" debits 80 that the account of the payee is debited as of the date on which the cheque was payable rather than on the day it was cleared. The proper treatment of "float" in this environment is less clear.

The fact that demand deposits bear a negative yield in the form of service charges suggests that they would mostly be used for transactions purposes. On the other hand, they are a component of

(20)

Items in transit a re largely cheques written and received but not yet debited to the account of the payee. Over the intervening time period, a person could "kite" - i. e. have an undetected over-draft. 
wealth, and a wealth variable should also appear. The whole range of interest-rates available on alternative assets must also be included, as well as the liquidity effects of the average term to maturity of the public debt.

8.

$$
\begin{aligned}
D D^{d}: & \sum_{i}^{N} b_{i} \operatorname{GNP} * P_{t-i}, R_{91}, R C_{15}, R_{\text {ond }}, R_{\text {swd }}, \\
R_{t c d}, A T M, u_{6} & \text { ATM }
\end{aligned}
$$

Equation 8. is to provide the principal link between Block One and the short term money market. It is the money market adjustment equation. Accordingly it was decided that the equation should be normalized on $\mathbf{R}_{91}$ before being estimated. This procedure is justified if one has good reason to believe that the adjustment process in the market is felt primarily on price and if re-normalization yields a reasonable demand (or supply) equation. In our case it is undoubtedly $R_{91}$ that adjusts, because $D D^{s}$ is residually determined and $R_{91}$ must change to clear the market (i. e. the demand curve shifts.) We can easily test for the second condition after we have estimated the equation. The equation normalized on $R_{91}$ yielded:

$$
\begin{aligned}
& \text { 8. } \mathbf{R}_{91}=-.00108385 \mathrm{DD}+.00018434 \mathrm{GNP} * \mathrm{P}+2.42334 \mathrm{X}_{3} \\
& (1.6457784) \quad(2.376522) \\
& \text { +. } 18265159 \text { ATM + 1.243718 LQD } \\
& \text { (1.786535) (4.273953) } \\
& \bar{R}^{2}=.92403 \quad S u / \bar{y}=12.434 \text { D. W. }=1.98463
\end{aligned}
$$


Re-normalization yields:

$$
\begin{aligned}
D D^{d}= & .17007 \text { GNP *P }+68.4669 A T M-922.636 R_{91} \\
& +1182 . \text { LOD }+2042 . x_{3}
\end{aligned}
$$

which except for the unusually large dummies is a reasonable demand for DD equation.

The LOD dummy enters in 1956 and 1957 to account for the uncertainty in the money markets caused by the reaction of the chartered banks to the "imposition" of a $15 \%$ liquid asset requirement. That institutional change had the effect of increasing the banks' demand for securities and presumably changed expectations about the future course of bond prices hence increasing liquidity requirements. The equation is immensely improved by including this variable.

F. The Supply of Demand Deposits

In order to close off this block, we must determine the supply of demand deposits. The procedure adopted (following Courchene) ${ }^{(21)}$ is to determine the total volume of deposits (given the reserve base from block one) and to subtract ND, SD and government deposits (GD)-which are taken to be exogenous-to obtain $D D^{8}$.

The equation is:

9. $T D: R S, U_{7} \quad T D=D D+N D+S D+G D$

Fitting 9. proved to be quite difficult because of the fact that

(21) T. J. Courchene, op. cit. p. 16. 
reserve requirements were changed during the fitting period - as has been indicated in the discussion of equations 1. and 3. In addition to the difficulties encountered there, 9 has to make provision for the gradual adjustment of the banks to the new reserve calculation and of the effects on their excess reserves holdings of the establishment of a secondary market for treasury bills. In order to accomplish this, four shift variables were used.

The equation is presented below:

$$
\begin{aligned}
& \text { 9. } T D=9.84620 \text { RS* } x_{5}+10.985507 R \text { R } x_{6}+12.79421 R S * X_{7} \\
& \begin{array}{lll}
(106.05239) & (68.337224)
\end{array} \\
& +13.28847 \text { RS * } \mathrm{x}_{8}
\end{aligned}
$$$$
\text { (338. 64224) }
$$$$
\overline{\mathbf{R}}^{2}=.998371 \mathrm{Su} / \mathrm{y}=1.09471 \quad \text { D. W. } 1.65417
$$$$
X_{5} \text { covers the period from } 1947 \text { to } 1953 \text { and } X_{6} \text { is set to one }
$$
in 1954 and zero elsewhere. Similarly, $X_{7}$ is set to one in 1955 while $X_{8}$ covers the period from 1956 to 1966.

In addition to the shift variables, several attempts were made to include an adjustment for the fact that we have used month-end data rather than the average of Wednesdays data on which reserve calculations a re actually made. The adjustment used was the difference between average of Wednesdays and month-end holdings of Bank of Canada notes by the general public. This variable did not improve the fit of the 
equation and in many instances was incorrectly signed.

Equation 10. utilizes 9. and the other demand for deposit equations to determine the supply of demand deposits

10.

$D D^{8}=T D-N D-G D-S D$

Under the as sumptions that:

11. $\quad S D^{s}=S D^{d}$

12. $N D^{s}=N D^{d}$

13. $G D=\overline{G D}=$ exogenous

(iii) Block Three - Bonds; the term structure.

The B ond block of the Model is an extremely simplified attempt to describe the behaviour of the bond markets for government and private sector (corporate) securities. The method of approach is the use of term structure or quasi-reduced form equations.

Since the short-term rate $\left(R_{91}\right)$ is dete rmined in the preceding block we need only determine the long-short differentials for the longterm government and the long-term corporate and solve out for each. Many formulations of the term structure equations were tried and several fairly good equations were obtained. Because reduced forms are notoriously misbehaved in simulation, it was decided not to choose which equation was best before subjecting them to the simulation test. Accordingly several reasonable equations are presented here. A. The Corporate Rate.

The first equation tried in this set appears in the above cited 
work by T.J. Courchene. It is an attempt to capture the effects of both expectations and relative supply factors. (22)

14. $1 \quad R_{15}-R_{91}=-.5852461 \Delta R_{91}-.23255 \perp R_{91-1}$

$$
\begin{aligned}
& \text { (3.23066) (2. 106224) } \\
& -.00002338 \text { GNP } * P+3.72264 R_{-1}^{N}-.0010469 \\
& \text { (2. } 41543) \quad(3.34365) \\
& \Delta S_{-1}-.1640232 \text { ATM }-1.31790 x_{3}+4.23168 \\
& \begin{array}{llll}
\text { (1.29530) (1.96519) (4.95597) } & \text { (1. }
\end{array} \\
& \bar{R}^{2}=.88354 \quad \mathrm{Su} / \bar{y}=15.47203 \text { D. W. }=1.40185
\end{aligned}
$$$$
\text { S Stock of treasury bills }
$$$$
\text { outstanding }
$$$$
R C^{N} \quad R C_{15}-1.33 R C_{15}+.33
$$$$
\left.R C_{15-1}+.33 R C_{15-2}\right)
$$

Most of the parameter estimates are remarkably similar considering that different time periods and temporal disaggregations were used. The regressive expectations variable $\left(R C_{-1}^{N}\right)$ unfortunately acquires the wrong sign in our equation as does the ATM variable. Dropping ATM did not improve matters any, as $\mathrm{RC}_{-1}^{\mathbf{N}}$ was still positive.

(22) For easy reference, we report Courchene's results (in our notation, ) $R^{10}-R_{91}=.4501-.5339 \Delta R_{91}-.2335 \Delta R_{91-1}-.00010$ GNP*P

$+.2111 A T M-1.643 R_{-1}^{10 N}-.00131 \Delta S_{t}-.6876 x_{1}-.5947 x_{2}$

Where $R^{10}$ is the ten year government rate

$\mathbf{x}_{1}=$ conversion dummy

$X_{2}=$ austerity dummy

$R^{10 N}=R^{10}$ - (eight quarter average of $R^{10}$ ) 
Dropping also the normal rate variable yielded.

14.2

$$
\begin{aligned}
R C_{15}-R_{91}= & -.7047476 \Delta R_{91}-.407046 \Delta R_{91-1} . \\
& (3.86986) \quad(3.068117) \\
& -.00003092 G N P * P-.00011180 \Delta S_{-1}-.95850 x_{3} \\
& (2.73054) \\
& +3.42087
\end{aligned}
$$$$
\text { (7. 779364) }
$$$$
\overline{\mathrm{R}}^{2}=.776355 \mathrm{Su} / \overline{\mathrm{y}}=21.4406 \text { D. W. }=.82527
$$

The Durbin-Watson and the $\overline{\mathrm{R}}^{2}$ (in comparison with 14. 1)

indicate that by excluding the regressive expectations variable we lost considerable information about the interest rate determination process. Accordingly, we decided to approach the spread from an entirely different empirical point of view and attempt to fit the sort of expectations model presented by Modigliami and Sutch. ${ }^{(23)}$ Basically that model hypothesizes the same sort of expectation influences suggested by Courchene, but they are formulated in a different testable form. Specifically, their Preferred Habitat model collapses to: ${ }^{(23)}$
a.

$$
R C_{15}=+B_{0} R_{91}+\sum_{i=1} B_{i} R_{91-i}+E
$$

Subtracting $R_{91}$ from both sides yields

b. $\quad\left(R_{15}-R_{91}\right)=+\left(B_{0}-1\right) R_{91}+\sum_{i=1}^{N} B_{i} R_{91-i}+E$

(23) Franco Modigliani and Richard Sutch, "Inrovations in Interest Rate Policy", American Economic Review, Vol. 56, No. 2, pp. 178-196. 
Attempts to fit b. directly were unsuccessful in that the parameter on $R_{91}$ was consistently greater than one and given that "the coefficient A (our Bo) should be positive but distinctly below unity ... (24) led us to believe that perhaps we had in some way mis-specified the equation for the Canadian data.

The single most important influence excluded from model b. is that of the level of U.S. rates. Since the capital market in the U.S. is much larger than that in Canada, one would expect that international arbitraging is a much more important influence in Canada than it is in the U.S. In particula $x$, if a significant (exchange covered) differential between Canadian and U.S. rates developed, the capital inflow might be large. The prospect of these flows would prompt the monetary authority to close the differential. This action would follow from its desire to maintain exchange rate stability.

The effect on the long-short spread of an increase in (USCBR $\mathrm{RC}_{15}$ ) would be negative - given that the monetary authority reacts in the way that we have represented it. This follows from the fact that monetary restraint would work through the short end pushing up $R_{91}$ and lessening the differential. In subsequent periods, the effect would be positive as the higher short rates in the preceding period filter through to the long end.

(24) Ihid. pp. 187-188 
Model b. adjusted for these influences yields

$$
\begin{aligned}
& 14.3\left(R_{15}-R_{91}\right)=-.72219907 R_{91}+.16626 R_{91-1}+.09352 R_{91-2} \\
& \begin{array}{lll}
(8.01496) \quad(3.20266) \quad(3.20266)
\end{array} \\
& +.04156 R_{91-3}+.01039 R_{91-4} \\
& \text { (3.20266) (3.20266) } \\
& \text { - } 1.07960 \text { (USCBR - RC } 15 \text { ) +. } 1892212 \\
& \text { (4. 961926) (1.112102) } \\
& \begin{array}{ll}
\left(U S C B R-R_{15}\right)_{-1} & +2.6003 \\
(14.811050)
\end{array} \\
& \bar{R}^{2}=.962495 \mathrm{Su} / \bar{y}=8.78015 \text { D. } W_{0}=1.3312
\end{aligned}
$$

14. 3 is by far the best fit obtained in any of our attempts but it is not really in agreement with the Modigliani - Sutch results either. Their equation fitted best when the lag pattern on $R_{91}$ was constrained to lie along a fourth degree polynomial. This produced an inverted - u shaped lag distribution - quite at variance with our geometrically declining weights. We had no success at all with fourth degree polynomials and produced the best results with a second degree polynomial. The shape of the distribution is not changed if the polynomial is not constrained to have zero slope at the end point - we constrained it to be zero to save the degree of freedom which is lost if it is not so constrained.

In addition to the foregoing elaborate hypotheses, we also tested some simple mechanisms relating the corporate rate to the longterm government rate (which is linked to the short rate in the following 
section) and the average term to maturity of the public debt. The latter determines the degree of competition for funds which the public debt provides in the long end of the market.

The best equation obtained was:

14.4 $\mathrm{RC}_{15}=.120222 \mathrm{ATM}+.8348009 \mathrm{R}_{15}+.242129$

$$
\begin{array}{lll}
(1.78665) & (9.096523) & (.35703207)
\end{array}
$$

$\overline{\mathrm{R}}^{2}=.836830 \mathrm{Su} / \overline{\mathrm{y}}=8.31263$ D. W. 2.0696

\section{B. The Government Rate}

Essentially the same equations which were tried in the preceding section were also tried with the long government - treasury bill spread.

The Courchene equation (15. 1) produced uniformly poorer results with the government rate. Both the ATM and $R_{15}^{N}$ variable were wrongly signed and the overall fit was very poor.

15. $1 \quad\left(R_{15}-R_{91}\right)=-.65081644 \Delta R_{91}-.344067 \Delta R_{91-1}$

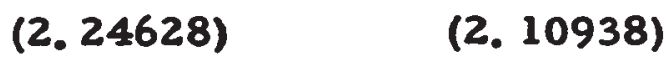

$$
\begin{aligned}
& -.00002527 \text { GNP*P }+.08711443 R_{15-1}^{N}-.00021408 \\
& \begin{array}{lll}
(1.537014) & (15909) & \text { (. 18999) }
\end{array} \\
& \Delta S_{-1}-.1893254 A T M+.29633 x_{3}+4.11751 \\
& \begin{array}{lll}
(.958324) & (.27837) & \text { (3.0708) }
\end{array} \\
& \bar{R}^{2}=.519264 \mathrm{Su} / \bar{y}=32.76196 \text { D. W. }=1.2523
\end{aligned}
$$

Deleting the regressive expectations and ATM variables improved the fit slightly (15.2) but did not "save" the equation as it did for RC 15. 
$15.2\left(R_{15}-R_{91}\right)=.462616 \Delta R_{91}-.313773 \Delta R_{91-1}-.00003352 G N P * P$
(2. 30261$)$
(2. 14378)
(2. 68335)

$$
\begin{array}{ccc}
-.0002058 \Delta S_{-1} & -.480833 x_{3}+2.941183 \\
(.212594) & (.75054) & (6.0626)
\end{array}
$$

$$
\overline{\mathrm{R}}^{2}=.57109 \mathrm{Su} / \mathrm{y}=30.94564 \text { D. W. } 1.390185
$$

Attempts were also made to generate a "Preferred Habitat" equation for $R_{15}$ along the lines which were found to be successful in the preceeding section.

In the simple form generated by model $b$. of section (iii) $A$. the Preferred Habitat equation fit much better than it did for $\mathrm{RC}_{15}$. $R_{91}$ entered with a negative coefficient less than one - a result not obtained when model b. was used in the unadulterated form to explain $\mathrm{RC}_{15}$. Also, it was found that a third degree polynomial constrained to have zero slope at the end point worked better than the second degree similarly constrained. Here, as with the corporate rate, no success was had with various configurations of a fourth degree polynomial. The equations obtained for the second and third degree polynomials distributed over $t-1$ to $t-5$ are as follows: Second degree.

$$
\begin{aligned}
& 15.3\left(R_{15}-R_{91}\right)=-.711304 R_{91}+.19769 R_{91-1}+.1112 R_{91-2} \\
& \begin{array}{lll}
(6.51406) \quad(3.1846) & \text { (3. 1846) }
\end{array} \\
& +.04942 R_{91-3}+.01236 R_{91-4}+2.65673 \\
& \text { (3. 1846) } \\
& \text { (3. 1846) } \\
& \text { (12. 33856) } \\
& \bar{R}^{2}=.77269 \mathrm{Su} / \bar{y}=22.52803 \quad \text { D. W. }=1.826
\end{aligned}
$$


Third degree.

$$
\begin{aligned}
& \text { 15. } 4\left(R_{15}-R_{91}\right)=-.79994 R_{91}+.03559 R_{91-1}+.19345 R_{91-2} \\
& \begin{array}{lll}
(6.89881 & (.31077)
\end{array} \\
& +.16306 R_{91-3}+.06003 R_{91-4}+2.79664 \\
& \begin{array}{lll}
(2.30917) & (2.05479) & \text { (12.735451) }
\end{array} \\
& \overline{\mathrm{R}}^{2}=.799052 \quad \mathrm{Su} / \overline{\mathrm{y}}=21.18158 \quad \text { D. W. 2. } 19416
\end{aligned}
$$

The extra inflection point provided by the third degree lag distribution improved the fit slightly but the over-all fit was still rather poor. Introducing the instrument for the monetary authority's reaction to the domestic - U. S. rate spread improved the fit of both equations. In the case of the third degree polynomial the introduction of the (USCBR$R_{15}$ ) variable made the Almon variables become insignificant and the inverted "u" shaped lag distribution collapsed to an exponentially declining one.

When the stock of treasury bills was added to the equation, the third degree again seemed appropriate. The resultant equation was:

$$
\begin{aligned}
& \text { 15. } 5\left(R_{15}-R_{91}\right)=-.6223 R_{91}+.25957 R_{91-1}+.20378 R_{91-2} \\
& (10.03706) \quad(5.66836) \quad(5.66836) \\
& +.11624 R_{91-3}+.03548 R_{91-4}-1.11591697 \\
& \begin{array}{lll}
(3.28992) & (2.52754)
\end{array} \\
& \left(U S C B R-R_{15}\right)-.00079724 S+2.71260 \\
& \text { (3. 70903) (27.3482) } \\
& \bar{R}^{2}=.970137 \quad \mathrm{Su} / \bar{y}=8.16554 \text { D. W. }=1.67253
\end{aligned}
$$


The addition of ATM and/or income to 15. 5 did not improve the equation and it was decided not to pursue this sort of equation further. We did experiment with some simple mechanisms, however, again because of the unpredictable behaviour of reduced forms.

Our experimentation with simple equations departs radically from the foregoing in that we made the assumption that much of the variation in the long-term government rate is a product of debt management-monetary policy manipulations. Of course, all such manipulations are subject to mitigation by existing market forces and we attempt to account for this by the introduction of other variables.

Two measures of policy were tried; the total supply of government securities net of holdings of the Bank of Canada and tha average term to maturity of the public debt. Each of these was used in a regression containing short rates and income. The two equations obtained were 15.6 $R_{15}=.00023336($ GST - BOCS $)+.2991147 R_{91}+.00001641$
(1. 7193673)
(2. 93830$)$
(1. 67964)

$$
\begin{aligned}
& \text { GNP*P }+.58405 \mathrm{X}_{3}+2.52526 \\
& \text { (2. 96679) (14.70637) } \\
& \overline{\mathbf{R}}^{2}=.92409 \quad \mathrm{Su} / \mathrm{y}=7.3398 \quad \text { D. W. } 1.7366
\end{aligned}
$$


15.7 $R_{15}=.076305$ ATM $+.3348078 R_{91}+.00003884$ GNP *P

$\begin{array}{lll}(1.019979 & (2.66658) & (2.46213)\end{array}$

$+1.445196$

(2. 261705)

$\bar{R}^{2}=.87254 \quad S u / \bar{y}=8.7258 \quad$ D. $W_{0}=1.76059$

Both of the simple equations fit fairly well. No attempt will

be made to select which of these equations (simple or sophisticated) is best until preliminary simulations have been run.

(iv) Consumer Credit

This short section has been included to provide for the determination of non-bank sources of liquidity. Its inclusion is motivated by the rapid growth of non-bank credit over the sample period. The consumer debt variable (CONC) includes instalment loans, retail credit, and all manner of cash loans - it excludes chartered bank loans since they have been covered implicitly in the bank deposit block.

The total amount of consumer credit outstanding is postutated to depend, via a credit-expansion-multiplier process, on the total supply of money. A time trend is included to allow for the changing composition of the credit variable over time and for the proliferation of credit instruments.

The equation obtained was: (25)

(25) Primes on the variables indicate that they have been adjusted for the estimated autoregressive structure of the residuals. See Arthur S. Goldberger, Econometric Theory, (John Wiley \& Sons, New York, (1964), Pp. 236-238. 
16. $\operatorname{CONC}^{1}=.1005(\mathrm{ND}+\mathrm{SD}+\mathrm{DD}+\mathrm{Car})^{1}+92.68 \mathrm{TIME}^{1}$

$$
\begin{gathered}
(2.0122)) \\
-429.6^{1} \\
(1.53342) \\
\bar{R}=.97370 \mathrm{Su} / \bar{y}=4.95 \quad \text { D. W. } 1.8011 \\
\text { RHO }=.5813
\end{gathered}
$$

We have now finished the specification and estimation of the equations of the monetary sub-model. The next chapter deals with the equations of the real sector. In Chapter.IV, the equations of both submodels will be assembled for easy reference and a glossary of terms will be provided. 
APP ENDIX A CHAPT ER II

DATA

\section{Section A - Units of Measure}

The units of measure used in the equations are as follows:

(a) All monetary and real stocks and flows representative of value magnitudes are in millions of dollars: the real sector variables are in constant dollars with 1957 as a base year and the monetary variables are in current dollars.

(b) Monetary stocks are averages of monthly stocks (or quarterly if monthly were not available) and real stocks are estimated midyear approximations.

(c) All flows are at yearly rates.

(d) All dimensionless numbers are scaled per centum, i. e. five per cent is written as 5.00.

(e) Population and labour force statistics are in thousands.

(f) Hours of work are in hours per year per man.

(g) Wages are in constant dollars per man hour.

(h) Labour productivity is measured in constant dollars per man hour. 


\section{APPENDIX B CHAPTER II}

\section{DATA}

\section{Section A - Sources and Procedures}

Each of the series in section $A$ is identified by a single integer. In discussing the procedures used to derive them and/or indicating the source we shall refer only to that index. The corresponding name given to the variable in the model will be indicated and if it is a "real sector series" whether it is measured in current or constant dollars. Due to the fact that some of the variables in the model were constructed in the regression program itself, not all variables appear.

In general, the series for the real sector were obtained from Dominion Bureau of Statistics publications or directly from the Bureau if the data required were unpublished. In the following notes data taken from D. B.S. published material will be indicated as D. B.S. \#XXXX, TAB. YYY. COL. ZZZ (XXX referring to the publication number, YYY to the table number and $\mathrm{ZZZ}$ to the column number). If the data are unpublished, D. B. S. Work Sheets (W.S.) will be indicated.

Monetary series were obtained from the Bank of Canada Annual

Statistical Review and since the series are continuous only the name of the series as presented in the Review will be indicated. Researchers interested in following up these series should have no difficulty if they refer to the most recent Review and from there follow the series back. 
This is true of all the series except demand deposits of the Chartered

Banks--this series is erroneously presented in the 1966 review due to the mistreatment of "items in transit". (1)

Expenditure and Income

1. CND

Non-durable consumption expenditures

47-61 = D. B. S. 13-519: Table 9, Col. $4+$ Co. 2 . 61-66 = 11-003: Table 11; Col. 7 + Co. 6 (or)

(13-201) Table 48, Col. $11+\mathrm{Col}$. 12 .

Constant 57 dollars.

2. CD Consumer Durable expenditures

47-61 = D. B.S. 13-519: Table 9, Col. 3 ,

61-66 = D. B.S. 11-003: Table 11, Co. 5 or

D. B.S. (13-201) Table 48, Col. 10.

Constant 57 dollars.

3. GIBUS Gross Business Investment

D. B.S. (13-519): Table 18, Col. 7

D. B.S. (13-201): Table 5, Col. 5 .

Constant 57 dollars.

4. $\mathbf{H}_{\mathbf{j}}$

Mid-year stock of private sector inventories 1947 e stimate. from T. M. Brown, op. cit. 1964. p. 230. 1948-1966 = computed from

$\mathrm{H}_{\mathbf{j}}=\mathrm{H}_{\mathbf{j}-1}+1 / 2 \mathrm{DH}_{\mathrm{T}}$

Constant 57 dollars.

5. $\mathrm{H}$

47-61 D. B.S. (13-519): Table 9, Col 12

61-66 D. B.S. (13-201): Table 5, Col. 9

6. CONG

Total government expenditures on current account inclusive of Federal defence expenditures

D. B.S. - W. S.

Constant 57 dollars.

(1) I am indebted to T.J. Courchene for this observation. 
7. GIG

8. FDSK $\$$

9. F2

10. F1

11. FT2

12. FT 1

13. Pdi

14. Pid

15. GDP

16. GNP
Total government expenditure on capital account inclusive of Federal defence expenditures

D. B. S. - W. S.

Constant 57 dollars.

Total Federal defence spending as per D. B.S. - W.S. deflated by the NNP Deflator $P$.

Total Exports excluding interest and dividends = FT2 - PID.

Total Imports excluding interest and dividends $=$ FT 1 - PDI.

Total Exports inclusive of interest and dividends

47-61 = D. B.S. (13-519): Table 9, Col. 16

61-66 = D. B.S. (13-201): Table 5, Col. 12.

Total Imports inclusive of interests and dividends

47-61 = D. B.S. $(13-519)$ : Table 9, Col. 17

61-66 = D. B.S. (13-201): Table 5, Col. 13.

Interest and dividends paid from the domestic economy to the international sector

47-61 = D. B.S. $(13-519):$ Table 4, Col. 5

61-67 = D. B.S. $(13-201):$ Table 4, Col. 5

Deflated by the NNP deflator $P$.

Interest and dividends paid to the domestic economy from the international sector

47-61 = D. B.S. $(13-519):$ Table 4, Col. 4 61-66 = D. B.S. $(13-201):$ Table 4, Col. 4 Deflated by the NNP deflator $P$.

GNP + (PDI-PID).

GNE Gross national product assumed equal to gross national expenditure.

$47-61=$ J. B. S. $(13-519):$ Table 9, Col. 20

61-66 = D. B.S. $(13-201):$ Table 5, Col. 15

Constant 57 dollars. 
17. $w$

18. MPAA

19. PEY

20. JM

21. $\mathbf{T}_{\mathbf{i}-\mathbf{s m}}$

22. $D_{m}$

23. $\frac{1}{2} \mathrm{R} 1$

24. PCUM
Wage and Salary incomes plus military pay and allowances

47-61 = D. B.S. (13-519): Table 1, Col, 1 and 2 61-66 = D. B.S. (13-201): Table 1, Col. 1 and 2 Current dollars.

Military pay and allowances

Col. 2 .

Property and enterprise income of residents

47-61 = D. B.S. $(13-519):$ Table 1, Col. $3,4,5,6$ 61-66 = D. B.S. (13-201): Table 1, Col. 3, 4, 5, 6. Current dollars.

Capital gains on inventories = Negative of inventory valuation adjustment

47-61 = D. B.S. $(13-519):$ Table 1, Col. 8 61-66 = D. B.S. $(13-201)$ : Table 1, Col. 8.

Current dollars.

Indirect taxes less subsidies

47-61 = D. B.S. $(13-519):$ Table 1, Col, 10

61-66 = D.B.S. $(13-201)$ : Table 1, Col. 10. Current dollars.

Capital consumption allowances and miscellaneous valuation adjustments

47-61 = D. B.S. $(13-519):$ Table 1, Col, 11 61-66 = D. B.S. (13-201): Table 1, Col. 11 . Current dollars.

Residual error of estimate in GNP

47-61 = D. B.S. $(13-519):$ Table 1, Col. 12 61-66 = D. B.S. (13-201): Table 1, Col. 12.

Current dollars.

Undistributed corporate profits $47-61=$ D. B.S. $(13-519):$ Table 7, Col. 3 61-66 = D. B.S. $(13-201)$ : Table 17, Col. 49a. Current dollars. 
25. PWBM

26. Y YM

27. $Y M$

28. YPM

29. $\frac{1}{2} \mathbf{R} 2$

30. GNPM

31. PDPCM

32. D

33. PCU

34. $\mathbf{P}$
Wheat board profits

47-61 = D. B.S. $(13-519)$ : Table 7, Col. 5

61-66 = D. B. S. (13-201): Table 17, Col. 49 c. Constant dollars.

Government disposable income

D. B. S. (13-502): Table 9, row 18

- Table 10, row 21-- row 20(a)--row 20(b).

Current dollars.

Private sector disposable income $=$ YPM + PCUM + PWBM

Current dollars.

Personal disposable income

$47-61=$ D. B. S. (13-519): Table 4, Col. 13

$61-66=$ D. B. S. (13-201): Table 3, Col. 17.

Current dollars.

Residual error of estimate in GNE

47-61 = D. B. S. (13-519): Table 9, Col. 18 61-66 = D. B.S. (13-201): Table 5, Col. 14. Current dollars.

Gross national product

47-61 = D. B.S. $(13-515):$ Table 1, Col. 13 61-66 = D. B.S. (13-201): Table 1, Col. 13. Current dollars.

Price deflator for plant machinery and equipment

$\frac{1}{x} \overrightarrow{-61}=$ D. B. S. $(13-519):$ Table 19, Col. 9

61-66 - D. B. S. (13-201): Table 6, Col. 8.

$\mathrm{DM} \div$ PDPCM

PCUM :- PDPCM

NNP deflator

GNEM-PCUM-DM $\times 100$ 
35. TI-S

TI-SM $\div \mathbf{P}$

36. PEY

$\frac{P E Y M-P C U M}{P}+\frac{\text { PCUM }}{\text { PCPCM }}$

37. $Y G$

$\mathbf{Y G M}: \mathbf{P}$

Population, Employment and Wages

38. POP

Total Canadian Population

B of C ST. Sum. P. 117 of 1964; P. 135 of 1967

Thousands.

39. NI

Total Labour Force (including military and Northwest territories)

B of C ST. Sum. P. 131 of 1963

P. 120 of 1964

P. 139 of 1967

Plus digits for Northwest territories 8, 8, 8, 8, 9, 9, $9,10,10,11,11,11,11,11,11,12,12,12,13,13$ (1947-67).

40. NI-NM

Civilian Labour Force

B of C ST. Sum. P. 131-1963

P. 120-1964

P. 139-1967.

41. NE

Civilian Employment

B of C ST. Sum. P. 131-1963

P. 120-1964

P. 139-1967.

42. $\mathrm{NU}$

Unemployment

B of C ST. Sum. P. 131-1963

P. 120-1964

P. 139-1967.

43. NUPC

Unemployment as a percent of the Labour Force

B of C ST. Sum. P. 131-1963

P. 120-1964

P. 139-1967. 
44. NPG

45. NENP

46. $h$

47. I

48. Wh

49. $P_{L}$

Capital Stock

50. TPPIME

51. TPPIPC

52. TPPIH
Employed Paid Workers

B of C ST. Sum. P. 25-1963; P. 17-1965 through 1967.

Employed own account workers

Ne-NPG.

Average hours of work per worker per year

Special Surveys Division

D. B. S., Table 3(b)

All status groups total with weights

8. $0,20.0,30.0,40.0,49.0,55.0$.

Manhours of labour input per year

Ne $\times$ h.

$\frac{(W M-M P A A) / P}{(N P G \times h)}=$ Real Wages

Productivity Relative to Labour

(GDPc/Ne)

Total public and private investment in machinery and equipment

DBS (13-201) Table S4 col. 4 deflated by estimated 57 constant dollar index plus DBS (13-519)

Table 18 col. 10 and DBS (13-201) Table 5 col. 8.

Total public and private investment in plant and non-residential construction

DBS (13-201) Table 54 col. 3 deflated by estimated 57 constants dollar index plus DBS (13-519) Table 18 col. 9 and DBS (13-201) Table 5 col. 7.

Total public and private investment in housing DBS (13-201) Table 54 col. 2 deflated by estimated 57 constant dollar index plus DBS (13-519) Table 18 col. 8 and DBS (13-201) Table 5 col. 6. 
53. CSTOT

$\operatorname{CSTOT}_{\mathbf{t}}$

54. TPPSME

55. TPPSPCH

56. $D_{r}$

57. A
Total stock of fixed Capital. This series was generated from starting estimates of the stocks of TPPSME, TPPSPC and TPPSH made by T. M. Brown (op. cit. 1964), p. 228, 229, and the following formula

$($ TPPSME + TPPSPC + TPPSH) $(\text { TPPIME + TPPIPC + TPPIH })_{t}-D_{r}$ where depreciation was calculated from the formula $D_{r}=.0625(\text { TPPSME })_{-1}+.04(T P P S P C+T \text { PPSH })_{-1}$

Total Stock of machinery and equipment TPPSME $_{t}=$ TPPIME - . 0625 (TPPSME $_{t-1}+$ TPPSME $\left._{t-1}\right)$

Total stock of plant and construction

TPPSPC $=$ TPPIPC $-.04\left(\right.$ TPPSPC $_{t-1}+$ TPPSPC $\left._{t-1}\right)$

See note on 53.

Technical Progress taken from Brown, 1964, op. cit. , p. 218, col. 13.

Monetary Series

All series for the monetary variables were generated from the most frequently published series available (down to monthly). The procedure used was simple averaging and all series are taken at month end (whe re possible or applicable). In each case the under scored phrase refers to the name given to the series in the Bank of Canada Stat. Sum. If the series come fram elsewhere this is noted.

58. $\mathrm{CIC}$

59. Cur

60. COIN

61. HPM
Bank of Canada Notes and deposits held by the chartered banks

Currency outside Banks

Coin outside Banks

CIC $+($ CUR - COIN $)=$ High Powered Money 
62. RS

63. DD1

64. PGD

65. DD

66. SD

67. ND

68. DOB

69. SCDO

70. SCDF

71. SC

72. CONC

73. FIL

74. $\mathrm{RC}_{15}$
Supply of reserves to the bank HPM - (CUR - COIN)

Public Demand Deposits

Deposits of the Provincial Governments

DDI + PGD

Personal Savings Deposits

Other Notice Deposits

Other Banks Deposits

Bonds outstanding 1966 stock taken from 1967 B. of C. Statistical Summary P. 97 and includes Bonds payable in other currencies. The series is then generated by carrying the stock backwards using the Securities Issues series on P. 89 of the same copy of the Summary.

Bonds Outstanding including those issued in domestic currency as for 69.

Total securities outstanding and equals SCDO + SCDF

Total consumer credit excluding personal bank loans and includes credit from: Sales Finance Companies, Consumer Loan Companies, Dept. Store Credit, Furniture and Appliance Dealers, Motor Vehicles dealers and Other Retail Dealers in each case both installment and charge account credit a re included. The figure for 1947 is an estimate by the author .. based on various incomplete sources.

Finance and loan company credit and equals. Consumer Loan Companies credit.

High Grade corporate Bond yield Average of quarterly data where available.

$1947-1950$

Historical Statistics for Canada, M. C. Urquhart ed., Toronto, Macmillan, 1963. Series No. 591 in 1951-1962, McLeod, Young and Weir, in "Current Business Trends in Canada, in 1963 ed., p. 27 
1963-1966 McLeod, Young and Weir, Pamphlet entitled "Interest Rates" published by McLeod, Young and Weir.

75. USCB R Average Corporate Bond rate in the United States From. Business Statistics published by the U.S. Dept. of Commerce Series Finance - Security Markets, Bonds-Corporate Average.

76. $\mathbf{R}_{\text {ond }}$

Rate on notice deposits = dollar weighted average (with estimated weighting) of notice deposit rates. obtained from the Banking Section, Bank of Canada Research Dept.

77. $R_{91}$

Treasury Bills average yield, 91 day bills.

78. $R_{15}$

Government of Canada Direct and Guaranteed Securities. Bond prices and yields (approximate) 15 years.

79. GST

Government of Canada Direct and guaranteed Securities, total stock outstanding.

80. BOCS

Bank of Canada Holdings of Securities

81. $R_{\text {svd }}$

Chartered Bank savings deposit rate; source is same as 76 .

82. ATM

Average term to maturity of Government of Canada Securities, Direct and Guaranteed.

83. $I_{\text {cbpl }}$

Chartered Bank prime lending rate; sources is same as 76. 


\section{APPENDIX C CHAPT ER II \\ METHODS OF ESTIMATION}

Section A - Parameter Estimation

Single equation methods only were used in the estimation of the model - i. e., variants of ordinary least squares and two stage least squares.

Classical, or ordinary least squares was used for preliminary investigations and Principal Component-TSLS or instrumental variables for final fit.

Consider the single equation

1. $\quad \mathbf{Y}=\mathbf{X B}+\mathbf{u}$

assume

$E(u)=s$
$E\left(u^{2} u\right)=s^{2} I$

Rank $X=K \ll N$
$E(u(x-E x))=0$

Where $\mathrm{K}$ is the number of variables and $\mathrm{N}$ is the number of observations.

Then it can be shown that $B=\left(X^{\prime} X\right)^{-1} X^{1} Y$ is the best linear unbiased estimator of $B^{(1)}$. This is the classical least-squa res result.

The validity of the results depends on the validity of the assumptions made. One of the assumptions $\left(E\left(u^{\prime} u\right)=s^{2} I\right)$ means that we assume that no systematic variables of consequence have been omitted from the relationship and that successively drawn u's are therefore independent.

(1) J. Johnston, Econometric Methods, McGraw-Hill, New York, 1963, p. 108-113. 
If the variable being explained is a time series variable, the possibility that this assumption will be violated is quite prominent. This is so because if the small sources of variation omitted from the equation tend to move in phase (and in time series analysis this is most probably the case) and their serial correlation properties are pervasive the successive drawings of $u$ will not be independent.

Taking the off diagonal terms in the covariance matrix into account we have $\hat{B}=\left(X^{1} U^{-1} X\right)^{-1} X^{1} U^{-1} Y$ which is best linear unbiased. (2) This generalized least-squares estimator can be shown to be approximately equivalent to a two step procedure which requires that the variables be transformed according to the autoregressive structure of the error and that least squares be applied to the transformed variables. (3) Our procedure was to use an estimate of the autoregressive structure to transform the data. (A first order Markov process was assumed in each case.) Sample size permitting, this transformation process can be continued until all residual tracking has been eliminated. Because of the small sample we are using only one iteration of this process was used.

Thus far we have considered $Y=X B+u$ as a single self-contained equation. If it is in fact part of a simultaneous system, the assumptions made no longer apply and least squares of the classical variety will not yield best-linear-unbiased estimators.

(2) J ohnston, Ibid, . 184.

(3) J ohnston, Ibid, 186. 
Consider:

$$
\begin{aligned}
& Y_{1 t}=A+B Y_{2 t}+u_{t} \\
& Y_{2 t}=Y_{1 t}+Z_{t}
\end{aligned}
$$

where the $Z_{t}$ are exogenous.

$$
\begin{aligned}
& \text { Assume } \boldsymbol{E}\left(u_{t}\right)=0 \\
& \begin{aligned}
E\left(u_{t} u_{t}+d\right)=0 \text { d } \neq 0 \text { all } t \\
8^{2} d=0 \text { all } t
\end{aligned}
\end{aligned}
$$

In general, however, $E \mathcal{E} u_{t}\left(Y_{t}-\mathbf{E}\left(Y_{t}\right)\right), 0$ and least squares may not be applied. This inter-dependence of $u_{t}$ and $Y_{t}$ can be easily secri

$$
\begin{aligned}
Y_{2 t} & =a+B Y_{2 t}+Z_{t}+u_{t} \\
\text { or } \quad Y_{2 t} & =\frac{a}{1-B}+\frac{1}{1-B} Z_{t}+\frac{u_{t}}{1-B}
\end{aligned}
$$

Hence $E\left(Y_{2 t}\right)=\frac{a}{1-B}+\frac{1}{1-B} Z_{t}$

and $\quad E\left(u_{t}\left(Y_{2 t}-E\left(Y_{2 t}\right)\right)=\frac{1}{1-B} E\left(u_{2 t}\right) \quad 70\right.$

Not only will the estimators be biased under these conditions but the bias persists even for large samples--i. $e_{.}$, consistency is not obtained. (4)

A solution to this problem which confines itself to the specification information of the single equation but which yields consistent estimators has been proposed by Theil. (5) Essentially this approach entails the application of least squares twice. The first application is intended to

(4) J ohnston, Ibid, , p. 234.

(5) Theil, H. Economic Forecast and Policy, 2nd Ed. , Amsterdam North Holland, 1958. 
purge the endogenous variable $Y_{2 t}$ of its dependence on $u_{t}$. The second stage involves the use of the purged variable as a surrogate for $Y_{2 t}$ and the application of OLS to the modified equation.

The method used to purge $Y_{2 t}$ of its systematic dependence on $u_{t}$ is to regress $Y_{2 t}$ on the predetermined va riables in the system and to then use this estimated equation (with the residuals truncated) to generate a series for $\mathrm{Y}_{2 t}$ The problem with this method when the system is large is that the number of predetermined variables exceeds the number of observations. Hence, some method must be found to narrow the focus to the inclusion of only some of the predetermined variables in the first stage. (The number of variables is constrained from below by the condition that $K \geq M$ where $K$ is the number of predetermined excluded variables and $M$ the number of parameters of endogenous variables to be estimated.) One group of methods involves the deletion of variables until $(K+1) / T$ (where $K$ is the number of included predetermined and $T$ is the sample size) is small enough to ensure efficiency. Special casas of this group are the simple deletion of variables and the principal component approaches $(6)$.

Another class of cases not considered here involves the restructuring of the model into many submodels all of which are closed with identities.

(6) T. Kloeck, L. B. M. Mennes, "Simultaneous Equations estimation based on Principal Components of Predetermined Variables", Vol. 28 Econometrica Jan. 1, 1960. 
The principal component technique utilizes most of the information contained in the predetermined set and is therefore more satisfying statistically than the simple deletion technique. However it is still a deletion technique and a more mechanistic one than the simple one. The choice between the two rests on the trade-off between economic meaningfulness and statistical sufficiency.

Having indicated the conditions under-which the technique was used we now indicate the general procedure followed in its application. The problem simply stated is: obtain some linear combination of the predetermined set $Z$ such that the sum of the squares of the correlation coefficients of each va riate with that function is a maximum. Simply stated this means: find some subset (the elements of which are orthogonal) of $\mathrm{Z}$ which reflects to the greatest possible degree the variation in the elements of $\mathbf{Z}$.

One of the approaches to this problem is as follows:

Standardizing the $\mathrm{Z}_{i}$ and writing them in the linear combination form we have

$$
\begin{aligned}
& \mathrm{z}_{1 t}=\mathrm{K}_{11} \mathrm{U}_{1 t}+\mathrm{K}_{12} \mathrm{U}_{1 t}+\ldots+\mathrm{K}_{1 \mathrm{p}} \mathrm{U}_{\mathrm{pt}} \\
& \mathrm{z}_{\mathrm{pt}}=\mathrm{K}_{\mathrm{pl}} \mathrm{U}_{1 t}+\mathrm{K}_{\mathrm{pz}} \mathrm{U}_{2 t}+\ldots+\mathrm{K}_{\mathrm{pp}} \mathrm{U}_{\mathrm{pt}}
\end{aligned}
$$

where the $U_{i t}$ are the principal components and the $K_{i j}$ are constants.

The first condition was that the $U_{1}$ reproduce the correlation

(7) Due to Tintner, G. Econometric8, John Wiley \& Sons, New York, 1952 
between the $Z_{i}$, i. e.

$$
R_{i j}=K_{i 1} K_{i 1}+K_{i 2} K_{i 2}+\ldots+K_{i p} K_{i p}
$$

since the $U_{i}$ are orthogonal $(2)$

Gathe ring the terms associated with Ui we have the contribution of the $i$ th principal component to the variance of all $z_{i}$

$$
s_{i}=k_{1 i}^{2}+k_{2 i}^{2}+\ldots+k^{2}{ }_{p i}
$$

We must now maximize this contribution subject to preserving the relations implied by (2).

$$
\text { Since } s_{i}=\sum K_{i 1}^{2}
$$

we have

$$
F=\sum_{i=1}^{P} \quad K_{i i}^{2}-\sum_{i 1} \sum_{i=1}^{P} \sum_{j=1}^{P} \sum_{s=1}^{P} U_{i j} K_{i s} K_{i s}
$$

Differentiating partially with respect to $\mathrm{K}_{\mathrm{is}}$ and simplifying,

we get:

$$
\begin{aligned}
K_{i 1}=\sum_{j=1}^{P} U_{i} \quad K_{1}=0 & \\
\sum_{j=1}^{P} & U_{i j} K_{j s}=0 \quad S=2, \ldots . P
\end{aligned}
$$

(2) For $P=2$ we have

$$
\begin{aligned}
\mathrm{Z}_{\mathrm{it}} & =\mathrm{K}_{11} \mathrm{U}_{1 \mathrm{t}} \mathrm{K}_{12} \mathrm{U}_{1 \mathrm{t}} \\
\mathrm{z}_{2 t} & =\mathrm{K}_{21} \mathrm{U}_{1 \mathrm{t}}+\mathrm{K}_{22} \mathrm{U}_{2 t} \\
\mathrm{Z}_{1 \mathrm{t}}^{1} \mathrm{Z}_{2 t} & =\left(\mathrm{K}_{11} \mathrm{U}_{1 \mathrm{t}} \mathrm{K}_{12} \mathrm{U}_{2 t}\right)\left(\mathrm{K}_{21} \mathrm{U}_{1 \mathrm{t}} \mathrm{K}_{22} \mathrm{U}_{2 t}\right) \\
& =\mathrm{K}_{11} \mathrm{~K}_{21}+\mathrm{K}_{12} \mathrm{~K}_{22}
\end{aligned}
$$


Multiplying each equation by $\mathrm{K}_{\mathrm{il}}$ and summing over $\mathrm{i}$ we get

(6)

$$
\begin{array}{r}
\sum_{i=1}^{P} K_{i 1}^{2}-\sum_{i=1}^{P} \sum_{i=1}^{P} U_{i j} K_{i 1} K_{j 1}=0 \\
-\sum_{i=1}^{P} \sum_{j=1}^{P} U_{i j} K_{i 1} K_{j s}=0
\end{array}
$$

Observing from equation (5) that

$$
\begin{aligned}
& \stackrel{P}{\underset{E}{P}} U_{i j} K_{i 1}=K_{j 1} \quad \text { and setting } \\
& \underset{i=1}{P} K_{i 1}^{2}=x_{1} \quad \text { a constant, we obtain }
\end{aligned}
$$

$$
\begin{aligned}
x_{1} & -\sum_{j=1}^{P} k_{j 1}^{2}=0 \\
& -\sum_{j=1}^{P} K_{j 1} K_{j s}=0
\end{aligned}
$$

Multiplying each equation by $\mathrm{K}_{\mathrm{is}}$ and summing this time over s we have:

$$
x_{1} K_{i 1}-\sum_{j=1}^{P} \sum_{s=1}^{P} K_{j 1} K_{j s} K_{i s}=0
$$

By (2)

$$
\begin{aligned}
& \mathrm{K}_{11}+\mathrm{R}_{12} \mathrm{~K}_{21}+\ldots+\mathrm{R}_{1 \mathrm{p}} \mathrm{K}_{\mathrm{p} 1}=\mathrm{x}_{1} \mathrm{~K}_{11} \\
& \mathrm{R}_{1 \mathrm{p}} \mathrm{K}_{11}+\mathrm{R}_{2 \mathrm{p}} \mathrm{K}_{21}+\ldots \mathrm{K}_{\mathrm{p} 1}=\mathrm{x}_{1} \mathrm{~K}_{\mathrm{p} 1}
\end{aligned}
$$

which is a system of linear homogeneous equations having a non-trivial solution if and only if

$$
D_{\text {et }}\left|\begin{array}{llll}
\left(1-x_{1}\right) & R_{12} & \cdots & R_{1 P} \\
R_{1 P} & & & \left(1-x_{1}\right)
\end{array}\right|=0
$$

using (7) it can be shown that the largest root of (10) is associated with 
the first principal component. The coefficients of the first principal component may be extracted by back substitution from (9).

Computing the second largest root of (10) and inserting it into (9) instead of $X_{1}$, we compute the second principal component and so on.

An Algorithm which computes the roots of such a system iteratively and computes the factor loadings (the $\mathrm{K}_{\mathrm{pp}}$ ) is available on request from the author.

Section B - Non-linearities

The presence of non-linearities in the model poses some problems for the interpretation of two-stage least squares. In order to demonstrate the difficulties involved and the method of solution employed here, the following simple model is presented.

$$
\begin{aligned}
& \mathbf{Y}=\mathbf{C}+\mathbf{Z} \\
& \mathbf{C}=\mathbf{A}+\mathbf{B} \mathbf{Y}+\mathbf{U}
\end{aligned}
$$

Two-stage least squares applied to this model would yield the following second stage estimating equation for (2).

$$
\left(2^{1}\right) C=A_{1}+B_{1}(\hat{F}+\hat{P} Z)+(U+B e)
$$

The existence of such an equation rests on the fact that the model can be reduced to a closed form in the endogenous variables. Use of the exogenous variables to obtain surrogates for the troublesome righthand endogenous is then justified.

However, consider the following equation as a replacement 
for (2)

$$
C=A+B Y^{2}+U
$$

By substitution

$$
C=A+B\left(Z^{2}+2 C Z+C^{2}\right)+U
$$

Hence the reduced form cannot be represented in closed form and the ordinary two stage procedure is not well defined. Two-stage least squares can still be used, however, if it is interpreted in the following way.

Since the reduced form is now a polynomial in the endogenous and exogenous variables we can get a linear surrogate only if we somehow approximate the function. Hence, the first stage in the two stage procedure must be regarded as a Taylor series expansion approuimation to the true non-linear reduced form.

Having decided to use this interpretation one must decide on the particular form which the non-linearities will take in the first stage. (That is, do we get a surrogate for $Y$ and square it or square $Y$ and get a surrogate for it.) Relying on research conducted by Richard Quandt and Stephen M. Goldfeld, we opted for the latter procedure.

(8) Goldfeld, S. M. and R. E. Quandt, "Non-Linear Simultaneous Equations: Estimation and Prediction", Paper presented to the World Congress of the Econometric Society, Rome, (September, 1965). 


\section{APPHNDIX D CHAPT ER II}

Section A - Lagged Variables and Structural Hypotheses

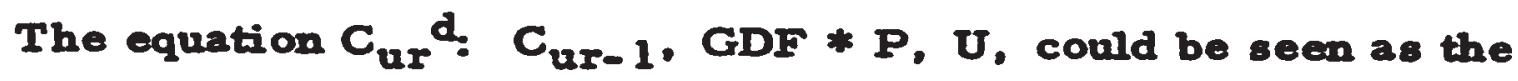
testable form of two distinguishable hypotb eses. If we believe that the current demand for currency is dependent on the previous stocks demanded in a direct causal sense, we would write the habit-persistence formulation(1)

$$
C_{u r} \text { : } C_{u r-1}, C_{u r-2} \cdot . \cdot C_{u r-N}, \operatorname{GDP} * P, U_{2}
$$

However, since $C_{u r-1}$ embodies the inertial effects of $C_{u r-2} \cdot \cdot C_{u r-n}$ we can write

$$
C_{u r} \text { : } C_{u r-1}, \operatorname{GDP} * P, U_{2}
$$

If a delayed-response, stock-adjustment-type hypothesis is used and the optimal stock of currency is $C_{u r} *=f(G D P * P)$ and we postulate the following adjustment mechanism $\left(C_{u r}-C_{u r-1}\right)=b\left(C_{u r} *-\right.$ $\mathbf{C u r - 1}_{\mathrm{ur}}$

Substitution yields $C_{u r}=b C_{u r} *(1-b) C_{u r-1}$

$$
=b(G D P * P)+(1-b) C_{u r-1}
$$

which yields (2) as a testable form.

The stock-adjustment hypothesis and habit-persistence hypothesis thus appear to be statistically indistinguishable. However, since the habit-persistence parameter $=(1-b)$ where $b$ is the stock adjustment parameter both kinds of information are yielded by testing (2).

(1) see T. M. B rown, ㅇp. cit, 1952. 
Another model can arise from (1) if it is transformed to get rid of second order lags along the lines suggested by Koyck(2). This model may be written

$$
C_{u r}^{d}=a_{0}(1-F)+a_{i} G D P-A_{1} F G D P=1+\left(b_{2} F\right) C_{u x-1}
$$

where exponential decline of influence is assumed.

We could test this hypothesis as

$$
C_{u r}^{d}: \text { GDP, GDP-1 }, C_{u r-1}, U_{2}
$$

Actual tests on (3) indicated that the parameter of GDF_1 was not significantly different from zero - a possible consequence of the fact that $C_{u r-1}$ and $G D P_{-1}$ are almost collinear.

In any event, (3) did not explain variations in $C_{u r}$ to a sufficiently greater degree than (2) to warrant more extensive analysis.

(2) L. M. Koyck, Distributed Lags and Investment Analy sis, North-Holland Publishing Company, Amsterdam, 1954. 


\section{APPENDIX E CHAPT BR II}

Section A - Taylor Series Approcimation

The purpose of this appendix is to outline a general approximative non-linear approach to the construction of statistical hypotheses. The motivation behind the non-linear approach may be that the theory suggests a non-linear functional form or that linear forms refuse to fit when the functional form is not speciflable a priori.

The exercise presented here stems from Goldfeld's exposition of a particular case and is only meant to be a helpful summary of the sort of multiplicative linear testable hypotheses which can arise from a simple, a priori non-linear form and an indication of how a priori specifications can be used to restrict the forms tried. Substantial use of this sort of approximation has been made in this work and this appendix may be seen as justification for the usages.

A simple, non-linear function often used in economics is the Cobb-Douglas form. Since it is familiar it will be used throughout this exercise.

$$
\begin{aligned}
A_{i}=C R^{a} W^{b} Y^{c} & \text { where } A_{i} \text { is any asset (say) } \\
& R \text { is any interest rate (say) } \\
& Y \text { is any income variable and } w \text { is any wealth } \\
& \text { va riable. }
\end{aligned}
$$

Assuming that all other things are held constant (as we do, in fact, in multiple regression analysis) we expand the function, in turn, 
along each of its "branches" in a Taylor series (truncating higher-order terms)

$$
\begin{aligned}
A_{i}(R / W, Y) & =R_{0}^{a}+A R_{0}^{a-1}\left(R-R_{0}\right) \\
& =R_{0}^{a}+A R_{0}^{a-1} R-A R_{0}^{a-1} R_{0} \\
& =\left(R_{0}^{a}-A R_{0}^{a-1} R_{0}+A R_{0}^{a-1} R\right. \\
& =A_{0}+A_{1} R
\end{aligned}
$$

where $A_{0}=\left(R_{0}^{a}-A R_{0}^{a-1} R_{0}\right)$ and $A_{1}=A R_{0}^{a-1}$

Simila rly

$$
\begin{aligned}
& A_{i}(W / R, Y)=B_{0}+B_{1} W \\
& A_{i}(Y / R, W)=C_{0}+C_{1} Y
\end{aligned}
$$

Hence:

$$
\begin{aligned}
A_{i}= & \left(A_{0}+A_{1} R\right)\left(B_{0}+B_{1} W\right)\left(C_{0}+C_{1} Y\right) \\
R H S= & A_{0} B_{0} C_{0}+C_{0} A_{0} B_{1} W+C_{0} A_{1} B_{0} R \\
& +C_{0} A_{1} B_{1} R W+C_{1} A_{0} B_{0} Y+C_{1} A_{0} B_{1} W Y+A_{1} B_{0} C_{1} R Y \\
& +A_{1} B_{0} C_{1} R Y+A_{1} B_{1} C_{1} R Y Y \\
R H S= & C_{0}+C_{1} W+C_{2} R+C_{3} Y+C_{4} W R \\
& +C_{5} W Y+C_{6} R Y+C_{7} R W Y
\end{aligned}
$$

The number of variables appearing in (5) can be limited if one has a priori information on the forms of 2,3 , or 4 . For example, if it is deemed reasonable to assume that portfolio ratios are approximately constant, then a relationship of proportionality exists between $A_{i}$ and $W_{.}$, hence 3 become $A_{i}\left(W / R_{1} Y\right)=B_{1} W$ and correspondingly elements of (5) may be dropped. 
The use of approcimating equations in this way greatly simplifies the estimation procedure, since ordinary least squares can be applied without the necessity of assuming that the disturbances are multiplicative. 
CHAPTER III

THE REAL SECTOR

Section A - Introduction

The basic design of the real sector borrows heavily from a model constructed by Dr. T. M. Brown for the Royal Commission on Health Services. Substantial structural modifications were made to allow for the introduction of monetary variables and all of the equations were refitted to the 1947-1966 data sample used for this study. The purpose of this chapter is to present these modified and re-estimated realsector equations.

The equations of the real sector are separated into three blocks, one for dermand, one for supply and, finally, a block including price determination and miscellaneous equations.

\section{(i) Aggregate Demand}

Aggregate demand is the sum of the effective demands of the private sector and the government sector. Within each of these sectors, various elements of demand can be recognized. We first consider the private sector.

\section{A. Private Sector Demand}

Prirate sector demand is the sum of the demand for consumption goods, for investment goods and for exports. These categories can in turn, be decomposed into more specific groups. In this model total consumption expenditures a re split only into durables and non-durables. 
Investment demand is disaggregated into capital investment and inventory demand.

a. Consumption Expenditures

1. CND: CND $1, Y, P O P, \frac{\text { CONC }}{\mathbf{P}}, \frac{\mathrm{DD}+\mathrm{SD}}{\mathbf{P}}, \mathrm{U}$,

2. CD: $\sum_{i-1}^{N} B_{i} Y_{t-i} \frac{\text { CONC, }}{P}, R_{15}, R C_{15}, R_{\text {svd }}, \frac{D D+S D}{P}, U_{2}$

CND Consumer non-durable expenditures inclusive of services.

CD Consumer durable expenditures

Y Private sector disposable income

POP Total Canadian population

Consumer non-durable expenditures are assumed to be subject

to habit ${ }^{(1)}$ and influenced by real income, the availability of consumer credit and the wealth effects of liquid asset holdings. Consumer credit appears because it enables individuals to make purchases in excess of their current income. That is to say, the total income relevant for this equation is really $Y$ + CONC, however, we shall test for their separate contributions. The population variable appears in the non-durables equation to provide for the expansion of "needs" as the economy grows.

1. CND $=.2720 \mathrm{Y}+.3505$ POP $+.5135 \mathrm{CND}_{-1}+.151359 \frac{\mathrm{CONC}}{\mathrm{P}}$

$$
\text { (4. 27278) (3.06355) (4.37547) }
$$

(1) T. M. Brown, op. cit, 1952. 
$-3026.0$

(3. 81503)

$\bar{R}=.9936 \quad S u / \bar{y}=.8 \% \quad$ D. $W_{.}=2.10$

Consumer credit influence on durables plus that on non-durables was restricted to equal one. The unrestricted regressions yielded a total effect of about 1.2 which is a fairly close empirical approximation to unity. However, in order to make the results more in line with a priori notions, we restricted the parameter on consumer credit in the non-durables equation to be 1 minus the parameter in the durables equation. The total effect was thus restricted to be 1.

The durables equation includes a wealth proxy variable, interest rates, consumer credit and a liquid assets proxy.

$$
\text { 2. } \begin{aligned}
C D=- & 57.71527 R_{15}+.1135791 \mathrm{Y}+.848641 \frac{\text { CONC }}{P}+.208679 \\
& (1.80345) \quad(2.74055) \quad(2.784468) \\
& \frac{(S D+D D)}{P} \\
\bar{R}^{2}= & .977232 \mathrm{Su} / \mathrm{y}=5.2545 \mathrm{D} . \mathrm{W} .=1.029
\end{aligned}
$$

The distributed lag on private sector income did not do as well as the current level, so the former was dropped in favour of the latter.

\section{b. Investment Expenditures}

Private sector investment demand is composed of fixed and non-fixed investment. Inventory or non-fixed investment is motivated. by transactions and speculative requirements. The transaction requirement 
is indicated by the total volume of sales, while speculative activities are represented by the capital gains on inventories. In view of the fact that inventories constitute final goods not produced for immediate sale, they must be "financed". Accordingly, the volume of inventories kept will vary inversely with the rate of interest which the firm has to pay on the funds acquired to finance the inventory stock. Also, a decision to allocate part of the current flow of funds to the accumulation of deposits at the chartered banks will, other things being equal, mean that inventory investment will be less- at least to the extent that inventories are kept for s peculative purposes.

Finally, since technical progress (the advances in communication and transportation) will in general tighten the consumer-producer linkage, it will have the impact of decreasing the volume of inventories required to support a given volume of sales. Time is included as an indicator of such technical progress.

$$
\text { In summary - }
$$

3. $\mathrm{H}_{\mathrm{j}}: \mathrm{SA}, \mathrm{J}, \mathrm{T}, \mathrm{ND} / \mathrm{P}, \mathrm{R}_{91}, \mathrm{U}_{3}$

J Capital gains on inventories Negative of inventory valuation adjustment

$\mathrm{H}_{\mathrm{j}}$ mid-year stock of inventories

SA GNP $-\triangle H+F 1=$ Total Sales

$\Delta i$ Change in inventories over the year

F1 Imports inclusive of interest and dividents 
Brown's original attempt to fit an equation with inventories as the dependent variable proved to be unsatisfactory. In discussion with him it was decided that we should look at the inventory-sales ratio. This alternative formfits remarkably well and promises to perform much better than raw inventories. The equation obtained was:

3.

$$
\begin{aligned}
& \frac{\mathrm{H}_{j}}{\mathrm{SA}}=.0000121 \mathrm{~J}-.003465 \mathrm{Time}-.000013333 \frac{\mathrm{ND}}{\mathrm{P}}-.001479 \\
& \begin{array}{ll}
(4.52584) \quad(9.63063)
\end{array} \\
& \text { (5. 48676) } \\
& \mathbf{R}_{91}+.2940
\end{aligned}
$$$$
\text { (234. 04818) }
$$

$$
\bar{R}=.99725 \quad S u / \bar{y}=.8197 \quad \text { D. W. }=1.74006
$$

Private fixed investment includes investment in dwellings, plant construction, machinery and equipment, and is inclusive of depreciation.

4. GIBUS: (PEY $+D_{-1}$, GIBUS $_{-1}, W H R, \mathrm{RC}_{15}, \mathrm{DIC} \triangle \mathrm{GDP}, \mathrm{U}_{4}$, GIBUS Gross business investment as defined in text above.

WHR Average constant dollar wage per man hour

DIC Direct (foreign) investment in Canada

PEY Property and enterprise income

D Capital consumption allowances and miscellaneous valuation adjustments.

Current investment depends, of course, on a host of "real" 
phenomena - of these we have included the flow of property and enterprise income inclusive of capital consumption allowances, the change in output, previous investment commitments (or a distributed lag of effects occurring subsequent to causes) and the flow of direct investment funds entering the capital market from abroad. The real wage per man hour is included as an indicator of the factor substitution process. The only monetary va riable chosen to enter directly is the current corporate bond rate. Monetary influences will also affect GIBUS indirectly through the effects which they have on income flows and other demand flows in the economy. Several "good" equations were obtained for GIBUS, of which I have included three.

4. 1 GIBUS $=-557.8 \mathrm{RC}_{15}^{1}+.2467 \Delta \mathrm{GDP}^{1}+.9255 \mathrm{GIBUS}^{1}-1$

$$
\begin{aligned}
& \begin{array}{lll}
(3.37406) & (3.00376) & (6.66806)
\end{array} \\
& +.3498(\mathrm{PEY}+\mathrm{D})_{1}^{1}-1142 \text {. }^{1} \\
& \text { (3. 70948) } \\
& \text { (2. } 30801) \\
& \bar{R}=.97497 \mathrm{Su} / \bar{y}=3.81 \quad \text { D. W. }=1.92446 \text { RHO }=.2759
\end{aligned}
$$

4. 2 GIBUS $=-649.9621 \mathrm{RC}_{15}+.1947212 \mathrm{GNP}_{+}+259337$ GIBUS $_{-1}$

$$
\begin{aligned}
& (2.593409) \quad(6.007052) \\
& +1.0096879 \quad D I C+1068
\end{aligned}
$$$$
\text { (1.358474) (2.287135) }
$$$$
\overline{\mathrm{R}}^{2}=.929349 \quad \mathrm{Su} / \overline{\mathrm{y}}=6.66745 \quad \text { D. } \mathrm{W} .=.93362
$$ 
4. 3

$$
\begin{aligned}
& \text { GIBUS }=.25975 \text { GIBUS }_{-1}+.11000 \mathrm{GNP}_{+}+.07040 \mathrm{GNP}_{-1} \\
& \text { (2. } 511233) \\
& \text { (6. 4206) } \\
& \text { (6. 4206) } \\
& +.03960 \mathrm{GNP}_{-2}+.01760 \mathrm{GNP}_{-3}+.00440 \mathrm{GNP}_{-4} \\
& \text { (6. 4206) } \\
& \text { (6. 4206) } \\
& \text { (6. 4206) } \\
& -914.42 \mathrm{RC}_{15}+1.06775 \mathrm{DIC}+1048 \text {. } \\
& \text { (3. 400128) } \\
& \text { (1. } 505214) \\
& \text { (2. 35750) } \\
& \overline{\mathrm{R}}^{2}=.935808 \\
& \mathrm{Su} / \mathrm{y}=6.35540 \\
& \text { D. W. }=1.09886
\end{aligned}
$$

\section{B. Government Demand}

The second category of demand emanates from the government sector. One could consider treating this whole sector as exogenous but in view of the fact that Brown's model explained these elements endogenously, we made the same attempt.

Government expenditures are disaggregated into investment expenditures and current or "consumption" expenditures. Current expenditures are treated net of military expenditures whereas expenditures on capital account are not because of unavailability of military investment figures.

The two hypotheses tested were:

5. CONG: GDP, POP, CONC $-1, U_{5}$

6. GIG: $\mathrm{CONG}^{*}, \mathrm{POP}, \mathrm{U}_{6}$

CONG Government expenditures on current account

GIG Gross government investment

CONG * CONG + (exogenous) defence expenditures on current account 
5. CONG $=.03522$ GDP +. 7477 CONG -306.7
(1. 84878)
(3. 94502)
(1. 82805)

$\bar{R}=.98850 \quad S u / \bar{y}=4.634 \quad$ D. $W .=1.53960$

6. GIG $=.3579$ CONG* +.2032 POP -2014.0
(3. 88169)
(28. 12073)
(16. 11761$)$

$\bar{R}=.98875 \quad S u / \bar{y}=4.943 \quad$ D. $W_{.}=2.06745$

C. Exports

The demand by foreigners for gross domestic production

is taken to be exogenous.

F2 = exogenous $\quad F 2=$ exports

We can summarize the elements of aggregate demand into

one equation for the demand for gross domestic product. We include the net impact of the foreign sector by subtracting imports from exports.

(Imports are determined endogenously in the next section).

7. $\mathrm{GDP}^{\mathrm{d}}=\mathrm{CND}+\mathrm{CD}+\mathrm{GIG}+\mathrm{CONG}+\Delta H+\mathrm{GIBUS}+\left(\mathrm{F}^{2}-\mathrm{F} 1\right)$

+ FDSK\$ $-\frac{1}{2}$ R2

FDSK\$ Federal defense spending

$\frac{1}{2}$ R2 Residual error of estimate in

GNE

GDP $\quad$ Gross domestic product demanded

(ii) Aggregate Supply

The second block of the real sector is concerned with the factors 
which govern the supply of gross domestic product. It contains the production function, wage and hours of work equations and miscellaneous income equations.

The production function is an extremely simplified attempt to provide a technical relationship between the supply of factors of production and the total final output of the economy. In our model it serves to determine the level of employment of man-hours. This is accomplished by the a ssumption that gross domestic output demanded is always equal to gross domestic supply. Since the supply of capital is determined by investment (already accounted for) the equilibrium condition serves to determine the required input of man-hours.

The level of employment is determined from the required man-hour input via the hours of work equation.
8. $\operatorname{GDP}_{\mathrm{C}}^{5}: \mathrm{A}, \mathrm{L}, \mathrm{Ku}, \mathrm{U}_{7}$
9.

$$
\mathrm{Ku}=\left(\mathrm{H}_{\mathrm{j}}+\mathrm{CSTOT}\right) * \frac{\mathrm{Ne}}{\mathrm{N} \mathrm{l}-\mathrm{NM}}
$$
10$$
L=\mathrm{Ne} * \mathrm{~h}
$$
A
disembodied neutral technical progress $^{(2)}$
I Man-hours worked
$\mathrm{Ne}$
Total civilian employment
N1-NM
Total civilian labour force

(2) See T. M. Brown, op. cit., 1964, p. 219 col. 13 and notes. B rown's estimates were extrapolated to cover our extended sample period. 
Ku Capital stock in use i. e. , capital stock in place adjusted for the proportion of the labour force employed

$\begin{array}{ll}\text { GDPs. Gross domestic (civilian) } & \text { supply }\end{array}$

GDP - MPAA

11. $\quad$ CSTOT $=$ CSTOT $_{-1}+$ GITOT $-D_{\mathbf{r}}$

12. GITOT = GIBUS + GIG

\section{$D_{r} \quad$ Real estimated depreciation on the capital stock}

Many forms of 8 . were tested and a separate section describing these efforts has been appended to the chapter. The most promising production functions obtained were:

8. $\log \mathrm{GDP}_{\mathrm{C}}^{\mathrm{s}}=.7332 \log \mathrm{A}+.6045 \log \mathrm{Ku}+.8008 \log \mathrm{L}-9.922$

$$
\begin{gathered}
(3.47677) \quad(7.09870) \\
\bar{R}=.99663 \quad \mathrm{Su} / \bar{y}=.1977 \quad \text { D. W. } .27602
\end{gathered}
$$

$8.1 \log \underline{G^{2} P_{c}^{s}}=.5459 \log \mathrm{Ku}+.8008 \log \mathrm{L}-9.429$

$$
\begin{array}{cccc}
A & (2.38298) & (1.04789) & (.94937) \\
\bar{R}=.99192 & \mathrm{Su} / \bar{y}=.6753 & \text { D. W. }=.2670
\end{array}
$$

8. $2 \quad \operatorname{GDP}_{C}^{\mathrm{sl}}=.1056 \mathrm{Ku}^{1}+.4753 * 10^{-8}(\mathrm{Ku} * \mathrm{~L})^{1}+4662 .^{1}$

$$
\begin{aligned}
& \text { A (4.32102) (3.33759) (7.82073) } \\
& \bar{R}=.99833 \quad \mathrm{Su} / \bar{y}=.620 \text { D. W. }=1.73734 \text { RHO }=.4531
\end{aligned}
$$


In order to complete the employment portion of the model, we require an hours of work equation and the equilibrium condition mentioned above.

The average hours of work equation is a quasi-reduced form which attempts to capture both supply and demand factors. On the supply side, hours of work tend to decline as the affluence of the economy grows and productivity increases. (3) A buffer on this process is provided by the degree to which workers spread their expected earnings over the present and future - i. e. by the amount of indebtedness which workers incur. As far as demand elements are concerned, hours demanded per worker is strongly pro-cyclical - as an indicator of this cyclical demand factor, we have included the rate of unemployment.

13. h: $P L_{-1}, N_{u p c}=\frac{\text { CONC }}{P}, W e, u_{8}$

$$
\begin{array}{ll}
\text { We } & \text { Wealth proxy } \\
\frac{\text { CONC }}{P} & \text { indebtedness proxy }
\end{array}
$$

13. $h=-.0115514$ We $-14.6157 \mathrm{~N}_{\text {upc }}+.05137 \frac{\text { CONC }}{\mathrm{P}}-60.8110$

$$
\begin{gathered}
(3.3467) \quad(4.9528) \\
\text { PL-1 }+2612 . \\
(29.8519) \\
\bar{R}^{2}=.982469^{\mathrm{Su} / \bar{y}}=.56871 \text { D. } w .=2.1066
\end{gathered}
$$

(3) T. M. Brown, Forthcoming. 
14. $\operatorname{GDP}_{C}^{8}=$ GDPd - MPAA which, when normalized on I, determines Ne; given 13.

As indicated above, imports constitute part of the supply of final goods on the domestic market and as such should be treated in the supply portion of the sector. Our very simple import demand equation relates imports to the level of income, the level of gross national investment, the number of workers unemployed and the domestic price level (assuming it to be more volatile than the world price level.)

15.

$$
\begin{aligned}
& F^{1}=3614 . P^{1}+.4803 \text { GITOT }^{1}+.09379 \text { GDP }^{1}-1.816 \mathrm{Nu}^{1} \\
& \begin{array}{llll}
(1.1619) \quad(3.2201) & (1.80128) \quad(1.82432)
\end{array} \\
& -1252.1 \\
& \text { (1. 97520) } \\
& \mathbf{N u}=(\mathbf{N} \mathbf{1}-\mathbf{N m})-\mathbf{N e} \\
& \overline{\mathbf{R}}=.98285^{\mathrm{Su}} / \overline{\mathrm{y}}=3.40 \quad \text { D. W. }=1.55561 \text { RHO }=.4202
\end{aligned}
$$

The remainder of this section concerns itself with the development of income variables.

From the average hours of work equation and the total employment level generated by 14., we can compute total man-hours worked. Relating this to an average real wage level yields the real civilian wage bill. Equation 16. is an attempt to relate the average (economy-wide) real wage to labour productivity, excess supply in the labour market and the growing bargaiming power of unions - the latter being represented by a time trend. 
16. $\mathrm{Wh}_{\mathrm{r}}=-.01544 \mathrm{~N}_{\text {upc }}+.3656 \mathrm{Pl}+.01252 \mathrm{TIME}+.6686$

$$
\begin{aligned}
& \begin{array}{llll}
\text { (2. } 10614) \quad(2.13474) \quad(1.91945) & \text { (2. 07593) }
\end{array} \\
& \bar{R}=.98636 \mathrm{Su} / \bar{y}=2.145 \quad \text { D. } W .=1.76405 \\
& W \frac{W m-M P A A}{N e * h} \\
& \text { Wm Wage and salary incomes including } \\
& \text { military } \\
& \text { MPAA Military pay and allowances } \\
& \text { PL } \quad \text { GDP/I }
\end{aligned}
$$

Using 16. we derive the civilian wage bill

17. $\mathrm{w}_{\mathrm{c}}=\mathrm{w}_{\mathrm{hr}} * \mathrm{~L}$

In order to generate private sector income and property and enterprise income, we require several additional stochastic equations.

Government disposable income can be related to Gross Domestic Flow - as the base of most of the governments tax revenue-and to the number of persons unemployed as a measure of the current flow of transfer payments.

18.

$$
\begin{aligned}
& Y_{\mathbf{g}}=.1879 * \mathrm{GDF}-3.763 \mathrm{Nu}-642.0 \\
& \begin{array}{lll}
(29.7018) & (6.88758) & \text { (3.1359 }
\end{array} \\
& \bar{R}=.99165 \quad \text { Su } / \bar{y}=3.627 \quad \text { D. W. }=1.25640
\end{aligned}
$$

Capital consumption allowances and miscellaneous valuation adjustments (essentially an adjustment for omitted transactions in the national accounts) are made a function of the level of GDP and the stock of fixed capital. The level of GDP is included because it is likely that the transactions omitted from the national accounts will grow at about the 
same rate as the general level of activity. The lagged stock of fixed capital is included because it is against it that capital consumption allowances are made:

19.

$$
\begin{aligned}
& D=.05418 \text { GDP }+.02647 \text { CSTOT }_{-1}+68.82 \\
& \text { (1. 90074) } \\
& \text { (2. 18292) }
\end{aligned}
$$

Equations 17., 18. and 19. together with an identity (20.) defining GNP allow us to determine private sector disposable income. 20. $\mathbf{G N P}=\mathbf{G D P}+\mathbf{P}_{\mathbf{i d}}-\mathbf{P}_{\mathbf{d i}}$

$$
\mathbf{P}_{\mathbf{i d}}
$$

Interest and dividends received from abroad

$\mathbf{P}_{\text {di }}$ Interest and dividends paid abroad

21. $\quad Y=G N P-J-Y_{g}-D-\frac{1}{2} R I$

$\frac{1}{2} \mathrm{RI}$

Residual error of estimate in GNP

One further stochastic equation enables us to determine property and enterprise income. 22. $\mathrm{T}_{\mathrm{i}-\mathrm{s}}=.07572$ GDF $+.4524 \mathrm{~T}_{\mathrm{i}-\mathrm{s}-1}-707$.

$$
\begin{aligned}
& \text { (3. 7355) } \\
& \text { (2. 56237) } \\
& \text { (4. 0882) } \\
& \bar{R}=.99479 \mathrm{Su} / \bar{y}=3.161 \\
& \text { D. W. } 1.3129
\end{aligned}
$$

23. $\mathrm{PEY}=\mathrm{GNP}+\mathrm{J}-\mathrm{W} C-\mathrm{MPAA}-\mathrm{D}-\mathrm{T}_{\mathrm{i}-\mathrm{s}}-\frac{1}{2} \mathrm{R} \mathbf{I}$

24. $G D P=G D P_{c}+M P A A$ 
(iii) Prices and Miscellaneous Equations

This final block of the real sector contains the price equation and miscellaneous equations required to complete the model.

25.

$$
\begin{aligned}
& D_{r}=.0600191 \text { CSTOT }-179.9379 \\
& \begin{array}{lll}
(72.392) & (2.88376) \\
\bar{R}^{2}=.996387 \mathrm{Su} / \bar{y}=1.6899 & \text { D.W. }=.210554
\end{array}
\end{aligned}
$$

26.

$$
\begin{aligned}
& P=-2.24684 \frac{H_{j}}{P}+.23962 P_{-1}+.15271 P_{-2}
\end{aligned}
$$

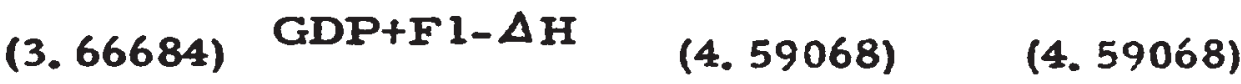

$$
\begin{aligned}
& +.08590 \mathrm{P}_{-3}+.03818 \mathrm{P}_{-4}+.00954 \mathrm{P}_{-5}-.0032560 \mathrm{~N}_{\text {upc }} \\
& \begin{array}{llll}
(4.59068) & (4.59068) & (4.59068)
\end{array} \\
& +1.0737173 \\
& \bar{R}^{2}=\begin{array}{l}
(4.334654) \\
.98872
\end{array} \mathrm{Su} / \bar{y}=1.48943 \quad \text { D. W. }=1.8645
\end{aligned}
$$

Equation 26, is essentially an orthodox price equation relating current prices to the inventory-sales ratio, the rate of unemployment and past prices. Other price equations were obtained which one might choose to call quantity-theory equations - $i, e_{0}$, they relate the price level directly to the stock of money. One such equation is: 26. $1 P=.0000281407(\mathrm{Cur}+\mathrm{DD}+\mathrm{ND}+\mathrm{SD})+.000012507(\mathrm{Cur}+\mathrm{DD}$

$$
\begin{aligned}
& \text { (2. 30740) } \\
& \text { (2. 3074) } \\
& +\mathrm{ND}+\mathrm{SD})_{-1}+.0000031267(\mathrm{Cur}+\mathrm{DD}+\mathrm{ND}+\mathrm{SD})_{-2} \\
& \text { (2. 3074) } \\
& +.5710419 P_{-1}-.002295 \mathrm{~N}_{\text {upc }}+.21055 \\
& \begin{array}{lll}
(2.848438) & (1.56850) & (2.63993)
\end{array} \\
& \overline{\mathbf{R}}^{2}=.982372 \quad \mathrm{Su} / \overline{\mathrm{y}}=1.52062 \quad \text { D. } \mathrm{w} .=2.20427
\end{aligned}
$$


85

Both forms of price equation will be tested in the preliminary

simulation experiments.

27. $\Delta H=2\left(H_{j}-H_{j-1}\right)-\left(H_{-1}-H_{-2}\right)$

28. $\mathrm{Nu}=(\mathrm{N} 1-\mathrm{Nm})-\mathrm{Ne}$

$29 \quad \mathrm{~N}_{\text {upc }}=(\mathrm{Nu} /(\mathrm{N} \mathrm{l}-\mathrm{Nm})) * 100$.

30. $\mathrm{PL}=\mathrm{GDP}_{\mathrm{c}} / \mathrm{L}$

31. $W_{e}=.176 \sum_{i=0}^{7} \cdot 9^{i}$ GNP $_{t-i}$ 


\section{A PPEINDIX A CHAPT ER III \\ Production Functions}

In order to simplify the exposition in this appendix, we introduce several notational changes:

$$
\text { Let } \begin{aligned}
\frac{\operatorname{GDP}_{\mathrm{C}}^{8}}{\mathrm{~A}} & =\mathbf{Q} \\
\mathrm{Ku} & =\mathbf{K} \\
\text { and } \mathrm{L} & =\mathrm{L}
\end{aligned}
$$

In our experimentation with production relationships, we started with the general hypothesis:

$$
\text { 1. } \mathbf{Q}=\mathbf{F ( K )} \cdot \mathbf{F}(\mathrm{L})+\mathbf{u}
$$

1. Can give rise to many empirical formulations; the most familiar of which is the Cobb-Douglas form:

$$
\text { 2. } Q=K^{a} \mathbf{L}^{b} \mathbf{u}
$$

To get from 1. to 2. it is necessary to assume that the a are multiplicative - not a usual assumption of economic hypotheses. However, if we are willing to grant that the $u$ are in fact multiplicative then we can transform 2. to get the log-linear form.

(1) The Cobb-Douglas, it should be stressed, has no claim to universal validity as a representation of technology - its use must be justified by the properties which it exhibits in each case where it is used. See, for example, L. R. Klein, Introduction to Econometrics, Prentice-Hall, New Jersey, 1965 , pp. 90-100. 
3. $\log Q=a \log K+B \log L+\log u$

Fitting 3. to our sample yields.

3.

$$
\log Q=\underset{(2.38298)}{.5459 \log K+\underset{(1.04789)}{.8008} \log L}-\begin{gathered}
9.492 \\
(.94937)
\end{gathered}
$$

$$
\bar{R}=.99192 \quad S u / \bar{y}=.6753 \quad \text { D. } w .=.2670
$$

Fitting the same equation without adjusting $\operatorname{GDP}^{8}$ for $A$

yields.

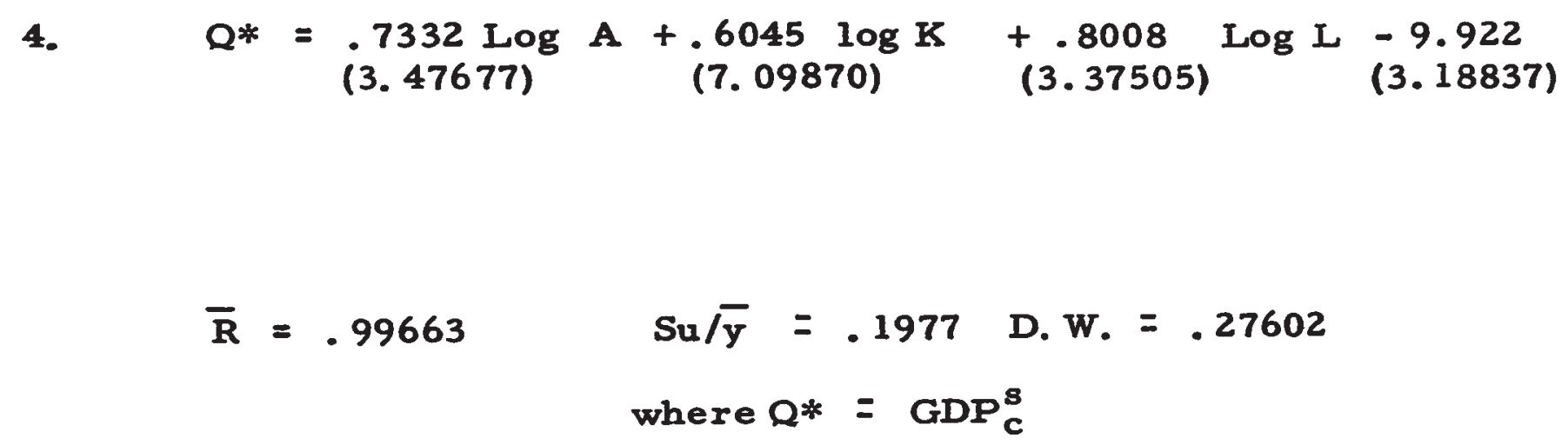

More complex formulations of the basic Cobb-Douglas form

were also tried.

5. $\quad Q^{*}=e^{(a+b \text { Nupc })} e^{T}\left(K^{c * L^{d}}\right)$

which in the estimated form is written $^{(2)}$ :

(2) See, for examples of this form: Lester C. Thurow, a Fiscal Policy Model of the United States. Survey of Current Business, OBE, washington D. C. , June 1969. And, Nanda K. Choudh ry et alia, , an Annual Econometric $M$ odel of the Canadian Economy, 1928-1966, working paper 6818, Institute for the Quantitative analysis of Social and Economic Policy, University of Toronto, Nov. 1968. , p. 32. 


$$
\begin{aligned}
& \text { 5. } \log \frac{Q^{*}}{L}=\underset{(0.55232)}{-.7129}-\underset{(4.17745)}{.02668 \text { Nupc }}+\underset{(.20492)}{.001392} \mathrm{~T} \\
& +1.025 \mathrm{~K} \quad \text { where } T=\text { time } \\
& \text { (4. 29178) } \frac{\mathrm{L}}{\mathrm{N}} \quad \text { Nupc }=\text { per cent unemployed } \\
& \bar{R}=.99311 \quad \mathrm{Su} / \overline{\mathrm{Y}}=.3465 \quad \text { D. W. }=1.30036
\end{aligned}
$$

All of the foregoing estimates involved the logarithmic transformation of the basic functions (2. or 5.) to get a linear -in-theparameters form. A different production function, which is linear in the parameters, can also be obtained from 1.

Assuming $F(K)$ and $F(L)$ to be simple polynomials, we

have:

6. $Q=K^{a} L^{b}+a$

Expanding each branch of 6 . in a Taylor series gives

6a. $Q(L / K, u)=L_{0}^{b}+B I b_{0}^{b-1}\left(L-L_{0}\right)$

$$
\begin{aligned}
& =L_{0}^{b}+B L_{0}^{b-1} L-B L_{0}^{b-1} L_{0} \\
& =\left(L_{0}^{b}-B L_{0}^{b-1} L_{0}\right)+B L_{0}^{b-1} L
\end{aligned}
$$

6. b. $\quad=C+D L$

where $C=L_{0}^{b}-B L_{0}^{b-1} L_{0}$

and $\quad \mathbf{D}=\mathrm{BL}_{\mathrm{O}}^{\mathrm{b}-1}$

7. a. $Q(K / L, u)=K_{0}^{a}+A_{0}^{a-1}\left(K-K_{0}\right)$

$$
\begin{aligned}
& =K_{0}^{a}+A K_{0}^{a-1} K-A K_{0}^{a-1} K_{0} \\
& =\left(K_{0}^{a}-A K_{0}^{a-1} K_{0}\right)+A K_{0}^{a-1} K
\end{aligned}
$$

7. b. $\quad=E+G K$

where $E=\left(K_{0}^{a}-A K_{0}^{a-1} K_{0}\right)$

and $\quad G=A K_{0}^{a-1}$ 
Substituting 6. b. and 7. b. into 1. yields

8. $\quad \mathbf{Q}=\mathbf{C E}+\mathrm{EDL}+\mathrm{CGK}+\mathrm{GDL} \mathbf{K}+\mathbf{u}$

Fitting 8. to the data revealed that CG was not significantly different from zero so it was dropped to yield.

8.

$$
\begin{gathered}
Q^{1}=\underset{(4.32102)}{.1056 \mathrm{~K}^{1}}+\underset{(3.33759)}{.4753 * 10^{-8}}(\mathrm{~K} * \mathrm{~L})^{1} \begin{array}{c}
+4662 \\
(7.82073)
\end{array} \\
\bar{R}=.99833 \quad \text { Su } / \bar{y}=.620 \quad \text { D. W. }=1.73734 \\
\text { RHO }=.4531
\end{gathered}
$$

8. is a variable elasticity production function yielding increasing returns to scale and exhibiting marginal factor productivities compatible with the real wage and return on capital which would be expected from casual observation of these magnitudes over the fitting period.

(3) The elasticity of output with respect to input may be written $\frac{D Q}{D R} \cdot \frac{R}{Q}$ where $Q$ is output and $R$ is the input scale. Hence we have. $K+2 R K I, R=K R+2 R^{2} K L$ Hence we have. $\frac{K+2 R K L}{K R+R^{2} K I}+C=\frac{K R+2 R^{2} K L}{K R+R^{2} K L+C}$ which is $\gtreqless 1$ as $R^{2} \mathrm{KL}+\frac{2 \mathrm{R}^{2} \mathrm{KL}}{\mathrm{C}} \gtreqless 1$ 
CHAPTER FOUR

Assembling the Model

Section A - The Monetary Sector

1.

$$
\begin{aligned}
& \text { HPM }=.03286 \text { GDF } * P-135.8\left(U S C B R-R_{15}\right) * x_{1} \\
& \text { (19. 526) } \\
& \text { (3. 016) } \\
& +35.61 \mathrm{~N}_{\text {upc }}-92.14 \mathrm{X}_{2}+1002.0 \\
& \text { (3. 230) } \\
& \text { (1. 879) }
\end{aligned}
$$

$$
R=.99605 \quad S u / y=1.891 \quad \text { D. } F_{0}=1.84357 \text { TSLS }
$$

1.2 RS $=.0186134$ GNP $* P-65.5745\left(\right.$ USCBR $\left.-R_{15}\right) * \mathrm{X}_{1}$

$$
\begin{array}{lc}
(19.67772) & (-3.5979) \\
-138.51442 x_{2}+32.07 x_{3}+393.750 \\
(6.88636)
\end{array}(1.36573) \quad(21.4263)
$$

$$
\bar{R}^{2}=.98584 \quad S u / \bar{y}=2.60188 \quad \text { D. } W .=2.40073 \text { OLS }
$$

2. $\mathrm{C}_{\mathrm{ur}}{ }^{\mathrm{d}}=.01018$ GNP $* \mathrm{P}+.00707$ GNP $* P_{-1}+.00452$ GNP $* P_{-2}$

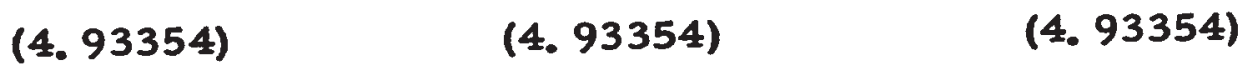

$$
\begin{aligned}
& +.00254 \text { GNP * } P_{-3}+.00113 \text { GNP * } P_{-4} \\
& \text { (4. 93354) (4. 93354) } \\
& +.00028 \mathrm{GNP} * \mathrm{P}_{-5}+.350096 \mathrm{C}_{\mathrm{ur}-1}+11.5578 \mathrm{ATM} \\
& \text { (4. 93354) (2.17337) (2.07749) } \\
& -23.5075 R_{15}+356.5568 \\
& \text { (1. 439602) (4.57755) } \\
& \bar{R}^{2}=.997884 \quad S u / \bar{y}=1.0910 \text { D. W. }=1.34890 \text { OLS }
\end{aligned}
$$


3. RS $=$ HPM $-\left(C_{u r}-\right.$ Coin $)$

4. $C_{u r}{ }^{8}=C_{u r}^{d}$

5. $\quad \mathrm{SD}^{\mathrm{d}}=.075$ GNP $* P+.052$ GNP $* P_{-1}+.033$ GNP * P-2 (15.47477) (15.47477) (15.47477)

+.019 GNP * $P_{-3}+.008$ GNP $* P_{-4}+.002$ GNP * $P_{-5}$ (15.47477) (15.47477) (15.47477)

$+161.7684 R_{\text {svd }}-254.77616 R_{15}+108.473 A T M$

$\begin{array}{lll}(1.080769) & (2.08578) & (3.13502)\end{array}$

$+713.9416$

(2. 6964)

$\bar{R}^{2}=.99535 \quad S u / \bar{y}=2.22913 \quad$ D. W. $=1.39560$ OLS

6. $\quad N D^{d}=.00769112$ GNP $* P+16.4467\left(R_{\text {ond }}\right)^{3}-66.17586 R_{\text {BwP }}$
(2. 73113)
(9. 37712$)$
(2. 45320)

+22.3263 ATM

(2. 3935)

$\bar{R}^{2}=.984135 \quad \mathrm{Su} / \bar{y}=9.84096$ D. W. 1.90662 OLS

7. $\quad R_{\text {ond }}=.1605882 i_{c b p l}+.317499 R_{\text {svd }}+.5703442 R_{91}$

$\begin{array}{lll}(5.33901) & (5.59728) \quad(18.473)\end{array}$

$\bar{R}^{2}=.979668 \quad S u / \bar{y}=10.6392 \quad$ D. W. $=.80108$ OLS 
3. $\quad$ RS $=$ HPM $-\left(C_{u r}-\right.$ Coin $)$

4. $\quad C_{u r}^{s}=C_{u r}^{d}$

5. $\quad \mathrm{SD}^{\mathrm{d}}=.075 \mathrm{GNP} * \mathrm{P}+.052 \mathrm{GNP} * \mathrm{P}_{-1}+033 \mathrm{GNP} * \mathrm{P}_{-2}$

$$
\begin{aligned}
& \begin{array}{lll}
(15.47477) & (15.47477) & (15.47477)
\end{array} \\
& +.019 \text { GNP } * P_{-3}+.008 \text { GNP } * P_{-4}+.002 \text { GNP * } P_{-5} \\
& \text { (15.47477) (15.47477) (15.47477) } \\
& +161.7684 R_{s v d}-254.77616 R_{15}+108.473 \text { ATM } \\
& \begin{array}{lll}
(1.080769) & \text { (2. 08578) }
\end{array} \\
& +713.9416 \\
& \text { (2. 6964) }
\end{aligned}
$$

$\bar{R}^{2}=.99535 \quad S u / \bar{y}=2.22913 \quad$ D. W. $=1.39560$ OLS

6. $\quad \mathrm{ND}^{\mathrm{d}}=.00769112$ GNP $* P+16.4467\left(\mathrm{R}_{\text {ond }}\right)^{3}-66.17586 \mathrm{R}_{\text {swp }}$
(2. 73113)
(9. 37712$)$
(2. 45320)

+22.3263 ATM

(2. 3935)

$\overline{\mathrm{R}}^{2}=.984135 \quad \mathrm{Su} / \overline{\mathrm{y}}=9.84096$ D. W. 1.90662 OLS

7. $\quad R_{\text {ond }}=.1605882 i_{c b p l}+.317499 R_{\text {svd }}+.5703442 R_{91}$
(5. 33901$)$
(5. 59728)
(18. 473)

$$
\bar{R}^{2}=.979668 \quad S u / \bar{y}=10.6392 \quad \text { D. W. }=.80108 \text { OLS }
$$


$7.1 \quad R_{\text {ond }}=.164062 i_{\text {cbpl }}+.320523 R_{\text {gvd }}+.872106 R_{91}$

$$
\begin{aligned}
& \text { (6. 4056) (6.64231) } \\
& -1.2265 \\
& \text { (2. } 73919)
\end{aligned}
$$$$
\bar{R}^{2}=.98529 \quad \mathrm{Su} / \bar{y}=9.04843 \quad \text { D. W. }=1.5388 \text { OLS }
$$

8. $\quad R_{91}=-.0010838 \mathrm{DD}+.0001843$ GNP $* \mathrm{P}+2.4233 \mathrm{X}_{3}$

$$
\begin{array}{ccc}
\begin{array}{c}
(1.645778) \\
+.1826515
\end{array} \text { ATM }+1.243718 \text { IQD } \\
(1.786535) & (4.273953)
\end{array}
$$$$
\bar{R}^{2}=.92403 \quad \mathrm{Su} / \bar{y}=12.434 \text { D. } \mathrm{W} .=1.98463 \text { OLS }
$$

9. $\mathrm{TD}=9.84620 \mathrm{RS} * \mathrm{X}_{5}+10.985507 \mathrm{RS} * \mathrm{X}_{6}+12.79421 \mathrm{RS} * \mathrm{X}_{7}$

$$
\text { (106. 05239) (68.337224) }
$$

+13.28847 RS * $x_{8}$

(338. 64224)

$\bar{R}^{2}=.998371 \mathrm{Su} / \bar{y}=1.09471$ D. W. $=1.65417$ OLS

$$
\begin{aligned}
& \text { 10. } \quad D^{s}=T D-N D-G D-S D \\
& \text { 11. } S D^{s}=S D^{d} \\
& \text { 12. } \quad N^{s}=N D^{d}
\end{aligned}
$$


13. $\mathrm{GD}=\overline{\mathrm{GD}}$

14. $1\left(R_{15}-R_{91}\right)=-.585246 \Delta R_{91}-.23255 \Delta R_{91-1}$

$$
\text { (3.23066) (2. 106224) }
$$

-.00002338 GNP *P+1.72264 RC ${ }_{-1}^{N}$

(2. 41543) (3.34365)

$-.0010469 \Delta S_{-1}-.1640232$ ATM $-1.31790 X_{3}$

$\begin{array}{lll}(1.50957) & (1.29530)\end{array}$

$+4.23168$

(4. 95597)

$\bar{R}^{2}=.88354 \quad S u \bar{y}_{\mathrm{y}}=15.47203$ D. W. $=1.40185$ OLS

$14.2\left(R_{15}-R_{91}\right)=-.7047476 \Delta R_{91}-.407046 \Delta R_{91-1}$

$$
\begin{array}{ccc}
(3.86986) & (3.068117) \\
-.00003092 & \text { GNP } * P-.00011180 \Delta S_{-1} \\
(2.73054) & (.1273531) \\
-.95850 x_{3}+3.42087 & (7.779364) \\
\bar{R}^{2}=.776355 \quad & S u / \bar{y}=21.4406 \text { D. W. } .82527 \text { OLS }
\end{array}
$$

$14.3\left(R_{15}-R_{91}\right)=-.72219907 R_{91}+.16626 R_{91-1}+.09352 R_{91-2}$

$$
\begin{array}{cc}
(8.01496) & (3.20266) \\
+.04156 R_{91-3}+.01039 R_{91-4} \\
(3.20266) \quad(3.20266) \\
\left.-1.07960 \text { (USCBR }-R_{15}\right)
\end{array}
$$$$
\text { (3.20266) }
$$$$
\text { (4. 961926) }
$$ 
14. 3 Continued

$$
\begin{aligned}
& +.1892212 \text { (USCBR }-R C)_{15-1}+2.6003 \\
& \begin{array}{l}
(1.112102) \\
(14.811050)
\end{array} \\
& \bar{R}^{2}=.962495 \quad \mathrm{Su} / \bar{y}=8.78015 \quad \text { D. W. }=1.3312 \text { OLS }
\end{aligned}
$$

14. $4 \quad \mathrm{RC}_{15}=.120222 \mathrm{ATM}+.8348009 \mathrm{R}_{15}+.242129$

$$
\begin{array}{lll}
(1.78665) & (9.096523) & (.357032)
\end{array}
$$

$\bar{R}^{2}=.836830 \quad S u / y=8.31263 \quad$ D. W. 2.0696 OLS

$15.1\left(R_{15}-R_{91}\right)=-.65081644 \Delta R_{91}-.344067 \Delta R_{91-1}$

$$
\begin{array}{cc}
(2.24628) & (2.10938) \\
-.00002527 & \text { GNP } * P+.08711443 R_{15-1}^{N} \\
(1.537014) & (.15909) \\
-.00021408 \Delta S_{-1}-.1893254 \text { ATM } \\
(.18999) \\
+.29633 x_{3}+4.11751 \\
(.27837) \quad(3.0708)
\end{array}
$$$$
\overline{\mathrm{R}}^{2}=.519264 \mathrm{Su} / \bar{y}=32.76196 \text { D. W. }=1.2523
$$

$15.2\left(R_{15}-R_{91}\right)=.462616 \Delta R_{91}-.313773 \Delta R_{91-1}-.00003352$

$$
\begin{array}{cccc}
(2.30261) & (2.14378) & (2.68335) \\
\text { GNP } * P & -.0002058 \Delta S_{-1} & -.480833 x_{3}+2.941183 \\
& (.212594) & (.75054301) & (6.062697)
\end{array}
$$$$
\overline{\mathbf{R}}^{2}=.57109 \mathrm{Su} / \overline{\mathbf{y}}=30.94564 \quad \text { D. W. } 1.390185 \text { OLS }
$$ 
$15.3\left(R_{15}-R_{91}\right)=-.711304 R_{91}+.19769 R_{91-1}+.1112 R_{91-2}$

$$
\begin{array}{ccc}
(6.51406) & (3.1846) & (3.1846) \\
+.04942 R_{91-3} & +.01236 R_{91-4} & +2.65673 \\
(3.1846) & (3.1846) & (12.33856)
\end{array}
$$

$\overline{\mathrm{R}}^{2}=.77269 \mathrm{Su} / \overline{\mathrm{y}}=22.52803 \quad$ D. $\mathrm{W} .=1.826$ OLS

$15.4\left(R_{15}-R_{91}\right)=-.79994 R_{91}+.03559 R_{91-1}+.19345 R_{91-2}$

$$
\begin{aligned}
& \begin{array}{lll}
(6.89881) & (.31077) \quad(3.2338)
\end{array} \\
& +.16306 R_{91-3}+.06003 R_{91-4}+2.79664 \\
& \begin{array}{lll}
\text { (2. 30917) (2.05479) (12.735451) } & \text { (2. }
\end{array}
\end{aligned}
$$

$\bar{R}^{2}=.799052 \quad S u / \bar{y}=21.18158 \quad$ D. W. $=2.19416$ OLS

$15.5\left(R_{15}-R_{91}\right)=-.6223 R_{91}+.25957 R_{91-1}+.20378 R_{91-2}$

$$
\begin{array}{lll}
(10.03706) & (5.66836)
\end{array}
$$$$
+.11624 R_{91-3}+.03548 R_{91-4}
$$
(3. 28992)
(2. 52754)

- 1.11591 (USCBR $-R_{15}$ ) - .0007972 $\Delta S+2.71260$

(7. 80987)

(3. 70903)

(27. 3482)

$$
\bar{R}^{2}=.970137 \quad \mathrm{Su} / \overline{\mathrm{y}}=8.16554 \quad \text { D. } \mathrm{w} .=1.67253 \text { OLS }
$$

$15.6 R_{15}=.00023336($ GST - BOCS $)+.299114 R_{91}+.00001641$ GNP $* P$

$$
\begin{aligned}
& \text { (1. 7193673) } \\
& \text { (2. 93830) } \\
& \text { (1. 67964) } \\
& +.58405 x_{3}+2.52526 \\
& \text { (2. 96679) } \\
& \text { (14. 70637) } \\
& \bar{R}^{2}-S_{\bar{y}}=7.3398 \quad \text { D. } w .=1.7366 \text { OLS }
\end{aligned}
$$


$15.7 \quad R_{15}=.076305 A T M+.3348078 R_{91}+.00003884$ GNP *P

$$
\begin{aligned}
& (1.019979) \\
& +1.445196 \\
& (2.261705)
\end{aligned}
$$

$$
\overline{\mathrm{R}}^{2}=.87254 \quad \text { Su } \bar{J}_{\mathrm{y}}=8.7258 \quad \text { D. W. }=1.76059 \text { OLS }
$$

16.

$$
\begin{aligned}
\mathrm{CONC}^{1}= & .1005(\mathrm{ND}+\mathrm{SD}+\mathrm{DD}+\mathrm{Cur})^{1}+92.68 \mathrm{TMM}^{1}-429.6^{1} \\
(2.01220) & (2.39116)
\end{aligned}
$$

$$
\begin{aligned}
\bar{R}=.97370 \quad \text { Su } / \bar{y} & =4.95 \quad \text { D. } w .=1.8011 \text { TSLS } \\
\text { RHO } & =.5813
\end{aligned}
$$

Section B - The Real Sector

17.

$$
\begin{aligned}
\mathrm{CND}= & .2720 \mathrm{Y}+.3505 \mathrm{POP}+.5135 \mathrm{CND}_{-1}+.151359 \frac{\mathrm{CONC}}{\mathrm{P}} \\
& (4.27278) \quad(3.06355) \quad(4.37547) \\
& -3026.0 \\
& (3.81503)
\end{aligned}
$$

$$
\bar{R}^{2}=.9936 \quad S u / \bar{y}=.8 \quad \text { D. } w=2.10 \text { OLS }
$$

18.

$$
\begin{gathered}
C D=-57.71527 \\
(1.80345)
\end{gathered} R_{15}+.1135791 \mathrm{Y}+.848641 \frac{\mathrm{CONC}}{\mathrm{P}}+.208679
$$

$$
\frac{(S D+D D)}{P}-2151
$$

$$
\bar{R}^{2}=.977232 \quad \mathrm{Su} / \overline{\mathrm{y}}=5.2545 \text { D. W. }=1.029 \text { OLS }
$$


19. $\frac{\mathrm{H}_{j}}{\mathrm{SA}}=.0000121 \mathrm{~J}-.003465 \mathrm{TIME}-.001479 \mathrm{R}_{91}-.00001333 \frac{\mathrm{ND}}{\mathrm{P}}$
$(4.52584) \quad(9.63063)$
(1. 39613)
(5. 48676)

$+.2940$

(234. 048)

$\bar{R}=.99725 \quad S u / \bar{y}=.8197 \quad$ D. $W .=1.74006$ TSLS

20.1 GIBUS $=-557.8 \mathrm{RC}_{15}^{1}+.2467 \mathrm{GDP}^{1}+.9255 \mathrm{GIBUS}_{-1}^{1}$

$$
\begin{aligned}
& \begin{array}{lll}
(3.37406) & (3.00376) & (6.66806)
\end{array} \\
& +.3498(\mathrm{PEY}+\mathrm{D})_{-1}^{1} \quad-1142 . \\
& \text { (3. 70948) (2.30801) }
\end{aligned}
$$

$$
\begin{aligned}
\bar{R}=.97497 \quad \mathrm{Su} / \bar{y} & =3.81 \quad \text { D. W. } 1.92446 \text { TSLS } \\
\text { RHO } & =.2759
\end{aligned}
$$

20. 2 GIBUS $=-649.962 \mathrm{RC}_{15}+.19472$ GNP +.259337 GIBUS 1

$$
\text { (2.593409) (6.00705) (2.38525) }
$$

+1.0096879 DIC + 1068 .

$$
\text { (1.358474) (2.287135) }
$$

$\bar{R}^{2}=.929349 \quad S u / \bar{y}=6.66745$ D. . $_{\cdot}=.93362$ OLS

20. 3 GIBUS $=.25975$ GIBUS $_{-1}+.1100$ GNP +.07040 GNP $_{-1}$

$$
\begin{array}{llc}
(2.511233) & (6.4206) & (6.4206) \\
+.03960 \mathrm{GNP}_{-2} & +.01760 \mathrm{GNP}_{-3}+.00440 \mathrm{GNP}-4 \\
(6.4206) & (6.4206) & (6.4206) \\
-914.42 \mathrm{RC}_{15} & +1.06775 \mathrm{DIC}+1048 . \\
(3.400128) & (1.505214) & (2.35750)
\end{array}
$$$$
\bar{R}^{2}=.935808 \quad \mathrm{Su} / \overline{\mathrm{y}}=6.35540 \text { D. W. }=1.09886 \text { OLS }
$$ 
21. CONG $=.03522$ GDP +.7477 GONG $_{-1}-306.7$

$$
\text { (1. 84878) (3.94502) (1.82805) }
$$

$\bar{R}=.98850 \quad S u / \bar{y}=4.634 \quad$ D. $w .=1.53960$ TSLS

22. $\mathrm{GIG}=.3579 \mathrm{CONG}+.2032 \mathrm{POP}-2014.0$

$$
\text { (3.88169) (28.12073) (16.11761) }
$$

$\bar{R}=.98875 \quad \mathrm{Su} / \bar{y}=4.943 \quad$ D. W. $=2.06745 \mathrm{TSLS}$

23. $G D P^{d}=C N D+C D+G I G+C O N G+\triangle H+G I B U S$

$$
+(F 2-F 1)+F D S K \$-\frac{1}{2} R 2
$$

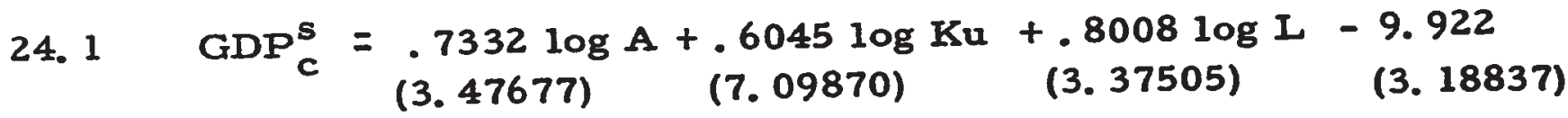

$\bar{R}=.99663 \quad$ Su $/ \bar{y}=.1977$ D. W. $=.27602$ TSLS

$24.2 \underline{G D P_{C}^{3}}=.5459 \log \mathrm{Ku}+.8008 \log \mathrm{L}-9.429$

$\begin{array}{llll}A & (2.38298) \quad(1.04789) \quad(.94937)\end{array}$

$\bar{R}=.99192 \mathrm{Su} / \bar{y}=.6753$ D. $\mathrm{w}_{.}=.2670 \mathrm{TSLS}$

$\begin{aligned} 24.3 \frac{G^{2} P_{C}^{s^{1}}}{A}= & .1056 \mathrm{~K}_{\mathrm{u}}^{1}+.4753 * 10^{-8}(\mathrm{Ku} * \mathrm{~L})^{1}+4662 . \\ (4.32102) & (3.33759)\end{aligned}$

$\bar{R}=.99833 \mathrm{Su} / \bar{y}=.620$ D. W. $=1.73734$ TSLS

$$
\mathrm{RHO}=.4531
$$


25. $\mathrm{Ku}=\left(\mathrm{H}_{\mathrm{j}}+\mathrm{CSTOT}\right) * \frac{\mathrm{Ne}}{\mathrm{N} 1-\mathrm{NM}}$

26. $L=\mathrm{Ne} * \mathrm{~h}$

27. $\quad$ CSTOT $=$ CSTOT $-1_{-1}$ GITOT $-D_{r}$

28. GITOT = GIBUS + GIG

29. $h=-.0115514 \mathrm{We}-14.6157 \mathrm{~N}_{\text {upc }}+.05137 \frac{\mathrm{CONC}}{\mathrm{P}}$

$$
\begin{aligned}
& \text { (3.3467) (4. 9528) } \\
& -60.8110 \mathrm{PL}_{-1}+2612 \text {. }
\end{aligned}
$$

$$
\text { (1.7792) (29.8519) }
$$

$\overline{\mathrm{R}}^{2}=.982469 \mathrm{Su} / \overline{\mathrm{y}}=.56871$ D. W. $=2.1066$ OLS

30. $\mathrm{Fl}^{1}=3614 . \mathrm{P}^{1}+.4803 \mathrm{GITOT}^{1}+.09379 \mathrm{GDP}^{1}-1.816 \mathrm{Nu}^{1}$

$$
\begin{array}{llll}
\begin{array}{l}
(1.1619) \\
-1252.1
\end{array} & (3.2201) & (1.80128)
\end{array}
$$$$
\text { (1. 97520) }
$$

$$
\begin{gathered}
\bar{R}=.98285 \quad S u / \bar{y}=3.40 \quad \text { D. } W .=1.55561 \text { TSLS } \\
\text { RHO }=.4202
\end{gathered}
$$

31. $W_{h_{r}}=-.01544 \mathrm{~N}_{\text {upc }}+.3656 \mathrm{PL}+.01252 \mathrm{TIME}+.6686$

$$
\begin{gathered}
(2.10614) \quad(2.13474) \quad(1.91945) \\
\bar{R}=.98636 \mathrm{Su} / /_{y}=2.145 \quad \text { D. } \mathrm{W} .=1.76405 \quad \text { TSLS }
\end{gathered}
$$


32. $W c=W h r * I$

33. $\mathrm{Y}_{\mathrm{g}}=.1879 * \mathrm{GDF}-3.763 \mathrm{~N}_{\mathrm{u}}-642.0$

$$
\begin{array}{lll}
(29.7018) & (6.88758) & (3.1359)
\end{array}
$$

$\bar{R}=.99165 \mathrm{Su} / \bar{y}=3.627$ D. $\mathbf{W} .=1.25640 \mathrm{TSLS}$

34. $D=.05418$ GDP +.02647 CSTOT $_{-1}+68.82$

$$
\begin{array}{lll}
(1.90074) & (2.18292) & (.37680)
\end{array}
$$

$\bar{R}=.98174 \quad \mathrm{Su} / \bar{y}=4.700 \quad$ D. $\mathrm{W} .=.49984 \mathrm{TSLS}$

35. GNP $=$ GDP $+P_{i d}-P_{d i}$

36. $\quad \mathrm{Y}=$ GNP $-J-Y_{G}-D-\frac{1}{2} R I$

37. $\mathrm{T}_{\mathrm{i}-\mathrm{s}}=.07572 \mathrm{GDF}+.4524 \mathrm{~T}_{\mathrm{i}-\mathrm{s}-1}-707$.

$$
\text { (3. 7355) (2.56237) (4.0882) }
$$

$\bar{R}=.99479$ Su $\bar{y}=3.161$ D. W. $=1.3129 \mathrm{TSLS}$

38. $\quad \mathrm{PEY}=\mathrm{GNP}+\mathrm{J}-\mathrm{W}_{\mathrm{C}}-\mathrm{MPAA}-\mathrm{D}-\mathrm{T}_{\mathrm{i}-\mathrm{s}}-\frac{1}{2} \mathrm{RI}$

39. $\quad \mathrm{GDP}=\mathrm{GDP}_{c}+\mathrm{MPAA}$

40. $D_{r}=.0600191$ CSTOT -179.9379

$$
\text { (72.392) (2.88376) }
$$

$\bar{R}^{2}=.996387 \mathrm{Su} / \bar{y}=1.6899$ D. $\mathrm{W} .=.210554$ OLS 
101

$41.1 P=-2.24684 \frac{\mathrm{Hj}}{\mathrm{SA}}+.23962 \mathrm{P}_{-1}+.15271 \mathrm{P}_{-2}+.08590 \mathrm{P}_{-3}$

(4. 59068)

(4. 59068)

(4. 59068)

$$
\begin{aligned}
& +.03818 P_{-4}+.00954 P_{-5}-.0032560 \mathrm{Nupc}+1.0737173 \\
& \text { (4. 59068) } \\
& \text { (4. 59068) } \\
& \text { (1. 934305) } \\
& \text { (4. 3346) } \\
& \bar{R}=.98872 \quad \mathrm{Su} / \bar{y}=1.48943 \quad \text { D. } \mathrm{W} .=1.8645 \text { OLS }
\end{aligned}
$$

41.2 $P=.0000281407(\mathrm{Cur}+\mathrm{DD}+\mathrm{ND}+\mathrm{SD})_{-1}+.0000031267$

(2. 30740)

(2. 30740)

$(\mathrm{Cur}+\mathrm{DD}+\mathrm{ND}+\mathrm{SD})_{-2}+.5710419 \mathrm{P}_{-1}$

(2. 84843)

-.002295 Nupc +.21055

(1. 56850)

(2. 63993)

42. $\Delta \quad \mathbf{H}=2\left(\mathrm{H}_{\mathbf{j}}-\mathrm{H}_{\mathbf{j}-1}\right)-\left(\mathrm{H}_{-1}-\mathrm{H}_{-2}\right)$

43. $\mathrm{Nu}=(\mathrm{N} 1-\mathrm{NM})-\mathrm{Ne}$

44. $\quad$ Nupc $=(\mathrm{Nu} /(\mathrm{N} I-\mathrm{NM})) * 100$

45. $\quad P L=G D P_{c} / L$

46. $w_{e}=.176 \sum_{i=0}^{7} .9^{i}$ GNP $t-1$ 
Section C - Glossary

In this section we present a glossary of all variables used in the model. Endogenous variables are underlined.

A

ATM

BOCS

CSTOT

CONC

Cur

Coin

CND

CD

CONG

DIC

$\underline{D D}$

$\underline{\text { Dr }}$

$\underline{\mathbf{D}}$

FDSK\$

F1

F2

GST
Neutral Technical Progress

Average term to maturity of the public debt.

Bank of Canada's holdings of Government Securities.

Total Stock of Fixed Capital.

Consumer Credit excluding chartered bank personal loans

Currency in the hands of the public (Notes plus coin)

Coin holdings of the public

Consumption of non-durables

Consumption of Darables.

Government Consumption

Direct Foreign investment in Canada.

Demand deposits - including provincial govermments and float.

Real depreciation

Capital Consumption allowances and miscellaneous valuation adjustments as per the national accounts

Federal Defense spending

Imports excluding interest and dividends

Exports excluding interest and dividends

Government Securities Outstanding 
GIBUS

GIG

GDP

CDP

GNP

GDF

GD

GITOT

HPM

Hj

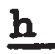

$\underline{\mathbf{H}}$

$i_{c b p l}$

J

$\underline{\mathrm{Ku}}$

$\underline{L}$

IQD

MPAA

N1

$\mathbf{N m}$
Gross Business Investment

Gross Government Investment

Gross Dome stic Product

Gross Domestic Product produced by the civilian economy.

Gross National Product

Gross domestic How

Government Deposits in the chartered banks.

Total national investment (gross)

High powered money $=$ sum of the reserves of the banking system and Cur - Coin.

Mid-year stock of inventories.

Average hours of work per worker per year.

Year-end stock of inventories.

Chartered Bank prime loan rate

Capital gains on inventories = negative of inventory valuation adjustment.

Capital stock in use.

Total man hours workad

Dummy for uncertainty during period when banks were adjusting to the imposition of secondary reserve requirement.

Military pay and allowances

Total labour force including North west territories. Military personnel employed. 
Ne

Nu

Nupc

ND

POP

$\underline{\text { PL }}$

P

pid

pdi

PEY

$R_{\text {ond }}$

$\mathbf{R}_{91}$

$\mathrm{R}_{15}$

$\mathrm{RC}_{15}$

$\mathbf{R}_{\text {swp }}$

$\mathrm{R}_{\text {svd }}$

$\underline{\mathrm{RC}^{n}}$

$\mathbf{R}_{15}^{n}$

RS

$\mathbf{S}$

SD

TIME
Number of civilians employed

Number of civilians unemployed

Nu as a per cent of (N1 - Nm)

Notice Deposits

Total Canadian population

Productivity per civilian man hour worked.

Implicit price deflator of Net National Product

Interest and dividends received from abroad.

Interest and dividends paid abroad.

Property and enterprise income

Chartered bank estimated average rate on Notice Deposits

91 day Treasury Bill yield.

Long term Government Bond yield

Long term corporate bond yield

Chartered Bank rate on swapped deposits

Chartered Bank rate on savings deposits

Normal corporate bond rate (a three period average starting in period $t$ )

Normal government bond rate

Reserves held by the banks

The stock of Treasury bills outstanding

Savings deposits

Time trend 
$\underline{\mathbf{I}-\mathbf{8}}$

USCB R

Wc

Whr

We

$x_{1}$

$\mathbf{x}_{2}$

$\mathbf{x}_{3}$

$\mathbf{x}_{5}$

$x_{6}$

$x_{7}$

$\mathbf{x}_{\mathbf{8}}$

$\mathbf{Y}$

$\underline{Y g}$
Indirect taxes 1 ess subsidies

Average high corporate bond yield in the United States

The civilian wage bill

Average hourly wage

Permanent Income Wealth proxy.

Dummy for Fixed exchange rate years.

Dummy for Reserve requirement change

Dummy for the conversion loan

Dummy for TD step function

Dummy for TD step function

Dummy for TD step function

Dummy for TD step function

Private Sector Disposable Income

Government disposable Income 


\section{CHAPT ER FIVE}

Preliminary Simulations and Structural Modifications.

\section{Section A - Introduction}

The equations presented in Chapter Four constitute a caricature of the Canadian economy. Individually, each of the equations is a fairly good approximation to the behaviour which it attempts to portray. The purpose of this chapter is to see how the equations function as a simultaneous system in portraying the dynamics of the economic process. The procedure used to analyze the dynamic properties of the system was to close-off the monetary and real sectors as separate models by treating first the real sector and then the monetary sector as exogenous. The truncated models so formed were then "run" over the fitting period. The equations altimately deleted from the monetary and real sectors by this process and the reasons for their deletion are indicated in sections $B$ and $C$ respectively. In section $D$, commentary is made on the ability of the whole model to track the endogenous variables over the fitting period and in Section $\mathrm{E}$ a prediction of the endogenous variables for 1967 is made.

\section{Section B - Monetary Dynamics.}

Very early in the simulations it became evident that equation 1. and the process of simulating total HPM instead of its components would have to be dropped. The trouble was not that 1 . predicted HPM badly or that 2. predicted Cur badly but that too often the errors were in the opposite direction. A positive error in 1. associated with an 
underestimate in 2: led to a fairly large over estimation of RS and consequently large movements in $\mathrm{DD}^{8}$. The problem with this interplay of forces is the fact that all errors of estimate which feed through to RS are amplified by the constant deposit multiplier (which varied in the step-function (9) from about 10. to about 13.) into much larger errors in $\mathrm{DD}^{8}$ which is residually determined in 10. These sometimes erratic movements in $D D^{s}$ might be tolerated were it not for the fact that $R_{91}$ is in part determined by $D D^{8}$. With a sharp movement in $D D^{8}$, $R_{91}$ is forced to move wildly to equilibrate the demand deposit "market" and this transmits directly through the term structure equations to provide similar erratic movements in the long term rates. Unfortunately, the interest sensitivities in the other deposit equations were not large enough to damp the erratic behaviour of $R_{91}$ and for some periods the system would generate large negative solutions for $R_{91}$ (Even if there were larger interest elasticities elsewhere, this would provide little comfort since the implication would be that these other equations would have to be in substantial error. Spreading the error around the system is really no solution to our problem. )

The adoption of 1.2 and the prediction of RS directly did some good, but was by and large still not satisfactory. The problem of error amplification via 9. and 10. still produced such outcomes as negative values for $R_{91}$ or values that overshot by several hundred per cent. The rather dismal outcome of these exercises was that RS had to be made exogenous. With RS exogenous, the model tracked DD and 
$R_{91}$ very well and all deposit equations performed well.

Problems still remained, however, in the term structure

equations which were ill-behaved in certain phases of the simulations.

The trouble here a rose from the lagged values of $R_{91^{*}}$ A slight

tendency for $R_{91}$ to overshoot in the early periods of the simulations caused a cumulative error to build up in the distributed lag on $R_{91^{\circ}}$ The result was a substantial error in the long rates. With certain of the distributed lag term structure equations "in" the sy stem became highly unstable and would converge to a solution only with much forcing and then only after several hundred iterations. Many trials with va rious combinations of the term structure equations presented in Chapter Four led to the deletion of all equations involving distributed lags and the selection of 14.2 and 15.7 as the term structure equations.

Although 14. 2 and 15. 7 do produce substantial errors for some years they produced a mean absolute deviation from the actual levels much smaller than that obtained. with the more sophisticated term structure equations.

A further alteration to the monetary sector was necessitated by the unstable relationship between $R_{\text {ond }}$ and $R_{91}$ via the $N D^{S}$ equation. It will be recalled that $R_{91}$ enters $R_{\text {ond }}$ with a positive sign - as suggested by the comparative static arguments presented in chapter 2 . section ii subsection $E$. Unfortunately, in a dynamic context this implies that a fall of $R_{91}$ from "equilibrium" will cause $R$ ond to fall, ND $D^{d}$ to fall 
sharply, $D D^{8}$ to rise and $R_{91}$ to fall further. To wit, the system is unstable. This situation could be corrected if we had another short te rm inte rest rate explained in the model. We could then substitute it for $R_{91}$ and presumably obtain a stable relationship between $R_{\text {ond }}$ and $R_{91}$. Since no other short term rate is determined endogenously $R_{\text {ond }}$ had to be made exogenous.

With the preceding changes having been made, the oystem worked well and 80 it was decided to turn to the Real Sector simulations. Section C - Testing the Real Sector.

The real sector worked much better than the monetary sector and our sole task is to indicate the final equations chosen (where several estimates were made).

Of the GIBUS equations estimated,20. 2 was found to be moot satisfactory and it was used in all of the simulations, 24. 3 was used in the production sector because it was the most atable in terms of the solution procedure. Both of the exponential forms were much more sensitive to step-size and equation order and for these practical reasons the multiplicative linear form was used. (The resulte generated by the three production functions were, however, almost identical, )

The quantity-theory equation (equation 41.2) performed very erractically and had to be replaced by equation 41.1 which worked well.

(1) We should indicate at this point that the government expenditures income equations were deleted, (i.e. equations 20, 21 and 27) and those variables were made exogenous. This was done to sharpen the focus on monetary policy. 
Th.: following section is devoted to a presentation of the results generated by the model for the period 1951-1966. Section D - The Control Solution.

Having obtained two sub-models which worked fairly well, we put them together and ran the resultant model over the fitting period to see how well it would track the various endogenous variables. (2) The procedure used in solving for the endogenous variables was to set the exogenous variables at their actual levels all through the run and to generate the lagged endogenous variables from the model. The solutions produced in this manner with the structure as estimated will be referred to here after as the control solution. As the graphs below indicate the model does quite well in tracking most of the endogenous variables.

The short term money market tracked the supply of demand deposits very well, considering that it is a residual, and consequently $R_{91}$ was predicted well except for a serious underestimate in 1962. The long rates were also predicted fairly well with $R_{15}$ doing slightly better than $\mathrm{RC}_{15}$. The other deposit categories and currency were on track throughout the run with currency performing better than either of SD or ND.

(2) For technical reasons only the period 1951-1966 is covered in the tracking experiment. 
The real sector equations performed satiefactorily with the exception of the prediction for 1957 and 1958. In both of those years there were substantial errors of estimate in most of the aggregate demand components. These errors led to an absolute decline in GDP in 1957 and a rise in 1958 when actual GDP only slowed in both those years. The principal source of this exror was the consumer durables equation which under-predicted in 1957 and over-predicted in 1958. The remainder of this section is devoted to the presentation of graphs which plot the actual and control solution values for selected variables. The actual series are represented on the graphs by a heavy line. 

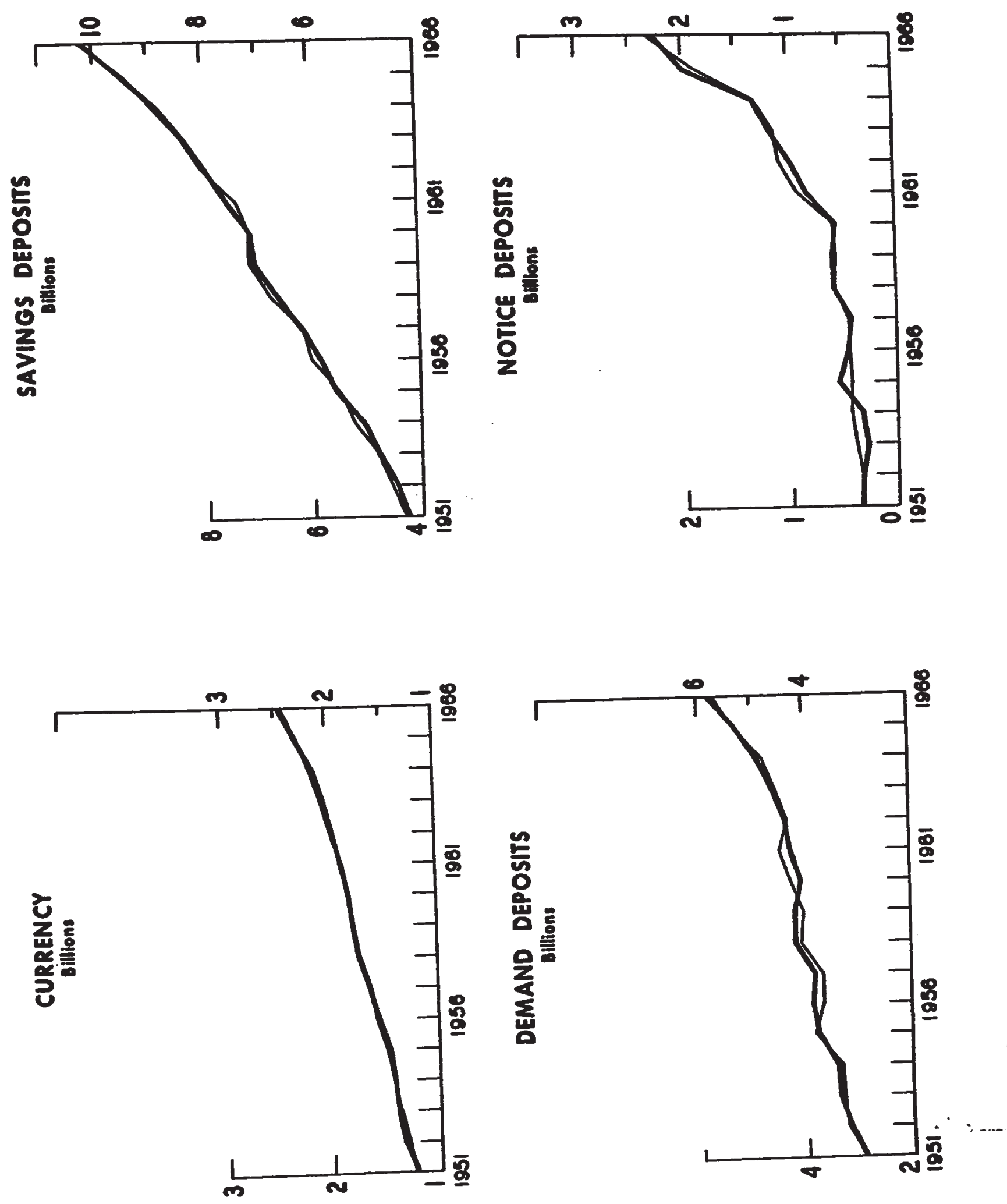

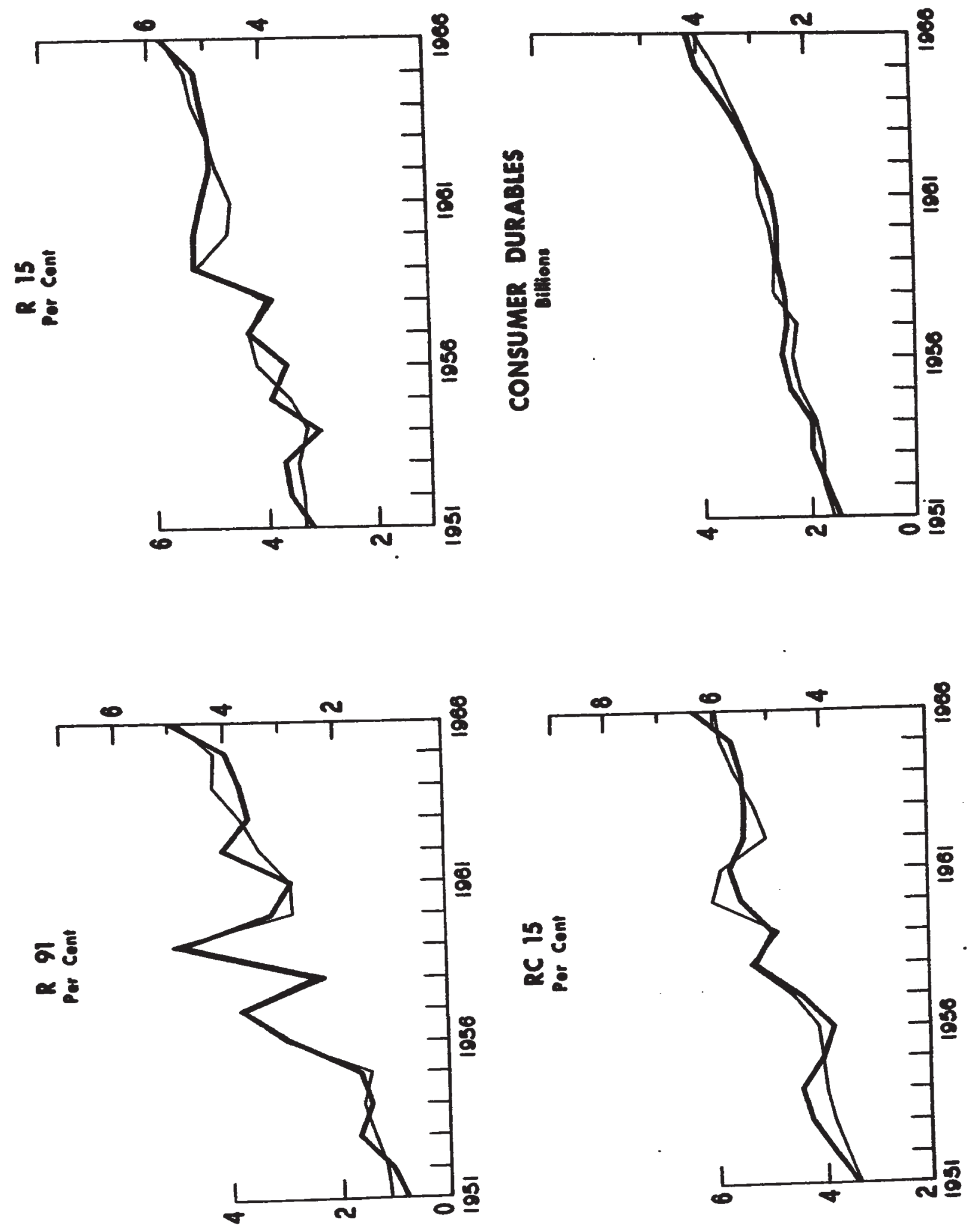

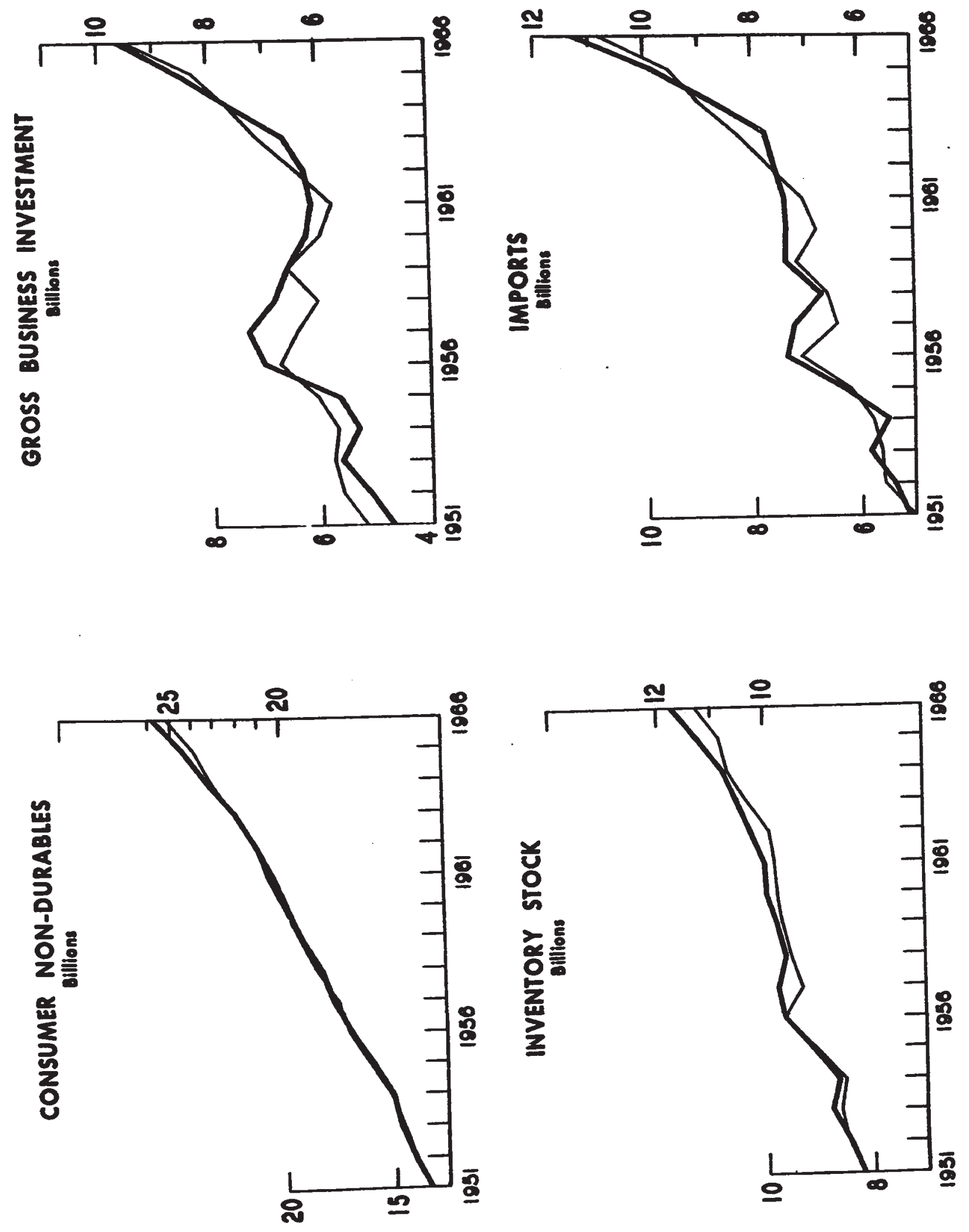

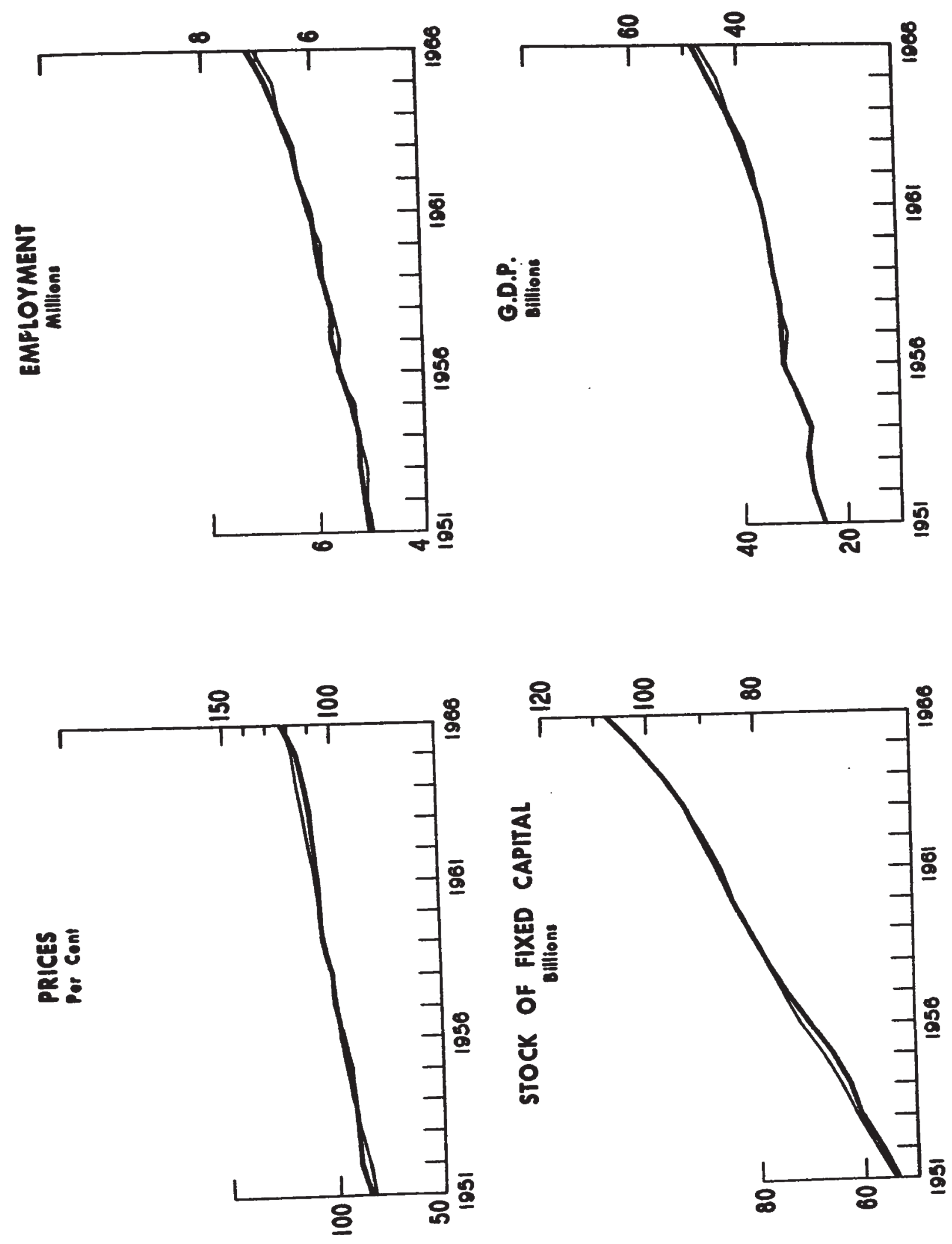
Section E - Predicting Beyond the Sample

In table IV - 1 the actual and predicted values for 1967 are exhibited. The results indicate that the model is a fairly good point predictor after 16 years.

It should be noted that an adjustment was made to the TD equation to account for the change in reserve requirements made in mid1967. It is also notable that the lagged endogenous variables used in the prediction were those generated on the control run: hence this prediction is a particularly severe test of the model's capabilities. 
TABLE V - 1

1. Curx

2. $S D$

3. DD

4. ND

5. $R_{91}$

6. $R_{15}$

7. $\mathrm{RC}_{15}$

8. CONC

9. CD

10. CND

11. GIBUS

12. $\mathrm{H}_{\mathbf{j}}$

13. FI

14. WHR

15. $\mathrm{H}$

16. $\mathrm{Y}_{\mathrm{g}}$

17. $T_{i-8}$

18. D

19. $D_{r}$

20. $P$

21. $G D P_{c}$
Actual

2664.

11188.

5935.

2857.

4. 64

5.93

5. 99

3571.

4258.

27069.

9318.

11931.

12004.

2. 053

1969.

9916.

6851.

5718.

6437.

127. 05

49356.
Predicted

2575.

10931.

6029.

3018.

5.23

5. 92

6. 15

3616.

4321.

26385.

9427.

11257.

11123.

2. 102

1914.

9916.

6784.

5618.

6438.

124.65

49445. 
TABLEV-1 (Continued)

22. $\mathbf{N}_{e}$

23. $\mathbf{K}_{\mathbf{u}}$

24. CSTOT

25. GITOT

26. $Y$

27. GDP

28. GNP

29. WC

30. PEY

31. $\Delta \mathrm{H}$

32. $\mathbf{N}_{\mathbf{u}}$

33. $\mathbf{N}_{\text {upc }}$

34. PI
Actual

7392.

119964.

112945.

11605.

33571.

49910.

49121.

25493.

10749.

225.

289.

3. 76

3. 39
Predicted

7284.

117420.

112557.

11714.

33840.

50010.

48990.

24938.

11468.

336.

396.

5. 16

3. 54 


\section{CHAPT ER SIX}

Section A - Introduction

The purpose of this chapter is to use the model presented in chapter four to simulate the effects on the economy, over the 1951-1966 period, of various monetary policies. The procedure used is that of comparing various test simulations (those in which the structure has been altered to simulate a policy) with the control simulation presented in the preceding chapter. The test simulations are compared with the control values rather than the actual values because the control values include the model errors. If test simulations were compared to the actual levels we would not know what part of the difference between the values was due to the policy change and what part was due to the errors generated by the model. Summary statistics for all of the variables and for each of the runs are appended to the chapter. Textual commentary is limited to the discussion of a few of the more important aggregates.

Section B - Some Technical Considerations

The results reported for each of the growth paths attempt to describe the principal characteristics of the paths.

The area under the growth profile is approximated by the average level of each of the variables, while the rate of growth is approximated by $\frac{1}{T}\left(\log X-\log X_{-T}\right)$. (Where $X$ is any variable and $T$ is time from the first observation on $\mathrm{X}$.) The stability properties of the paths are measured by the mean absolute period to period change while the "predictability" of a single year's outcome is measured by the mean 
relative dispersion or variation coefficient.

All of the final solutions were done with a modified GaussSeidel algorithm written specifically for the purpose. Solution order and step size were determined by numerically approximating the partial derivative matrix of the system. The Newton-Raphson method was used in some of the initial simulations where convergence could not be had with the Gauss-Seidel method.

The Gauss-Seidel algorithm can be easily summarized as follows. Starting from an initial value for each of the variable $x_{i}^{0}$

$$
\begin{aligned}
& x_{1}=F_{1}\left(x_{1}^{0} \ldots \ldots x_{n}^{\circ}\right) \\
& x_{1}=A_{1} F_{1}\left(x_{1}^{0} x_{n}^{\circ}\right)+\left(s_{1}-A_{1}\right) x_{1} \\
& x_{2}=F_{2}\left(x_{1} \ldots . x_{n}^{0}\right) \\
& x_{n}=F_{n}\left(x_{1} x_{n}\right)
\end{aligned}
$$

the equations for each variable are solved iteratively.

The results from each equation are weighted by the step size factors $A_{1},\left(S_{1}-A_{1}\right)$ and then used in the next equation to determine the next approximation. The step-size factors and the ordering of the equations is changed until a convergent sequence is obtained. It may also be necessary to re-normalize some of the equations (i. e. for example determine price from the supply equation instead of from the demand equation). Once a convergent combination of ordering, step size and normalization has been determined the method produces extremely cheap solutions - cheap enough to make extensive simulation with a system feasible. 
Section C - Monetary Rules

The first set of policy simulations is designed to test the hypothesis talat constant exogenous growth in the money supply is superior to the sort of policy currently followed. Supplementary tests of the uniqueness of a particular rule are also made.

$\underline{\operatorname{Run}(i)}$

On this run, the total money supply was constrained to grow at the same rate as it had exhibited on the control run. In view of the fact that we have not discussed the point before we should at this point indicate how the constraints are imposed.

As was noted in chapter two, the monetary authority is not able to determine the proportions of the money supply held in various forms but only its total. Given this restraint, the monetary authority moves to a money supply target by altering the supply of reserves to the banking system. Since no excess reserves are held in our model fixing $R S$ effectively fixes TD. These factors suggest the following equation. 1. $(1+\mathrm{GR}) * \mathrm{MS}_{-1}=\left(\log \mathrm{Cur}-\log _{\mathrm{Cur}}\right) * \mathrm{Cur}_{-1}+$

$$
(1+G R \text { 1)*TD-1 }
$$

where GR is the target rate of growth of the total money supply. Cur is currency holdings of the general public.

GR 1 is the growth rate of total deposits required in this period to yield GR as the growth rate of the money supply given that Cur is growing at rate $\left(\log \mathrm{Cur}-\log \mathrm{Cur}_{-1}\right)$. 
This equation together with the equation for Cur determines GR 1 which determines the required rate of growtb of reserves given the total deposit multiplier. Practically speaking, the latter step is not required so equation 9. Of the model can be deleted and the growth in total deposits determined directly from 1.above.

Setting GR = 0595954 produced the money supply series presented in table VI-1. These deviations from control produced the movements in GDP summarized in table VI-2.

\section{TABLE VI- 1}

Total Money Supply Including Government Deposits

Date

1951

1952

1953

1954

1955

1956

1957

1958

1959

1960

1961

1962

1963

1964

1965

1966

Test

8937.

9471. 10035. 10633.

11268.

11940.

12648.

13405.

14203.

15052.

15949.

16899.

17909.

18976.

20107.

21304.
Control

8937.

9502.

9887

10726.

11692.

12094.

12208.

13346.

14288.

14054.

14941.

15956.

16602.

17860.

19593.

21296.
Deviation

0
-31
148.
-93
-424
-154
240
59
-85
998
1008
943.
1307.
1116
514
8


TABLE VI-2

Deviations of Test GDP from Control GDP

1951

1952

1953

1954

1955

1956

1957

1958

1959

1960

1961

1962

1963

1964

1965

1966

0
$-\quad 19$.
85.
-45
-230
-170
134.
68.
46.
556.
677.
891.
1083.
1025.
771.
396.

Smoothing out the path of the money supply had the predictable effect of increasing the volatility of interest rates with short rates accommodatingmore than long rates. Remarkable is the fact that this increased volatility produced an increase in the stability of GDP, of which the mean absolute year to year change was down by $\$ 3$. million, and an increase in its rate of growth (6 basis points). The increased stability of GDP is explained by the more stable rates of advance of GIBUS, CD and Hj which in turn were stabilized by the more-sympathetically moving, lower interest rates.

The faster growing, higher GDP increased employment and raised prices slightly. The employment effects were mixed because the lower interest rates tended to stimulate investment expenditures more 
than consumption expenditures and this mix led eventually to labour being displaced by capital and an increase in the terminal rate of growth of unemployment.

Thus, apart from the pesky employment effects ${ }^{(1)}$ which eventually appear, the "real" growth path generated by smooth growth in the money supply would appear to be superior to the control path which closely resembled the actual path over the period.

As far as the monetary sector goes, the only notable fact is that the average period to period absolute change in interest rates increased. It could be argued that the only reason for success of the smooth money growth policy is the fact that the model does not account for "market tone" and that if such increased gyration of interest rates occurred in the economy the disruptive effects would be such as to far outweigh the beneficial effects of smooth money growth. Section $\mathbf{E}$ makes an attempt to treat this problem.

Before we get on to test the impact of interest rate volatility, we make two further tests of the constant money supply growth rule. The first of these involves constant growth in the money supply at a rate (1) It should be noted that these could very well be reflecting the inadequacy of the model. Two possibilities in that respect are suggested. First, the absence of an explicit marginal product of capital variable in the investment function allows investment to continue in spite of the decline in the yield on capital and second, the absence of a participation rate buffer precludes adjustment of the supply of labour in the face of rising unemployment. 
equal to the rate of growth of GDP on the control rum.

Run (ii) $\quad$ GR $=.0442668$

Implying as it did a substantial reduction in the money supply, this rule produced a much lower level of GDP and a. much slower growth rate. The decrease in the compound growth rate of the money supply of about 1.5 per cent brought about a reduction in the growth rate of GDP of about . 54 per cent. The decline in GDP was largely caused by the much higher level of interest rates (short rates were up 80 basis points on average). Unemployment was on average higher and interest rates were much more volatile.

It would seem that smooth growth in the money supply is of itself not a sufficient condition for improved performance of GDP. The first two tests taken together indicate that some rules improve matters and others don't. The preceeding test seems to indicate that the appropriate rule is not the growth rate of real output. To be certain that we had not prejudiced the result by our use of the 16 year compound growth rate, we tried the same sort of rule using a shorter time horizon.

Run (iii)

On this run GR was re-calculated for each 4 year sub-period. That is to say, the growth rate for the money supply in the period $1951-1955$, for example, was set equal to:

$$
G_{51-55}=.25 *\left(\log \operatorname{GDP}_{51}-\log \operatorname{GDP}_{47}\right)
$$

Unfortunately the four year plan didn't work as well as the longer horizon. The re-calculation of GR every four years led to a terminal 
growth in the money supply of only 3.55 per cent which caused a reduction in the growth rate of GDP of .84 basis points. In fact this growth path is inferior in every way (except stability) to all of the previous paths. The conclusions suggested by these three simulations are rather dismal as far as monetary rules are concerned. They indicate that although constancy can lead to a better growth path, the selection of the rate of growth is not a matter of indifference. In particular the knowledge that constancy can lead to a relative optimum is no more helpful from a growth point of view than the knowledge that expansionary monetary and fiscal policy can prevent a recession if undertaken at the right time. From the point of view of stability it would appear that constancy of monetary growth improves matters regardless of the rate chosen but this is really of small consolation when a less stable path produces a better all around performance of the economy. In a world where simple monetary rules instead of ad hoc policy were used research resources would presumably be devoted to the question of what the correct rate of growth of the money supply should be and the answers to that question would only be forthcoming if the research was successful in determining the exact structure of the economy. But it is precisely the lack of such information which prompts the apostles of the rule persuasion to press their case so strongly. Before getting into the consideration of more sophisticated rules and interest rate policies we should perhaps indicate how our results compare with similar tests which have recently been conducted on a model of the American economy. 
James L. Pierce ${ }^{(2)}$, using a version of the FRB-MIT model, simulated the effects of various policies over the five year period 1963-1968. His conclusions were essentially the same as ours: constant growth in MS at the control rate produced uniformly superior results while a 4\% rule and a $3.5 \%$ rule produced ambiguous performance. The $3.5 \%$ rule path was more stable than either of the other two but produced inferior all around performance of the economy.

Two aspects of the results are remarkable in more detail. In the first place, Pierce showed that adopting a constant monetary rule would have decreased the volatility of interest rates whereas we have found that constancy would have increased their volatility. These different results may indicate that the Canadias monetary authority in its attempt to stabilize interest rates has been in general successful while the American experience of volatile interest rates has been largely caused by the attempts of the monetary authority to anticipate movements which never would have materialized.

The second remarkable thing about our results is the degree of similarity of the response pattern of GDP to the constant growth in the money supply generated by the FRB-MIT model and that generated by

(2)James L. Pierce, "Some Rules for the conduct of Monetary Policy", in Controlling Monetary Aggregates: Monetary Conference June 1969, The Federal Reserve Bank of Boston, Sept. 1969. 
ours. Pierce's results (3) show a very gradual response during the first half of the period, a rapid ascent to peak in the third from last period and a rapid decline in subsequent periods. Like our results, his show a substantial positive deviation from control in the terminal period. All three of his experiments followed the same basic pattern of deviation from control whether the deviations were positive or negative however, all of his experiments were within a range of 75 basis points of the control rate of growth. Our results (table VI-3) were similar as long as we stayed within a similar band of growth rates. As the results for the 1.044266 path indicate, however, the response pattern was somewhat different outside that band. This compa rison makes it quite plain that our results for the four year plan (run iii) and the longer horizon GDP growth rule (run ii) may be the result of the inability of our model (or econometric models generally) to accurately capture behaviour which departs radically from the sample behaviour. This disclaimer does not, I think, alter our basic conclusion as to the ambiguity of simple rule policies because results which were in the relevant range (1. 054266 in table VI 3 and did display the characteristic response pattern also suggest the conclusions generated by runs (ii) and (iii) ${ }^{(4)}$.

(3) James L. Pierce, op. cit., Pp. 138-140.

(4) In any event, the response patterns are still basically the same - even on the 1.044266 run. 


\section{TABLE YI-3}

Deviations of Test GDP from Control GDP.

For the growth rates in MS indicated at the head of each column.

\begin{tabular}{|c|c|c|c|}
\hline Year & 1.044266 & 1. 054266 & 1.05959 \\
\hline 1951 & 0. & 0. & 0. \\
\hline 1952 & - $\quad 105$. & 48. & \\
\hline 1953 & $-\quad 105$. & 19. & 85. \\
\hline 1954 & - $\quad 378$. & -162. & -45. \\
\hline 1955 & - 733. & $-\quad 408$ & -230 \\
\hline 1956 & - 857. & -413. & -170. \\
\hline 1957 & - 736. & $-\quad 175$. & 134. \\
\hline 1958 & $-1,039$ & - 328. & 68. \\
\hline 1959 & $-1,307$ & $-\quad 440$ & 46. \\
\hline 1960 & $-1,089$ & $-\quad 38$. & $\begin{array}{l}556 . \\
677\end{array}$ \\
\hline 1961 & $-1,268$ & $\begin{array}{l}-\quad 27 . \\
+\quad 65\end{array}$ & $\begin{array}{l}677 . \\
891 .\end{array}$ \\
\hline $\begin{array}{l}1962 \\
1963\end{array}$ & $\begin{array}{l}-1,382 \\
-1,583\end{array}$ & $\begin{array}{r}+\quad 65 \\
+\quad 108\end{array}$ & 1,083 . \\
\hline $\begin{array}{l}1963 \\
1964\end{array}$ & $\begin{array}{l}-1,583 \\
-2,051\end{array}$ & $\begin{array}{l}+\quad 108 . \\
-\quad 100 .\end{array}$ & 1,025 . \\
\hline 1965 & $-2,702$ & $-\quad 506$. & 771. \\
\hline 1966 & $-3,556$ & $-1,062$ & 396. \\
\hline
\end{tabular}


Section D - A Digression on the Neutrality of Money

There is a question about monetary growth which, although implicit in the analysis which has preceded, has not been explicitly addressed thus far. That is the question of the long-term neutrality of money in the context of our model. Because of the low marginal cost involved in treating the question we have digressed from the main stream of our study to consider it.

The results of the previous section make it clear that money is not neutral in the sense that a higher or lower rate of growth of the money supply leaves the growth path of the real economy unaffected. In this section we attempt to discover in what sense money is neutral in our model. The analysis in this section differs - from that in other sections in that here we concern ourselves primarily with the evolution of growth rates along the time profile of the economy. Because this analysis is in some sense unrelated to the policy analysis which preceeds and follows we have attempted to make this section self-contained. In keeping with that objective we ran three simulations which are unrelated to those which have preceded.

The first of these simulations was run under the assumption that the growth rate of the money supply in each period was six percent this is used as the reference or control path for the purposes of this section. The other two simulations involved, respectively, a nonrecurring increase in the rate of growth of the money supply in one 
period and a permanent increase in the rate of growth of the money supply. Both of these shocks were administered in 1953. The "instantaneous" rates of growth(5) for output and the capital stock for each period on the simulation runs are presented in table VI-3A.

By comparing the first four columns in the table it can be seen that a once-for-all change in the money supply is neutral in the sense that the disturbed rate of growth sequence converges to the reference sequence after about twelve periods. However, the level at which the economy grew was not left unaffected. In particular GDP was raised, on average, 65 million above the reference path, while shortterm interest rates were three basis points lower. Also, since the capital stock was raised proportionately more $(240 \mathrm{mil})$ than the number of man-hours employed (-2.0 mil) the effect of the once-for-all

(5) The instantaneous rate of growth is the solution of the differential equation $\mathrm{g}=(\mathrm{d} \mathrm{Y} / \mathrm{dT}) / \mathrm{Y}$

Integrating we get $\log Y=g t+b$ and solving for $Y$ we find that $Y=\exp (g t)$. $\exp (b)$ where exp (b) is an arbitrary constant which we write as $Y \dot{0}$. Hence $Y=\exp (g t) \mathrm{Yo}$ or $Y / Y 0=\exp$ (gt). Solving for $g$ we get: ( $\log Y-\log Y o) / t=g$. For the finite difference analogue we have $Y_{t}=(1+g)^{t} Y_{t-T}$ which may be written $Y_{t} / Y_{t-T}=(1+g)^{t}$ or log $\begin{aligned} Y_{t}-\log Y_{t-T}=T \log (1+g) & \\ \text { Hence, since when } g \text { is small } \log (1+g) & =g \text { we can use the }\end{aligned}$ finite difference form as a good approximation to the instantaneous form. 
TABLE VI-3A.

Neutrality Results for Rates of Growth of MS at:

$6 \%$

\begin{tabular}{|c|c|c|c|c|c|}
\hline GDP & $\mathbf{K}_{\mathbf{p}}$ & GDP & $\mathbf{K P}$ & GDP & $\mathrm{K}_{\mathrm{p}}$ \\
\hline 5.35 & 5. 94 & 5.35 & 5.94 & 5. 35 & 5.94 \\
\hline 7.94 & 6.03 & 7. 94 & 6.03 & 7. 94 & 6.03 \\
\hline 2. 34 & 3.92 & 2.46 & 4. 03 & 2. 46 & 4. 03 \\
\hline-.0028 & 5. 12 & -.0026 & 5. 16 & -.0015 & 5.26 \\
\hline 7.57 & 3.86 & 7.61 & 3.92 & 7.75 & 4. 06 \\
\hline 7.93 & 8.50 & 7.92 & 8.52 & 8. 10 & 8.71 \\
\hline-.0096 & -.0030 & -.0095 & -.0027 & -.0077 & -.0004 \\
\hline 5.34 & 4.27 & 5.35 & 4.29 & 5.55 & 4.55 \\
\hline 3.05 & 5.37 & 3.06 & 5.39 & 3.27 & 5.68 \\
\hline 4. 16 & 2. 14 & 4. 17 & 2. 16 & 4. 40 & 2. 49 \\
\hline 3.54 & 4.94 & 3.55 & 4.96 & 3. 79 & 5. 30 \\
\hline 3.34 & 4.60 & 3. 34 & 4.62 & 3.60 & 4. 98 \\
\hline 6.57 & 4. 36 & 6.58 & 4.37 & 6.82 & 4.73 \\
\hline 6.33 & 5. 17 & 6.33 & 5. 18 & 6.54 & 5.54 \\
\hline 3.82 & 3.21 & 3.82 & 3.22 & 4.07 & 3.62 \\
\hline 7.31 & 5.64 & 7.31 & 5.64 & 7.51 & 6.01 \\
\hline
\end{tabular}

$6 \%$

$6.5 \%$ in 1953

6. $0 \%$ from 1954 to 1966
6. $5 \%$ from 1953 to 1966 
change in the money supply was to cause a once-for-all increase in the average capital-1abour ratio.

Hence, the determination of the neutrality of a one-for-all change in the money supply depends on the definition of neutrality that one chooses to employ. It is our opinion that neutrality in a growth sense should be couched in terms of rates of growth and not in terms of levels. In that sense a once-for-all change in money is neutral in our model. (6)

Comparing the last two columns in the table with the first two yields the result upon which the analysis in Section $C$ is based; i. e. , that a once-for-all change in the rate of growth of the money supply is $n$ eutral neither in the sense that it leaves the rate of advance of the economy unchanged nor in the sense that it leaves the level at which that growth proceeds unchanged. In the light of the evidence presented in Section C this resuli is, to say the least, anticlimastic. However, there is an interesting aspect of these results which hasn't as yet been pursued.

(6) Remarkable is the fact that neutrality in this sense is not an assumption of our model-as it is with most theoretical models-although it might follow from other assumptions which we have made. That our model does exhibit neutrality in this sense lends support to the assumption employed in theoretical analysis. On the matter of the assumption in theoretical models see: Harry G. Johnson, Essays in Monetary Economics, (Unwin, London), 1967, p. 163. 
It will be noted that since the rate of $g$ rowth of the capital

stock on the new growth path is higher than that obtaining on the reference path and population growth (exogenous) is the same on both paths, capital per head on the new path increases over time at a faster rate than it did on the reference path. This result is consistent with a similar result obtained from theoretical growth models if the Mundell real interest rate effect is assumed to hold. (7) The interesting thing is that we get this result in spite of the fact that our assumptions are radically different. A partial reconciliation can be made.

As noted below, monetary expansion in our model does not lead, willy-nilly, to inflation. This is due to the fact that a price equation embodying the assumption that monetary growth leads to price growth was not compatible with the empirical experience in our sample period. Furthermore, as a direct result of this, monetary expansion in our model does not lead to a long term increase in the nominal interest

(7) R. A. Mundell, "Inflation and Real Interest," Journal of Political Economy, Vol. 71, (June 1963), Pp. 280-283. See also, T. J. Courchene, Money and Economic Growth: an extension of the Mundell approach, forth coming.

The essence of Mundell's result is that increased monetary growth by increasing the rate of inflation reduces real wealth and increases the volume of savings forthcoming at a given real rate of interest. With a given investment demand this will tend to reduce the real rate of interest which means that a given degree of expected inflation will not all be reflected in higher nominal rates of interest since the real rate has fallen. Increased monetary growth is thus consistent with a rise in the money rate of interest and an increase in investment. The latter effect increases the capital per head. 
rate. However, as will be demonstrated in the next chapter, there is strong evidence to suggest that the so called Fisherine relationship between expected inflation and nominal interest rates is a discontinuous one that behaves in threshold fashion and that no such behaviour characterizes our sample period. Accordingly, we can pragmatically assume that over our sample period the real rate of interest and the nominal rate moved together and at about the same level. The combination of these empirical observations leads one to the conclusion that the capital per head ratio rises in our model because the real rate of interest (equal to the nominal rate) declines as the result of monetary expansion.

In summary, money is neutral in our model only in the sense that a once-for-all change in the money supply produces a growth rate sequence that converges to the reference sequence. In all other respects, money is not neutral. 
Section E - Interest Rate Rules.

The purpose of this section is to examine the impact of various market control policies which consist of the monetary authority pegging short term interest rates. The assumption is that the monetary authority behaves as it did on the control run unless interest rates rise or fall by a specified amount in any period - in that event the short term rate is set at the maximum or minimum allowable and the money supply is endogenously determined.

Run (iv) Maximum change set at. 70 .

Table VI-4 summarizes in deviation from control form the money supply, interest rate and GDP implications of a market peg policy where the pegs are set at \pm .70 per cent.

\section{$\frac{\text { TABLE VI-4 }}{\text { Deviations from Control }}$}

Year

$$
\text { Money Supply }
$$

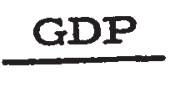

0.

1951

1952

1953

1954

1955

1956

1957

1958

1959

1960

1961

1962

1963

1964

1965

1966
0.

0.

0.

0.

0.

+5 .

+26 .

+34 .

+35 .

+34 .

+33 .

+15 .

+7 .

+5 .

+3 .

+2 .
0.

0 .

0 .

0.

+150 .

+450 .

+539 .

+587 .

+496 .

+471 .

$+96$.

+145 .

+183 .

+152 .

+139 .

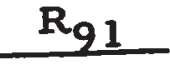

0.

0 .

0.

0.

0.

$-.818$

$-.962$

$+.376$

$-1.476$

$+.337$

$+.297$

-.030

$+.014$

$+.040$

$+.017$

$+.008$ 
The results are quite interesting for two reasons. In the first place they indicate that a more circumspect market policy around the time of the imposition of the secondary reserve requirement and the conversion loan might have prevented the recessions of 1957-1958 and 1960. They would certainly have been $1 e s s$ severe as the GDP results indicate. Notable is the fact that very small changes in the money supply would have been necessary to implement the policy.

The growth path generated by the "peg" policy was better in almost every respect than the control path. The rate of advance of GDP increased by two basis points while its stability in a year to year sense increased by 31 million. Employment fared 1 ess well because of the above mentioned labour-saving capital investment process which was stimulated by the slightly lower interest rates.

With these results in hand, a second interesting fact can be ascertained from the market peg experiment. Recall that in the constant growth of the MS tests. the result was always that interest rates became more volatile. We interpreted that result to mean that because interest rates were allowedto accommodate the movements of money demand and income movements they would move more in sympathy with the cycle providing an element of built in stability. The results of the present test indicate that stabilizing interest rates of itself leads to a more stable path for GDP implying that the results on the constant money supply run may have been due more to the lower average level of interest rates than to "more-sympathetically moving" rates. Comparative results for a 
monetary rule (GR $=.0595954)$ and the peg run are presented in table VI-5.

\section{TABLE VI-5}

\begin{tabular}{|c|c|c|c|c|}
\hline & & Stability & Average level & Growth \\
\hline peg: & $\begin{array}{l}R_{91} \\
G D P\end{array}$ & $1647^{.3650}$ & $\begin{array}{l}2.981 \\
36675 .\end{array}$ & 1.0444 \\
\hline & $\begin{array}{l}\text { R91 } \\
\text { GDP }\end{array}$ & 1675.8537 & $\begin{array}{l}2.945 \\
36799 .\end{array}$ & 1. 0448 \\
\hline
\end{tabular}

The constant money supply growth produced a less stable path than the market peg policy but the path was higher and GDP was growing faster. This substantial difference in the level at which GDP grew on the two runs and the much larger marginal increment in the growth rate of GDP are not traceable to the average level of rates since that difference is almost negligible. The much better stability performance of the peg run and the substantial difference in interest rate volatility do suggest, however, that a smoother path for interest rates leads to a more stable path for GDP. The fact that both of these policies produced a more stable path for GDP than that generated on the control run suggests that interest rate stability is sufficient to produce GDP stability but is not necessary. This in turn implies that constant money supply growth induces a characteristic dynamic pattern which is such as to smooth and accelerate GDP quite apart from any effects which increased interest rate variability may have. This latter observation suggests a further set 
of experiments involving compound policy rules (i. e. interest rate rules and monetary rules combined) to see what effect would be produced by constraining the monetary rule to produce less interest rate movement. The next section is devoted to a series of such tests. Before getting on to them we indicate the results obtained by altering the size of the band in the market peg experiment and suggest some conclusions which might be drawn.

Runs $(v)$ and $(v i)$ involved running the model under the same assumptions as used on run (iv) but on these runs the market peg range was changed. Run (v), which was a definite improvement over both control and run (iv), was made under the assumption that the market peg was \pm .40 per cent. On run (vi) the peg was set at \pm 1.20 per cent.

As in the case of monetary rules the choice of which rule to follow is not a matter of indifference. However, unlike the monetary rules, all interest rate rules tested produced uniformly better results than those achieved on the control run. The implication here is that interest rate policies are less sensitive to deviations from the optimal policy (whatever it may be) than are monetary rules. Accordingly, if a simple rule is to be adopted the current state of ignorance as to the structural properties of the economy together with these results indicate that interest rate rules a re more likely to be successful on all counts. Of course, to the extent that the monetary authority actually followed a market peg policy over the period this result is weakened. This follows from our use of 
the actual reserves series as a base for the market peg policies. Section E - Compound Rules.

This section summarizes the results obtained by combining monetary rules with various market peg policies. Each of runs (i), (ii) and (iii) were repeated with each of the three market pegs tried in Section $\mathbf{E .}$

Runs vii, viii and ix were run with run (i) as a base and the market pegs set at $.70, .40$ and 1.20. The growth path results for these three runs are summarized in table VI-6.

TABLE VI-6

\begin{tabular}{|c|c|c|c|c|}
\hline & Variable & Stability & Level & Growth \\
\hline $\begin{array}{l}\text { Run (vii) } \\
.70\end{array}$ & $\begin{array}{l}\text { R91 } \\
\text { MS } \\
\text { GDP }\end{array}$ & $\begin{array}{l}.4880 \\
844 . \\
1670\end{array}$ & $\begin{array}{c}2.834 \\
1525 . \\
36949 .\end{array}$ & 4. $5058 \overline{7}$ \\
\hline $\begin{array}{l}\operatorname{Run}(v i i i) \\
.40\end{array}$ & $\begin{array}{l}\text { R91 } \\
\text { MS } \\
\text { GDP }\end{array}$ & $\begin{array}{l}.3462 \\
844 . \\
1683 .\end{array}$ & $\begin{array}{c}2.696 \\
1525 . \\
37065 .\end{array}$ & 4. 56064 \\
\hline $\begin{array}{l}\text { Run (ix) } \\
1.20\end{array}$ & $\begin{array}{l}\text { R91 } \\
\text { MS } \\
\text { GDP }\end{array}$ & $\begin{array}{l}.5952 \\
844 . \\
1678 .\end{array}$ & $\begin{array}{c}2.892 \\
1524 . \\
36877 .\end{array}$ & 4. $4915 \overline{-}$ \\
\hline
\end{tabular}

Not surprisingly the combination policies produced results which we would not have inferred from their separate effects. In terms of the level and rate of growth there was a definite improvement caused by the peg policy; the narrower the spread the more pronounced the improvements. However, in terms of stability, the middle peg range (. 70) proved superior. It would appear that for all relevant ranges, market policies together 
141

with a monetary rule will improve both the level and rate characteristics of the growth path of GDP but only a limited range will also yield a more stable path. The automatic policy rule, ever elusive, eludes us again. The results for the other runs in this series were basically the same as these and suggest the same conclusions.

Before getting on to the final set of experiments where we make some stochastic tests of the rankings which we have established, we will briefly summarize the preceeding results. Table VI-7 reproduces some of the more important results for the various policies tested. 

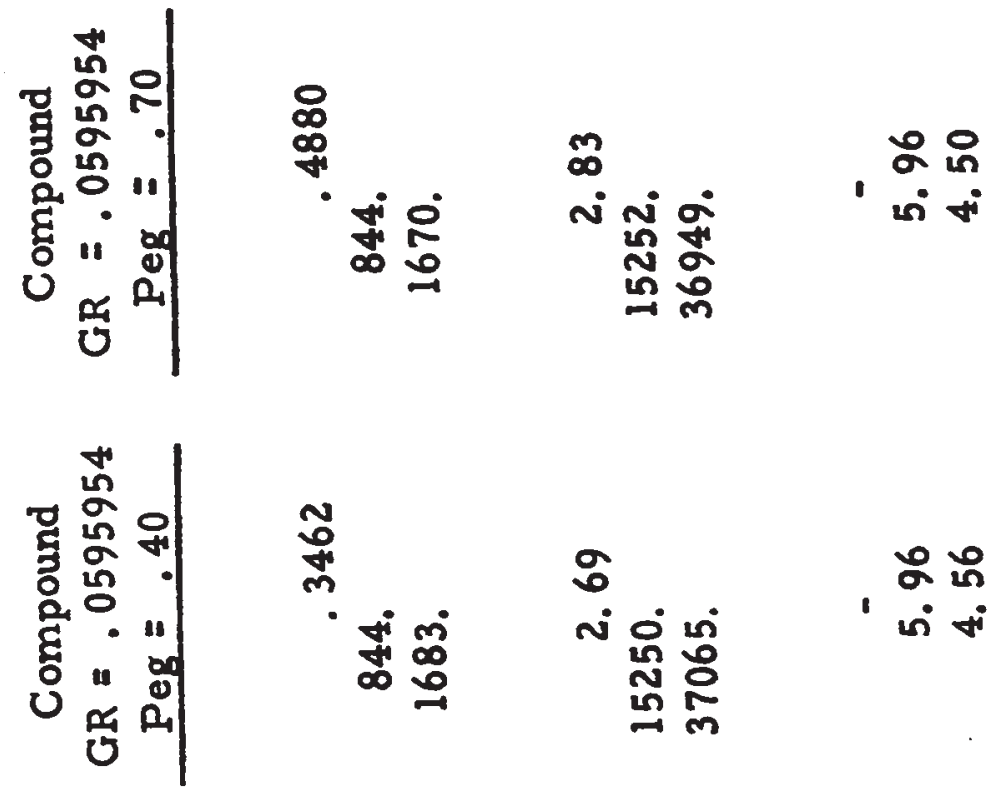

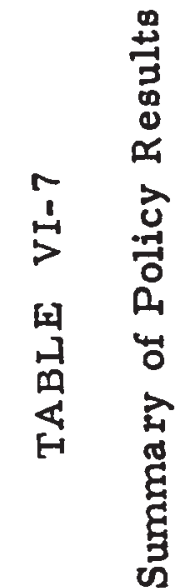
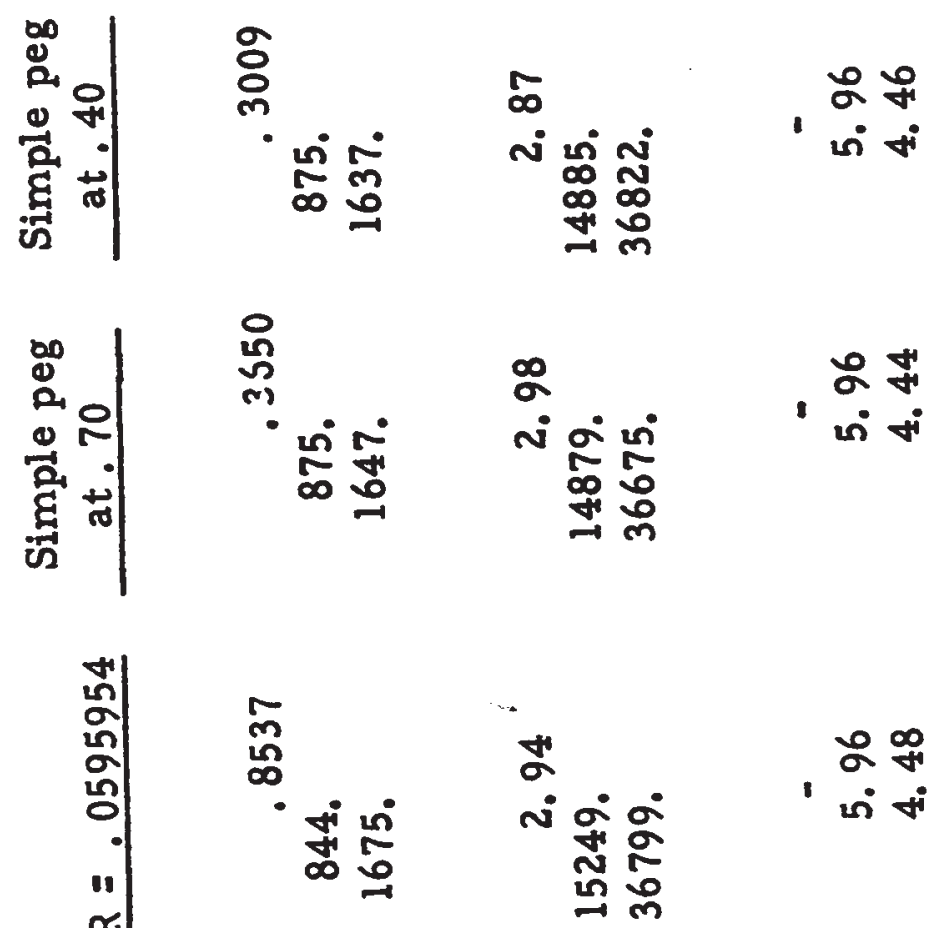

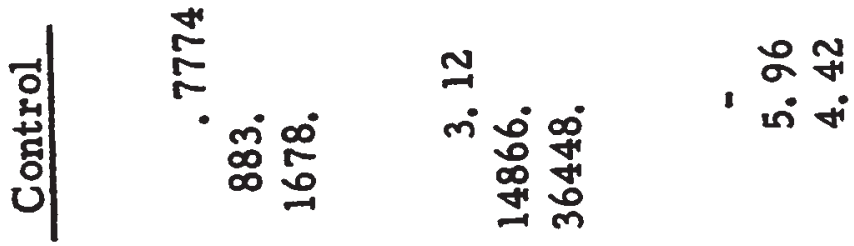

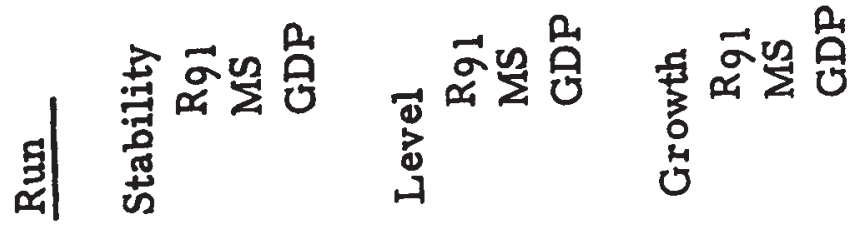


Section G - Policy Response to Random Shocks

In the preceeding sections we have built up a catalogue of policy rules and attempted to rank them according to the growth path of final output which they generated. The purpose of this final set of tests is to examine the behaviour of each of the paths under the influence of a series of random shocks. The random shocks are assumed to enter the system in the form of increased or decreased export demand determined from the following formula:

$$
F 2_{t}=F 2_{t}+(.5-R A N) * 200 . \text { million }
$$

where RAN is a random number uniformly distributed between zero and one. The results of adding the random shock device to the models which generated table VI- 7 are presented in table VI-8.

Since the results a re obviously compatible with the hypothesis that the ranking of policies established in preceeding sections is invariant with respect to alterations in the initial conditions little more need be said. However, it might be adviseable to indicate the limitations on the results of this section. The principal disclaimer is that although we have shown our ranking of policies to be invariant to exogenous shocks we have not demonstrated the superiority of the whole range of policies. That is to say, for some reasonable observations on RAN the system may not be amenable to stabilization by any of the rules which we have tested. Also, since the policy actually followed over the period would undoubtedly have been altered in the face of the shocks which we imposed ex post, the 

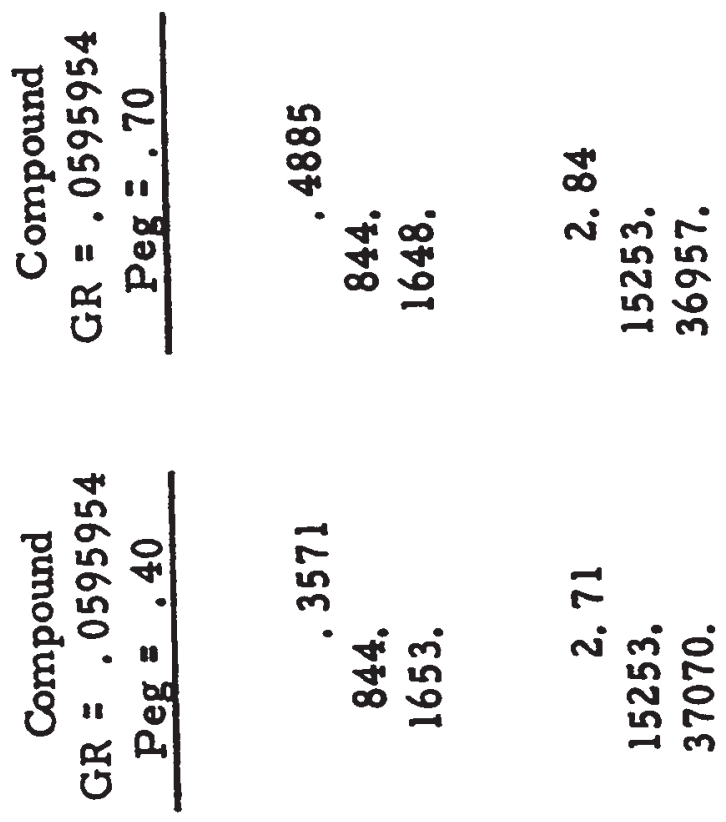

을
in
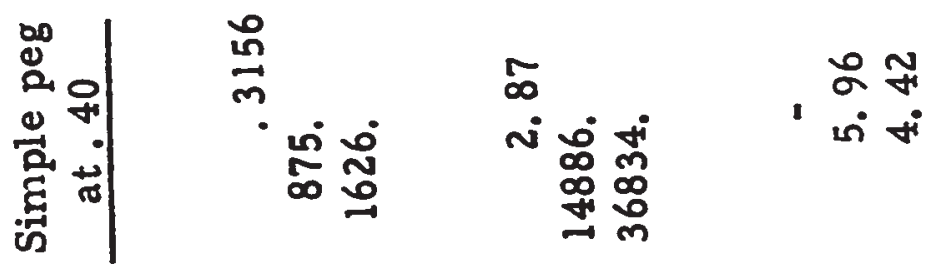

, ํํㅀ

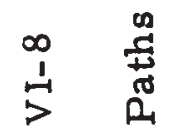

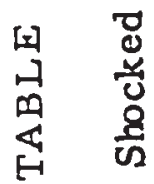
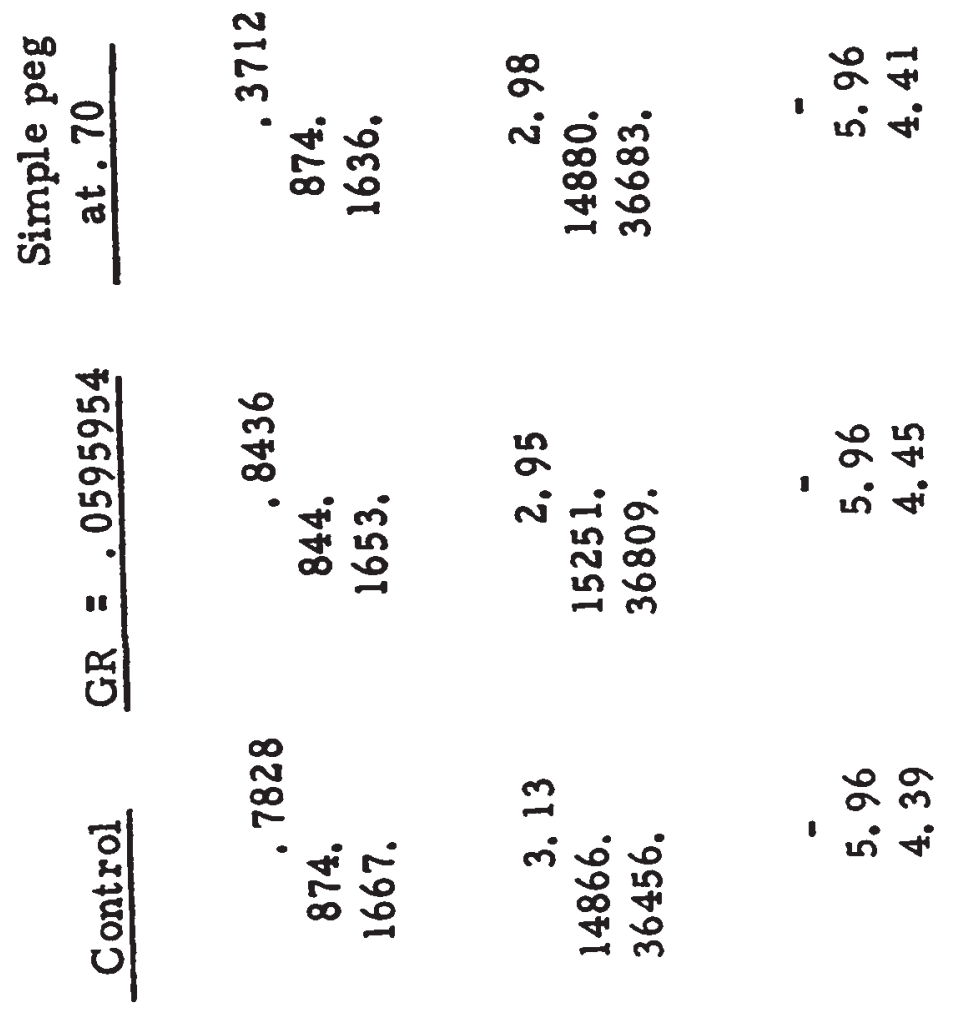

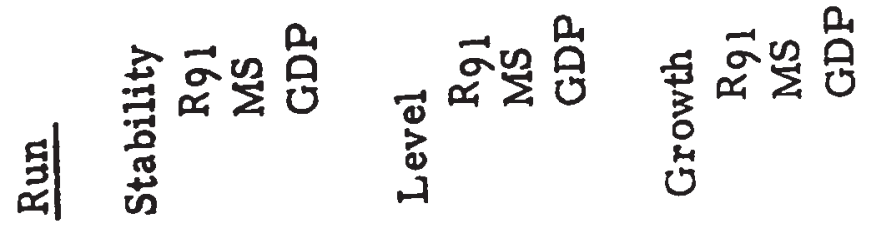


procedure of using the actual reserve series as the control policy makes impossible the meaningful comparison of the relative size of the improvement caused by various policies on the shocked paths.

Section H - Summary and Conclusions on Monetary Rules •

This chapter has attempted to evaluate the efficacy of prescriptions which advocate the adoption of policy rules by evaluating the empirical implications of the rules themselves. The results shed light on two issues.

First, they indicate that policy rules, either simple or compound, could have led to a growth path of output which would have been superior to that actually obtained in the period 1951-1966. Secondly they indicate that the selection of rules (or combination thereof) is crucial to the outcome.

Combining these two results yields the uninteresting conclusion that policy rules, if appropriate, can lead to superior growth paths. This information, as indicated in an earlier section, is no more useful than the knowledge that counter-cyclical policy of the right sort produces superior growth paths. (With the possible exception that the latter also involves a time dimension.) In particular, it cannot be claimed that policy rules are superior because they require less knowledge about the structure of the economy and that in the current state of ignorance we should adopt a rule.

We should perhaps stress the fact that these results, like all empirically determined conclusions, are a function of the data sample and empirical methods employed. We can make no claim that the model which was constructed is still relevant and accordingly are unable to prescribe from it the sort of policy which should currently be followed. (For more on the issue of structural change the reader is referred to Chapter Seven.) 


\section{APP ENDIX A CHAPTER VI}

A Tabular Summary of the Simulation Statistics 


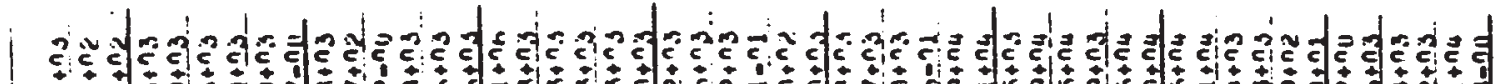
J

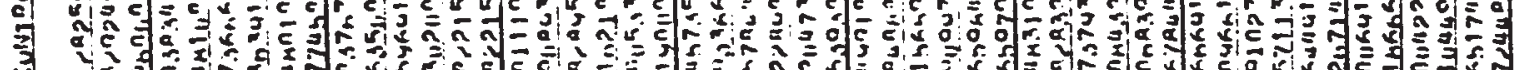

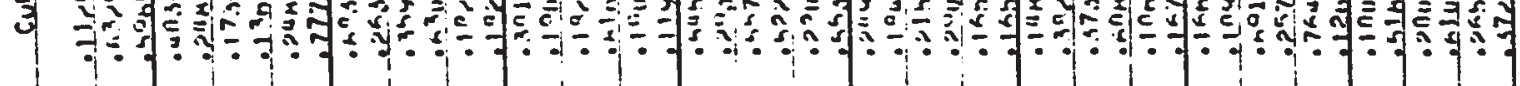

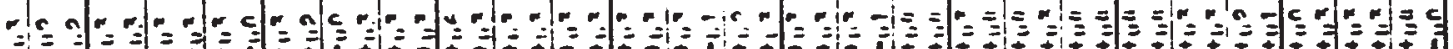

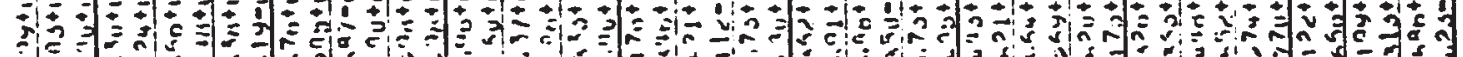
⿹ 口

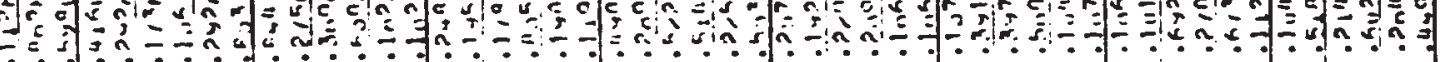

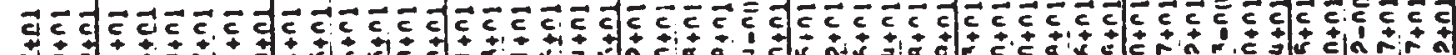

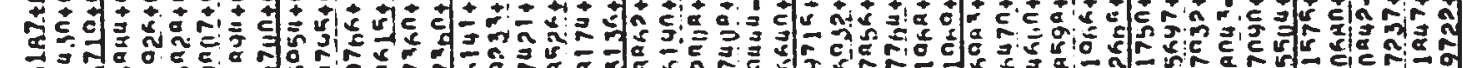

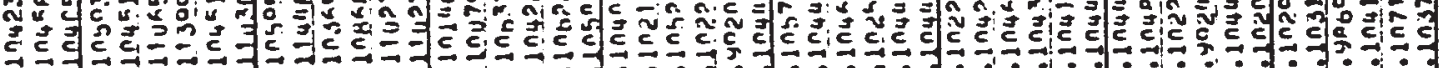

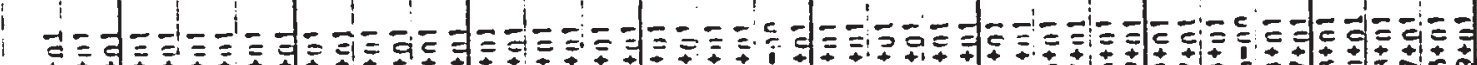

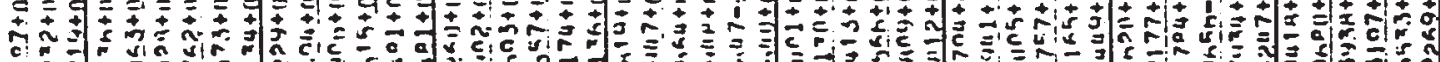
ñ -

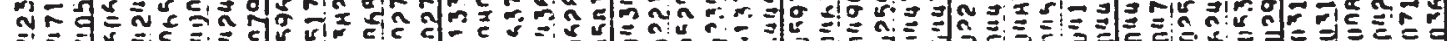

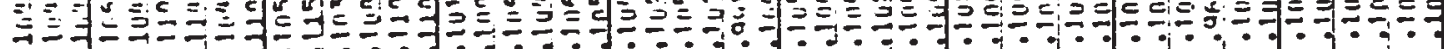

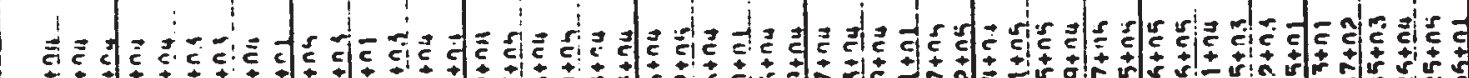
to

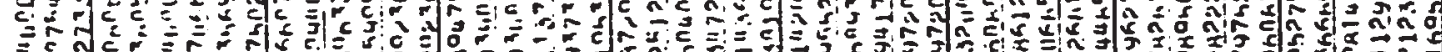

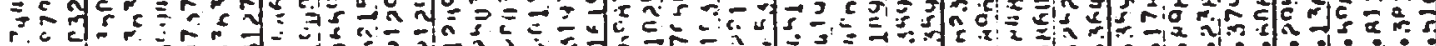

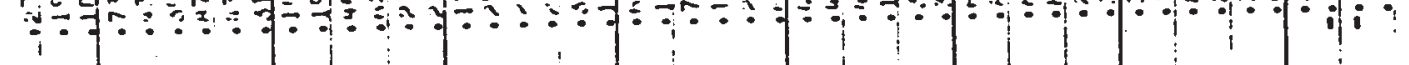

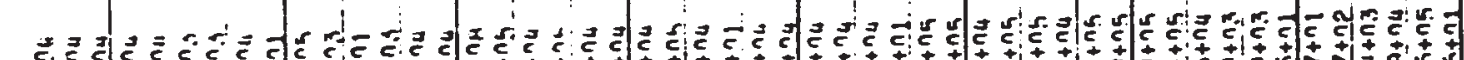

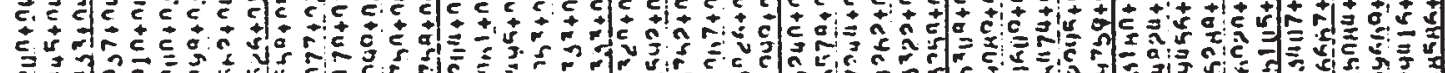
3 . 30 c $-4$ में ㄴำ

\section{(3)}

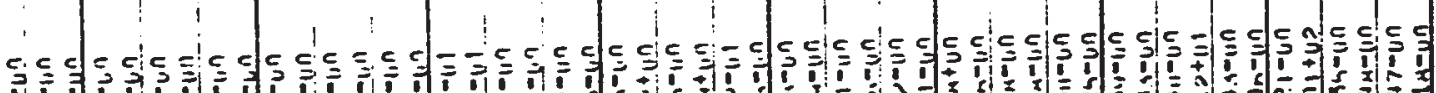

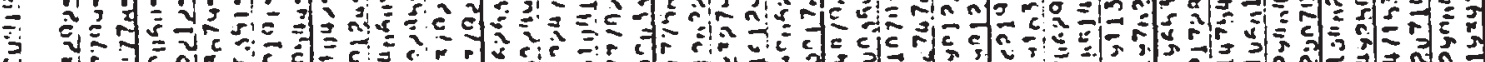
ac

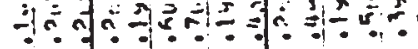

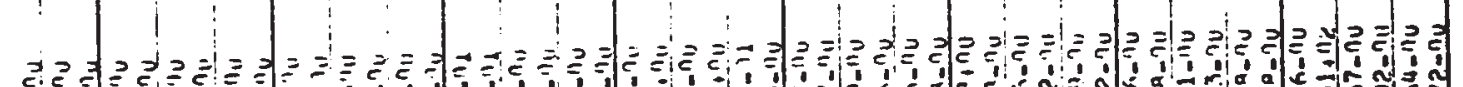
ñ $=0$

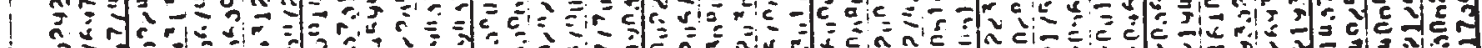

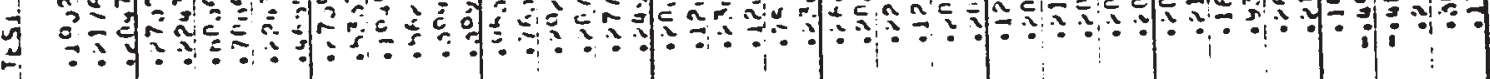

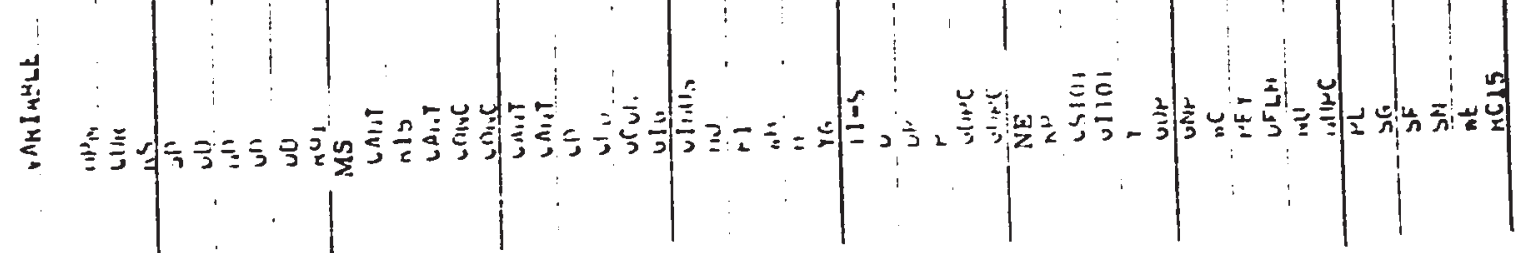




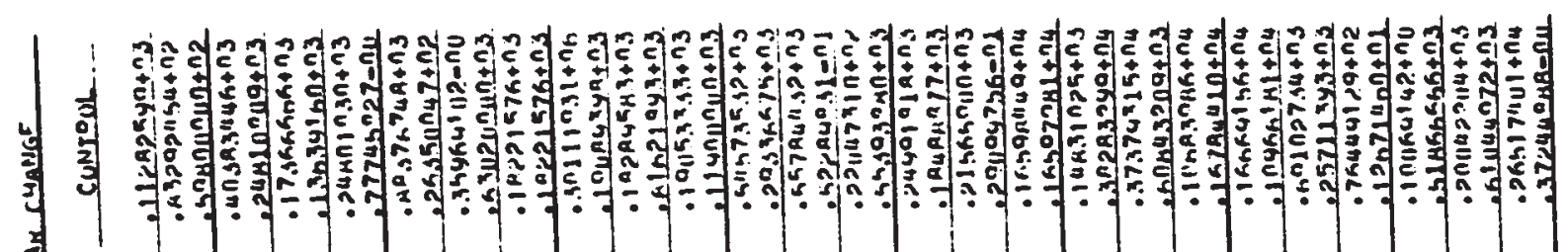

ำ

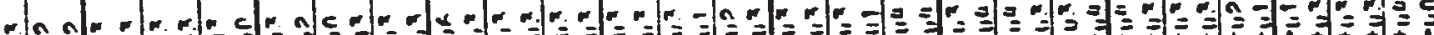

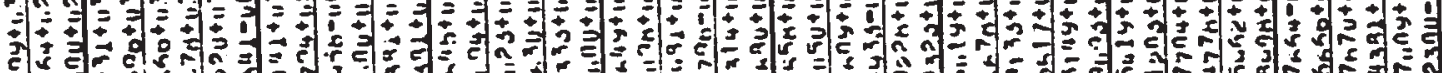
s.

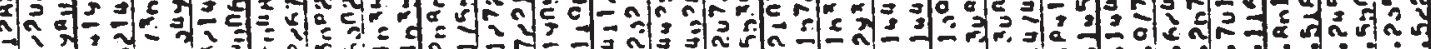
$2+1$

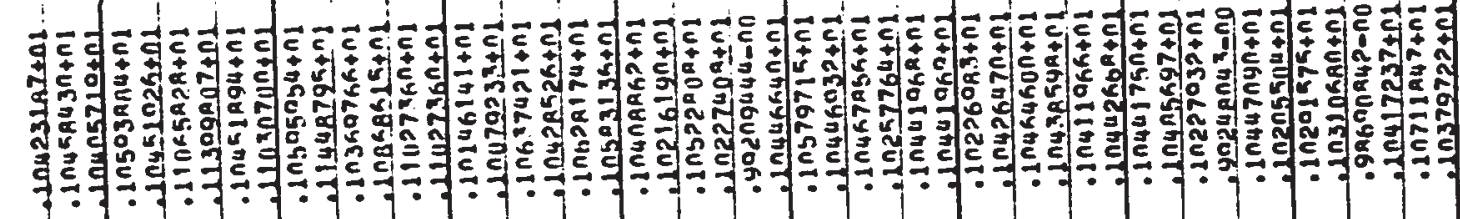

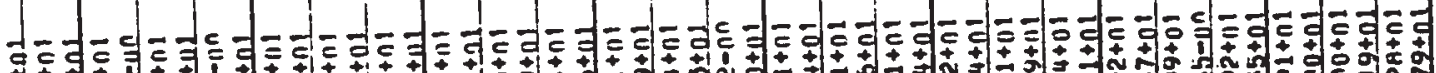

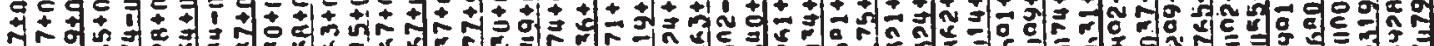
a

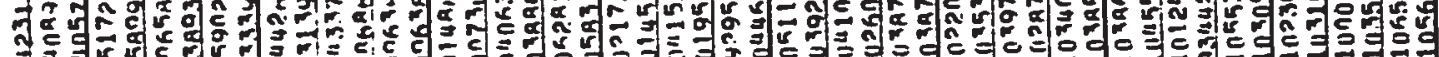

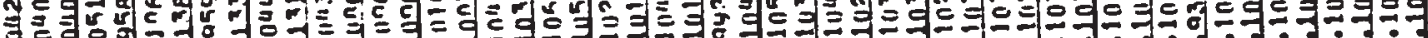

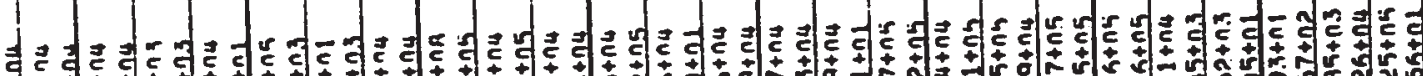

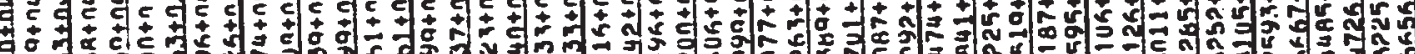

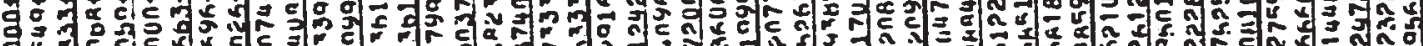

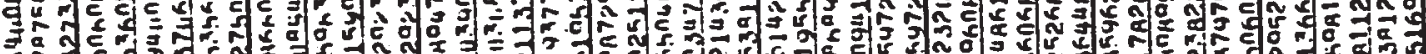

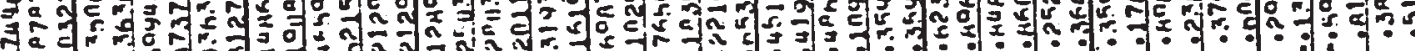
สำ

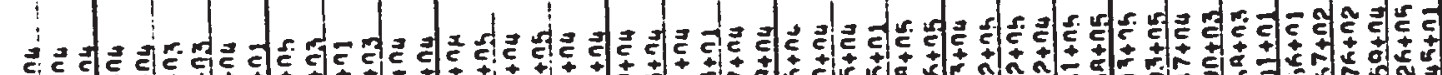
40

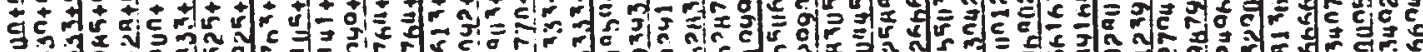
2ex 刍下独

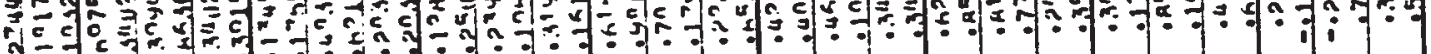

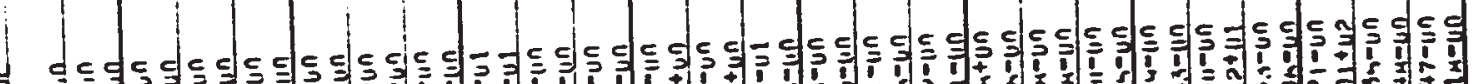

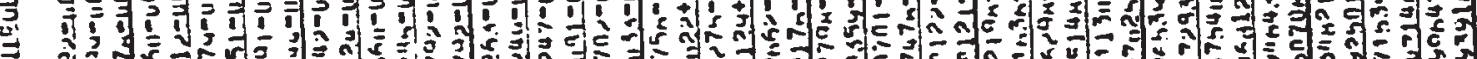

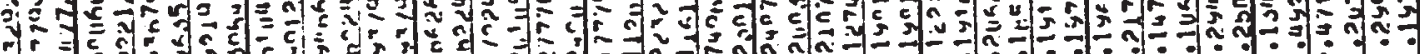
ปที่า

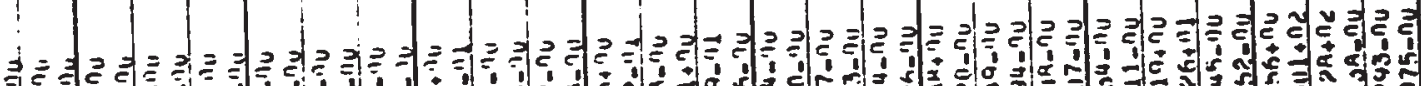

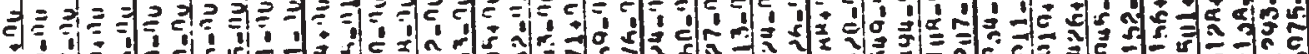

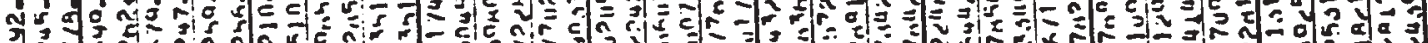

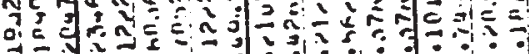
$\because \cdot 1 \cdot 1 \cdot 0.0$

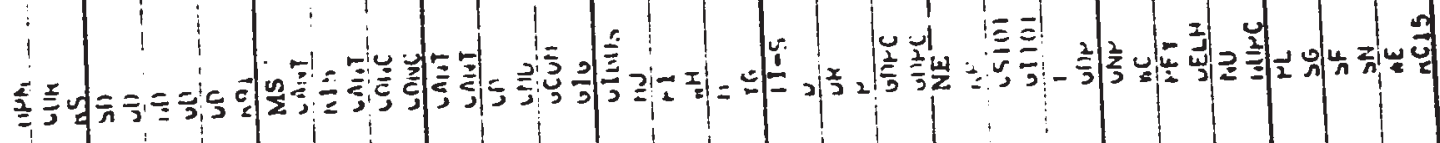




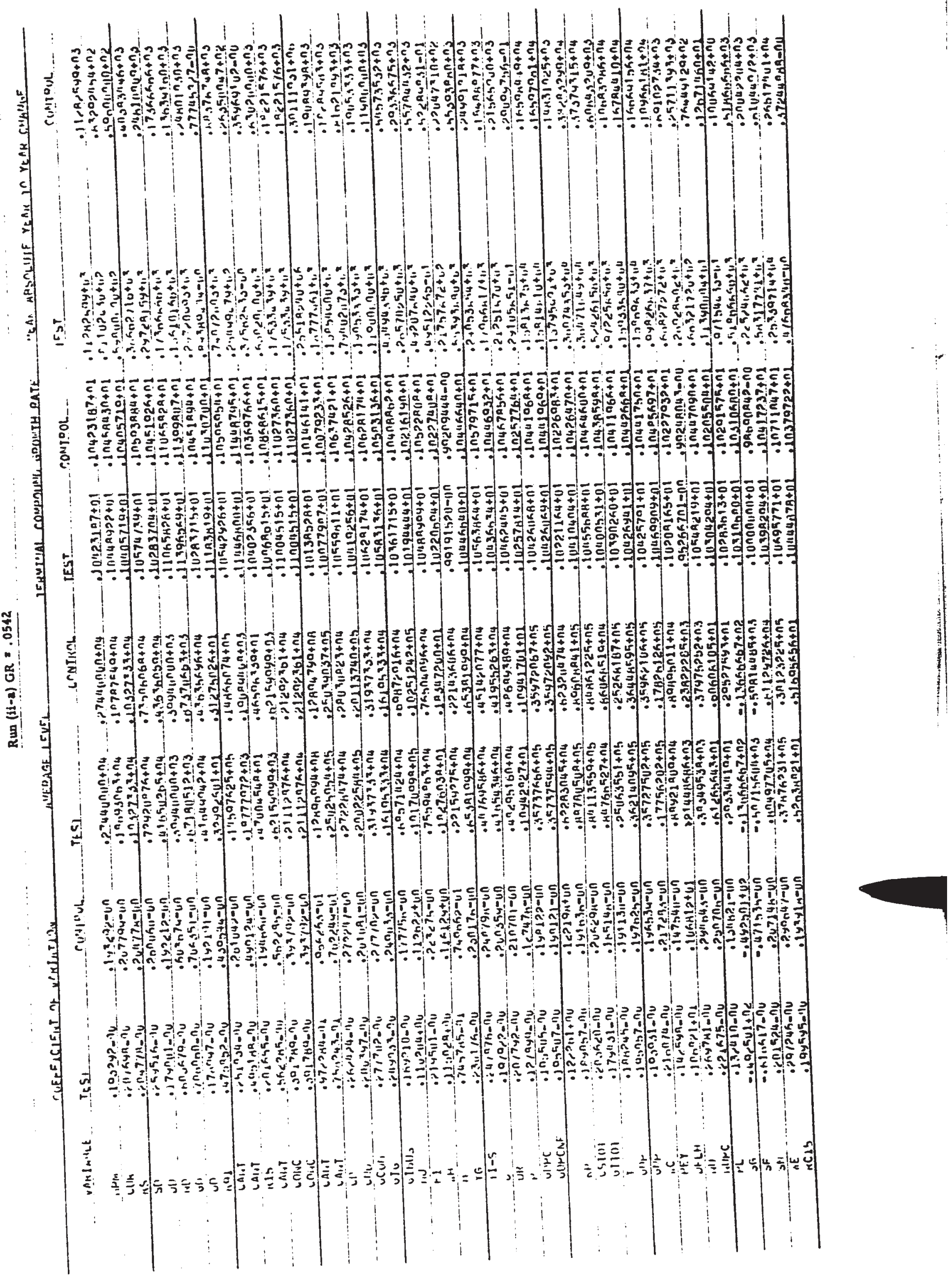




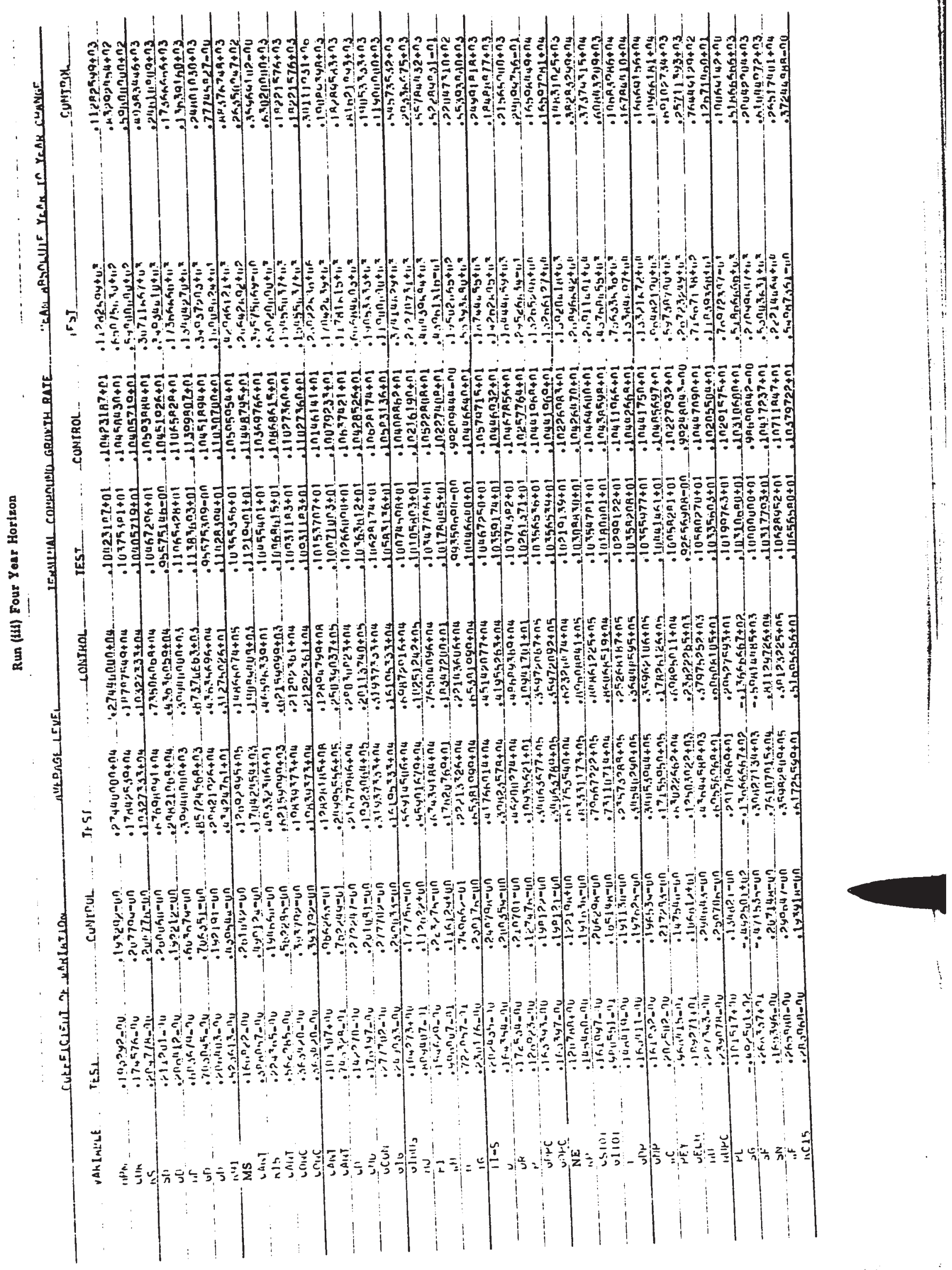




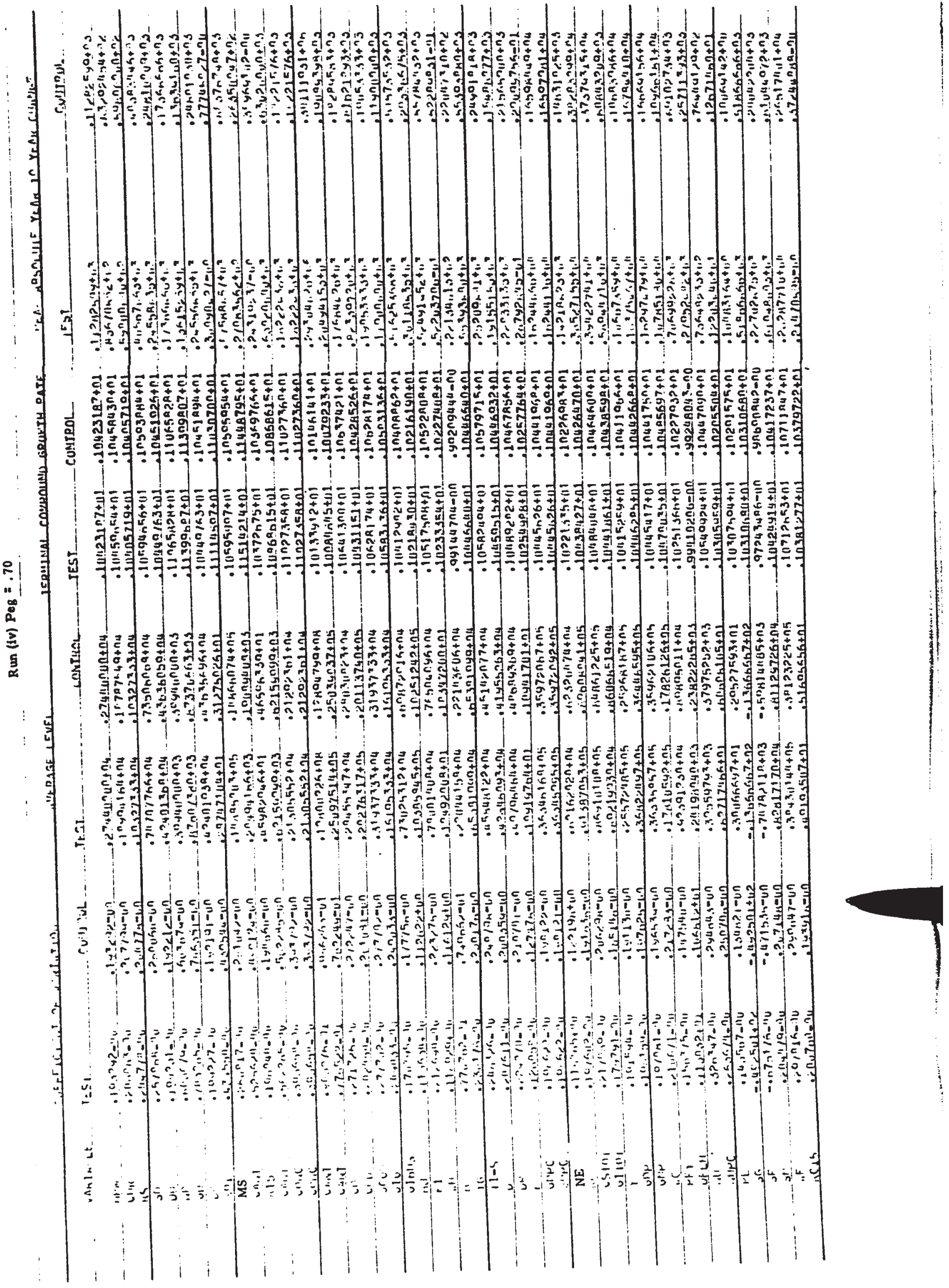




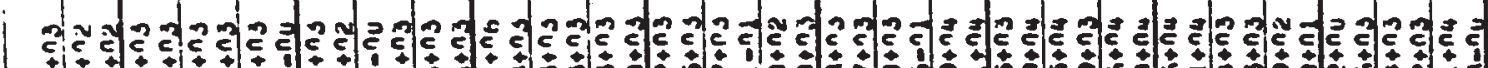

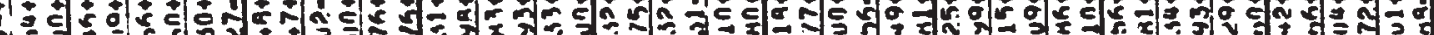
W

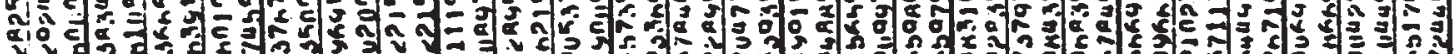

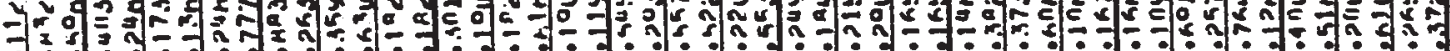

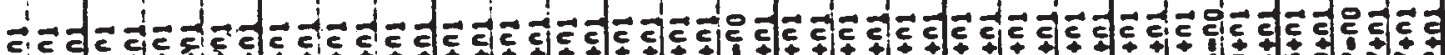

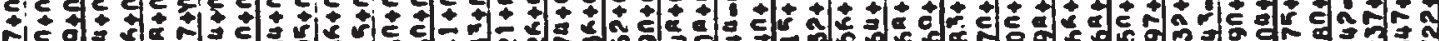
象等 3ᄅ

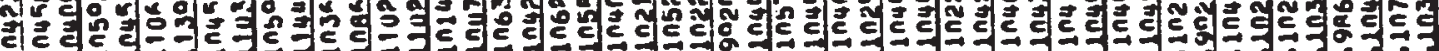

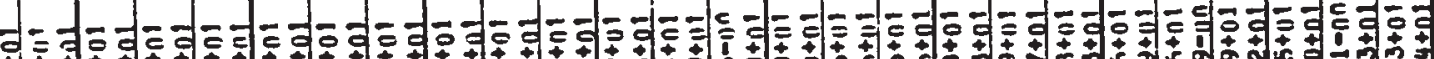

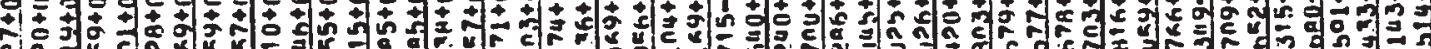

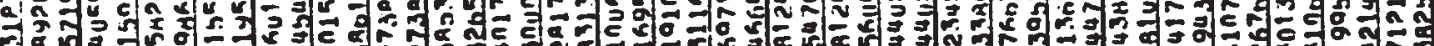

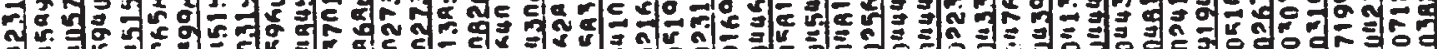

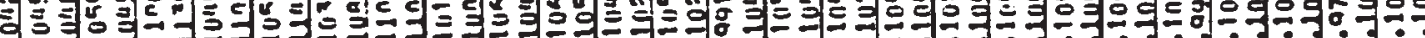

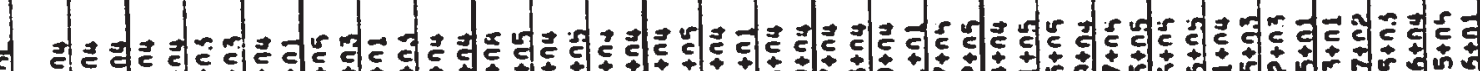

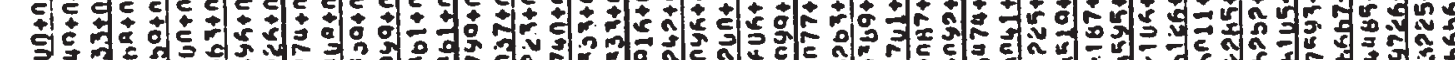

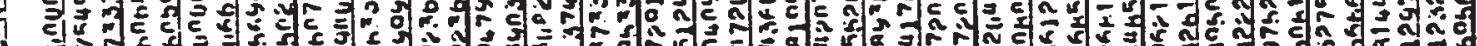

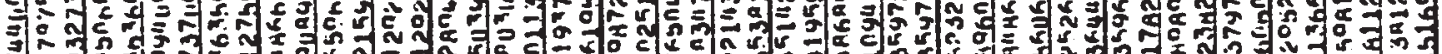

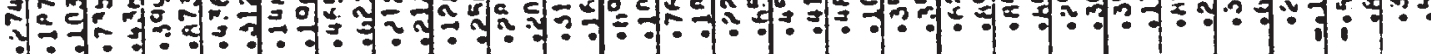

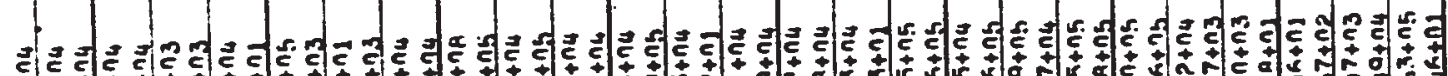
t. 딜

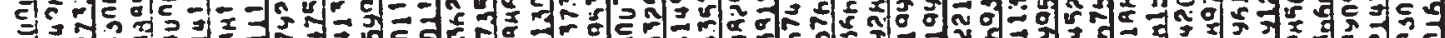

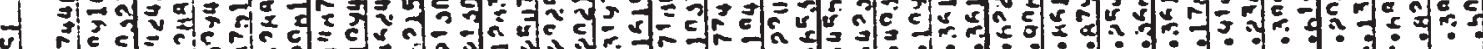

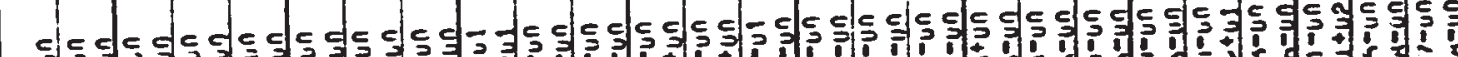

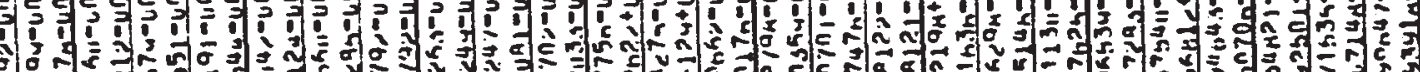

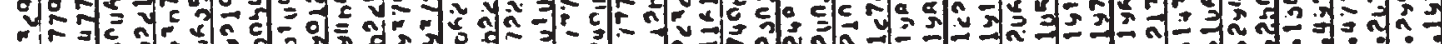
1 $\left.a^{2}\right)^{2}$

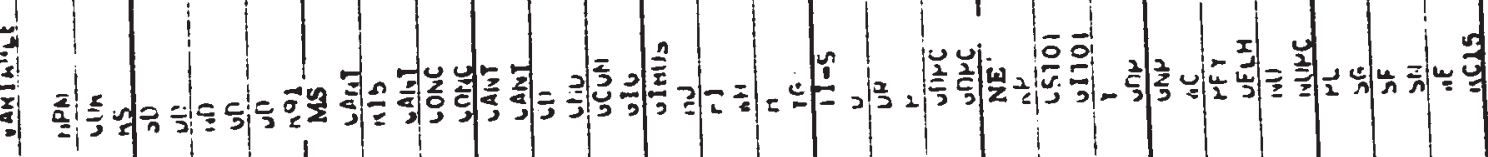

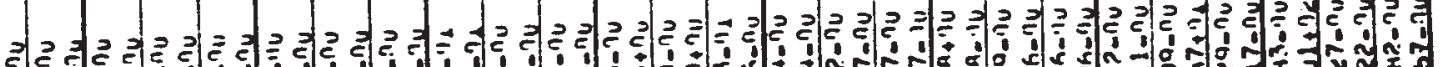
A $\because \div \div \div \div: \div: \div$ 


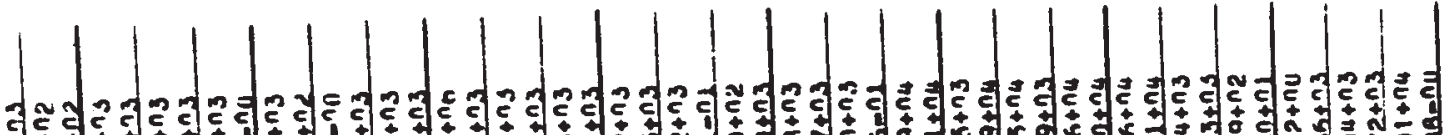

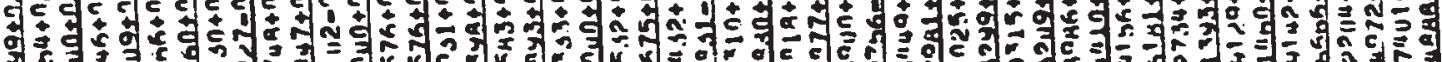
F

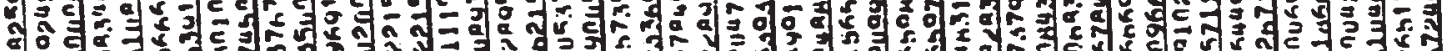

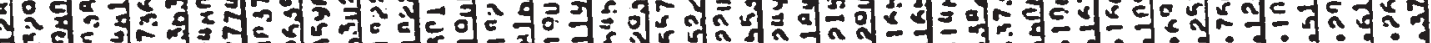
ำ

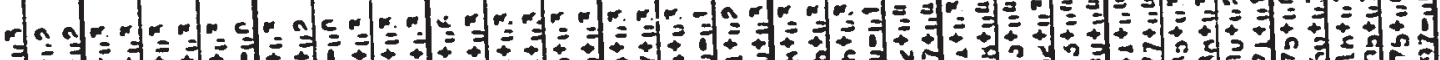

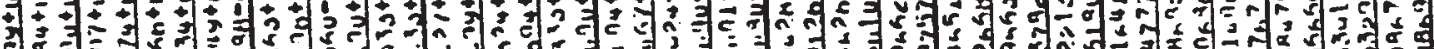

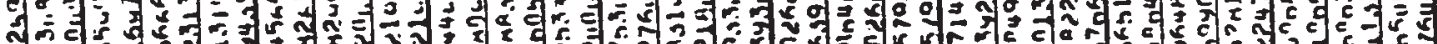

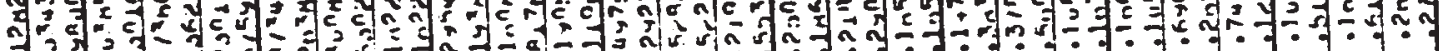
1 :

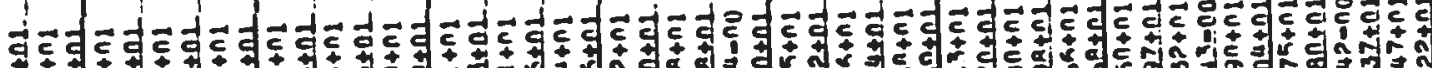

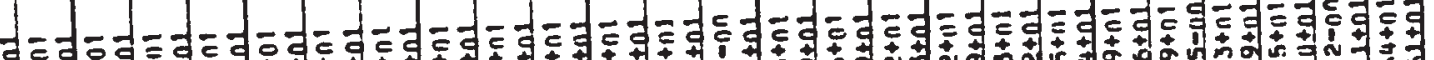

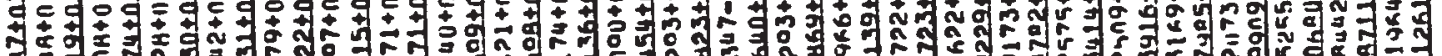
तु

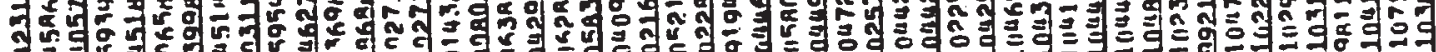

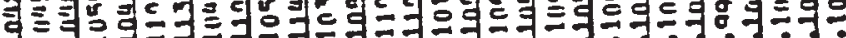

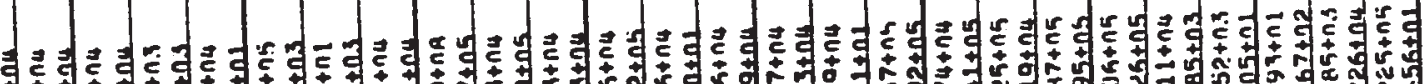

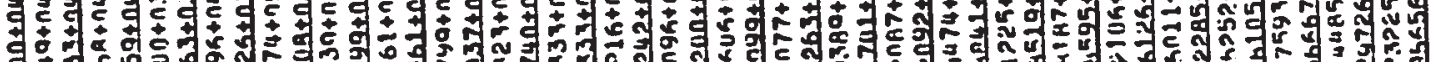
c

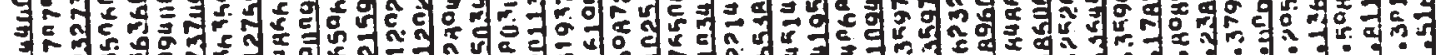

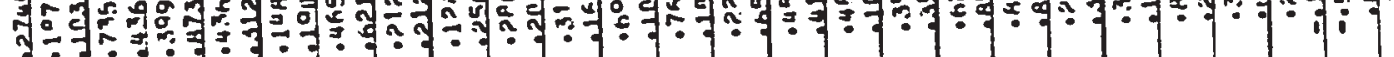

-

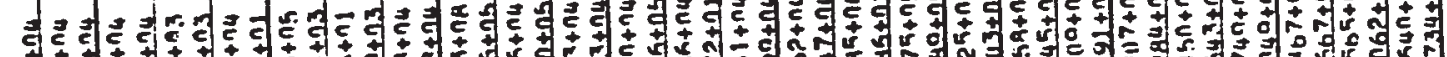

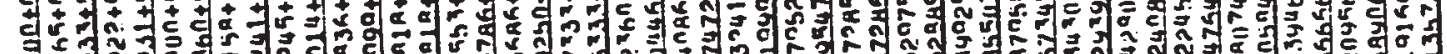

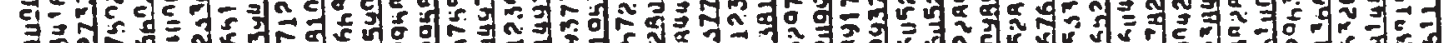

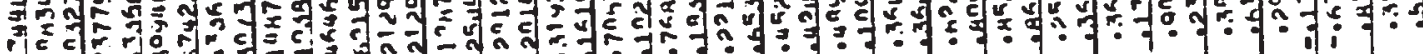

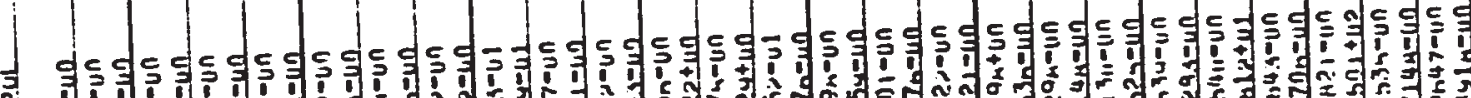

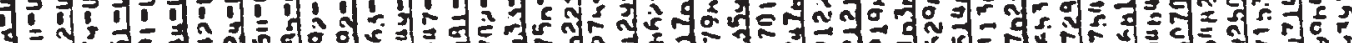

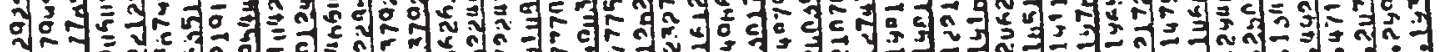
F

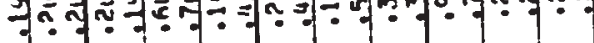

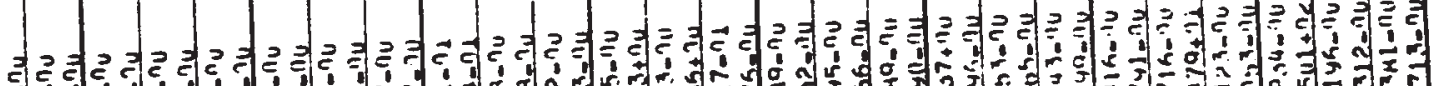
4 1 d d d औै 年

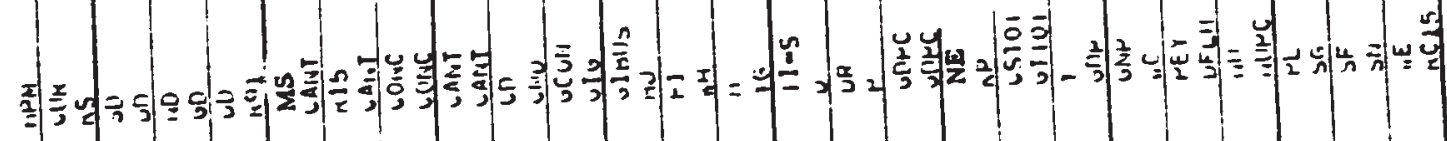




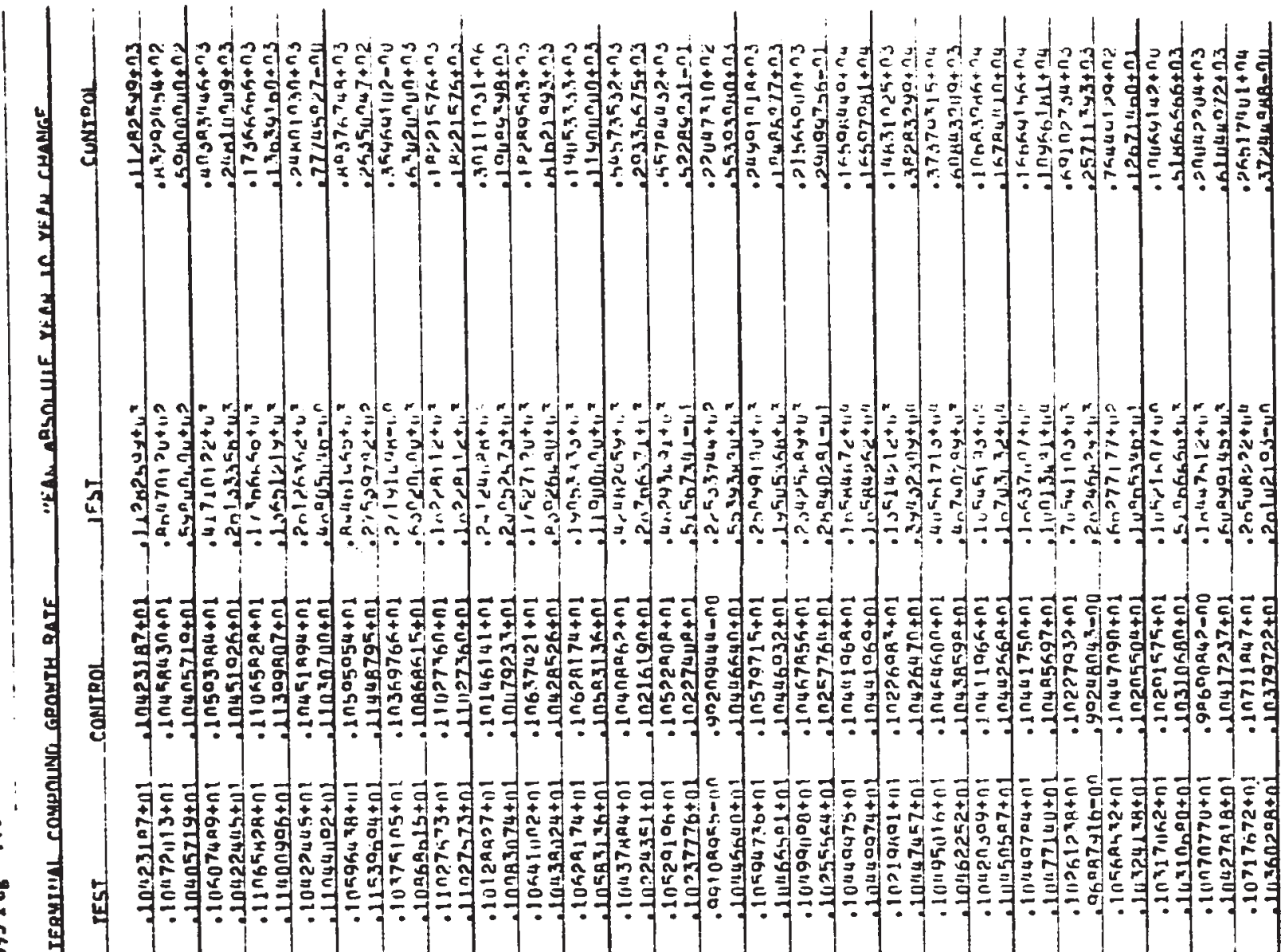

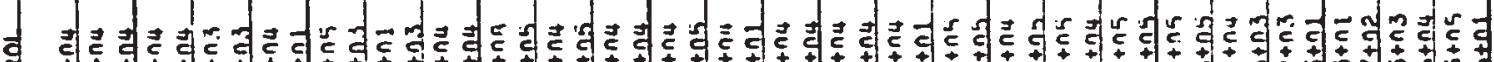

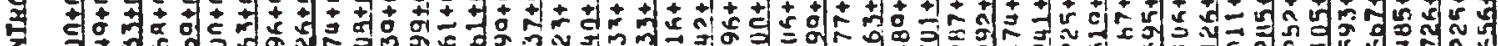

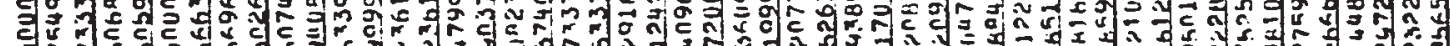

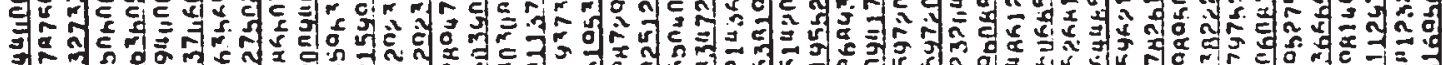

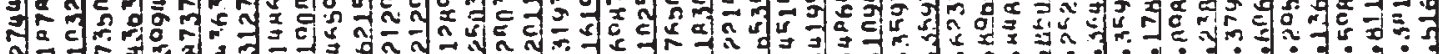

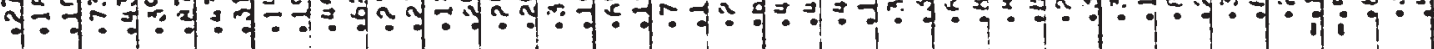

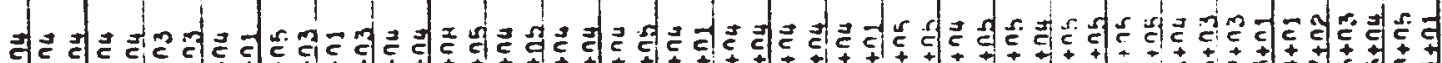

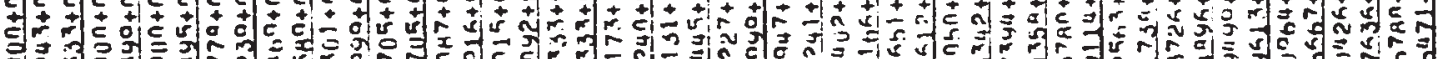
Es;

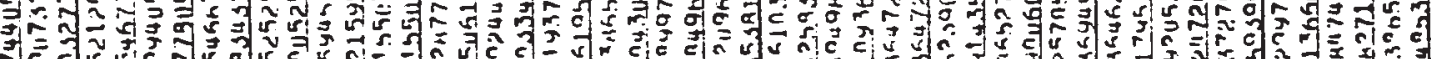

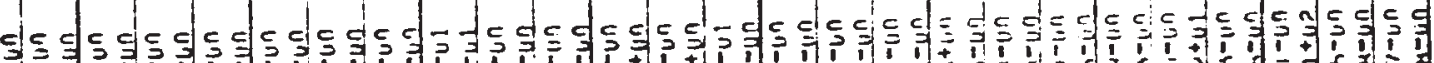

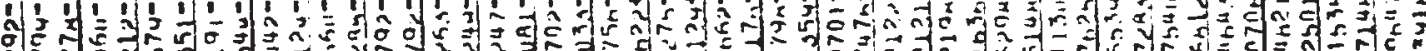

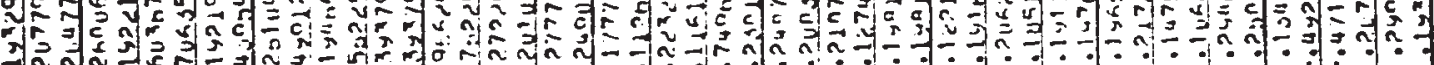

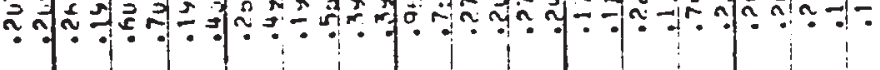

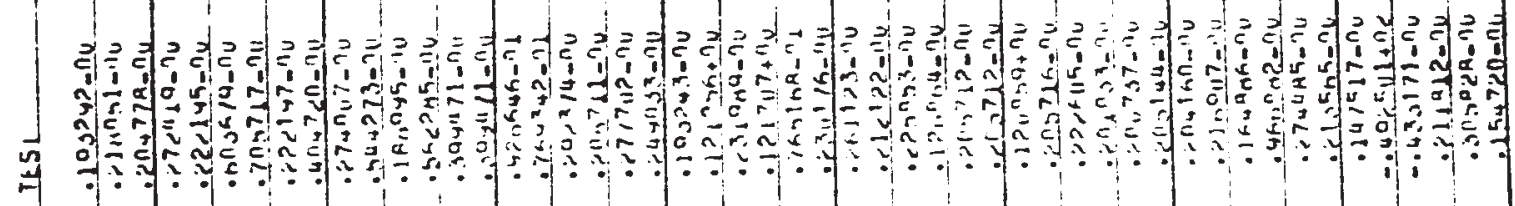




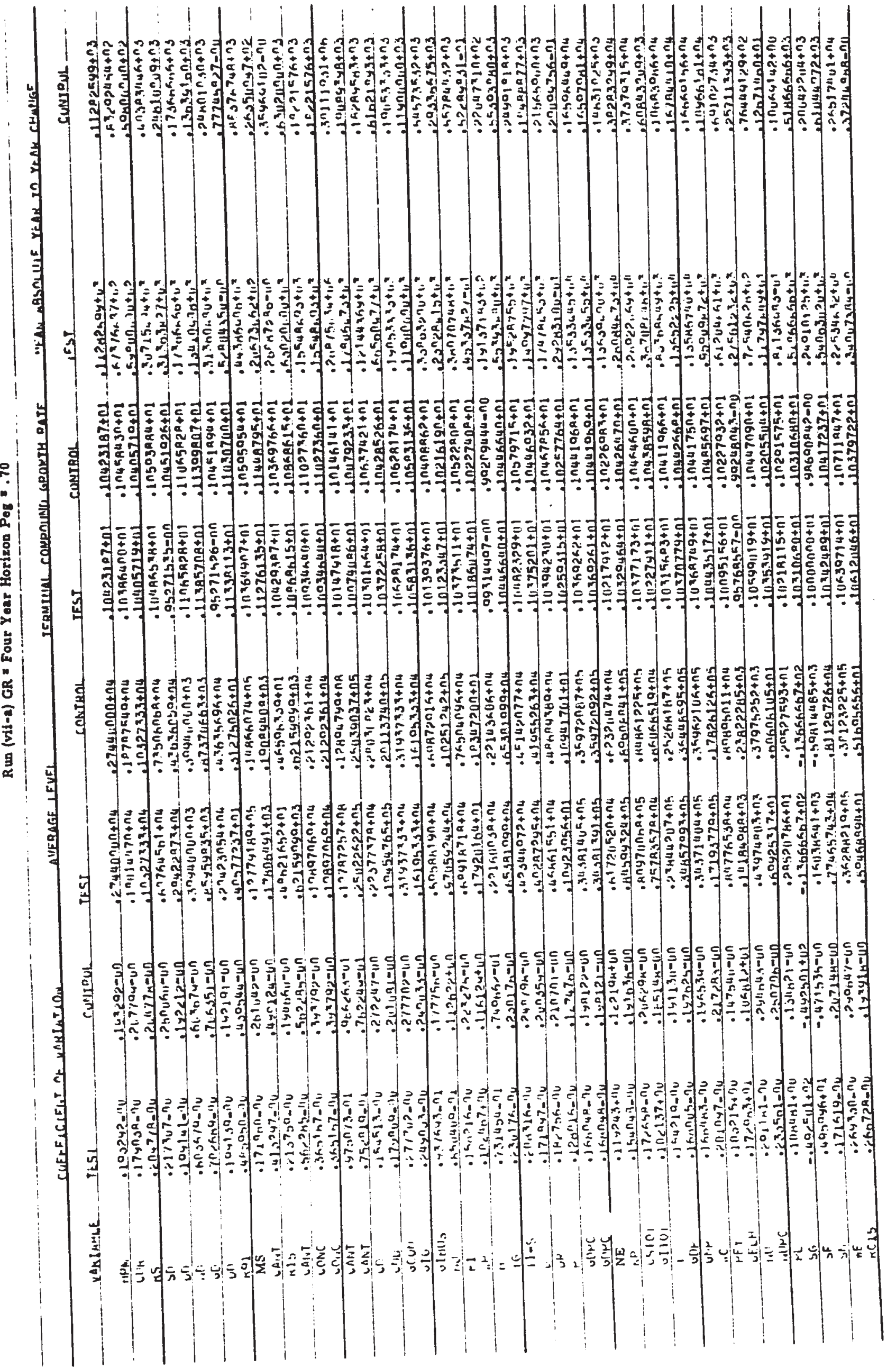




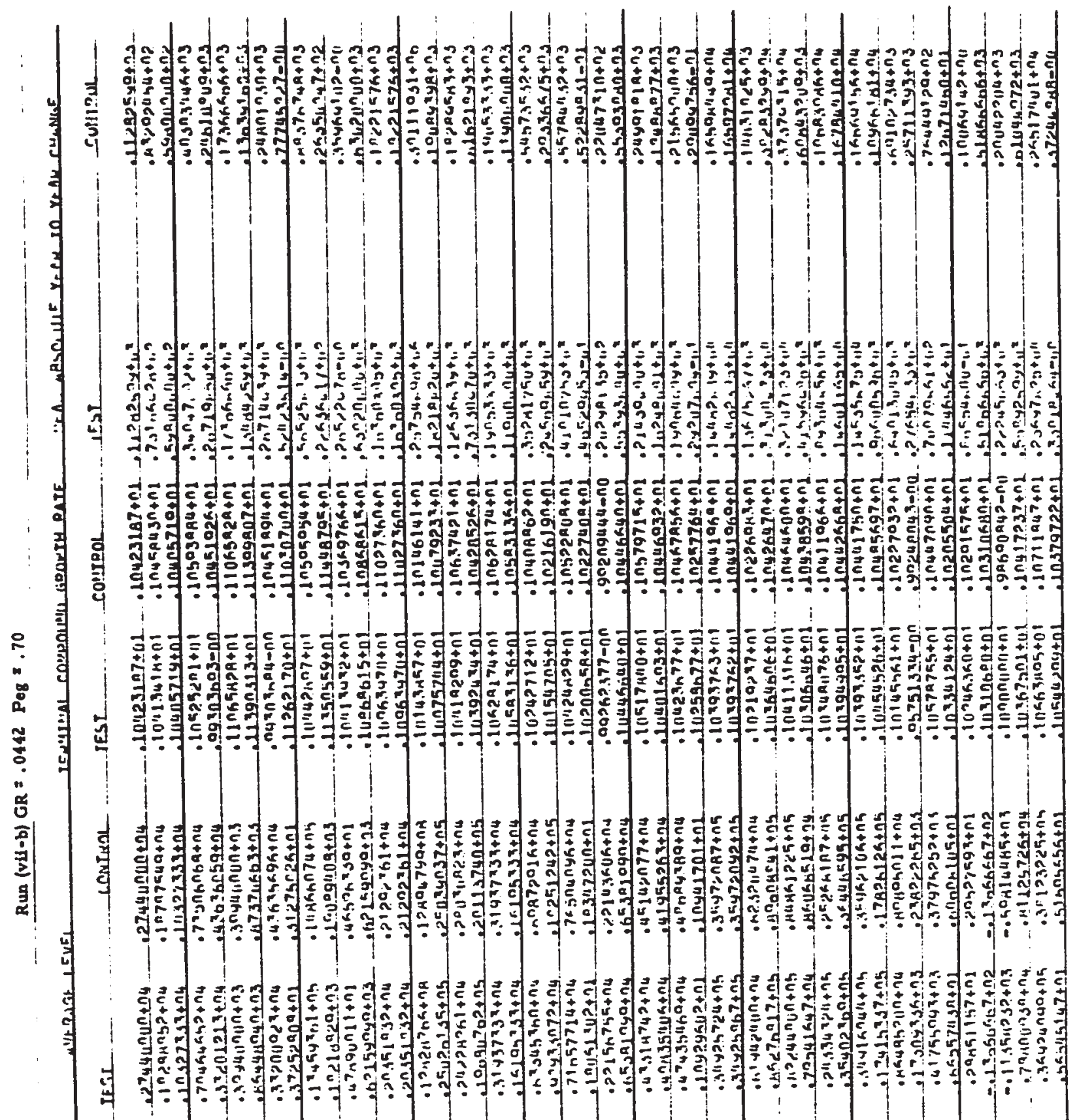




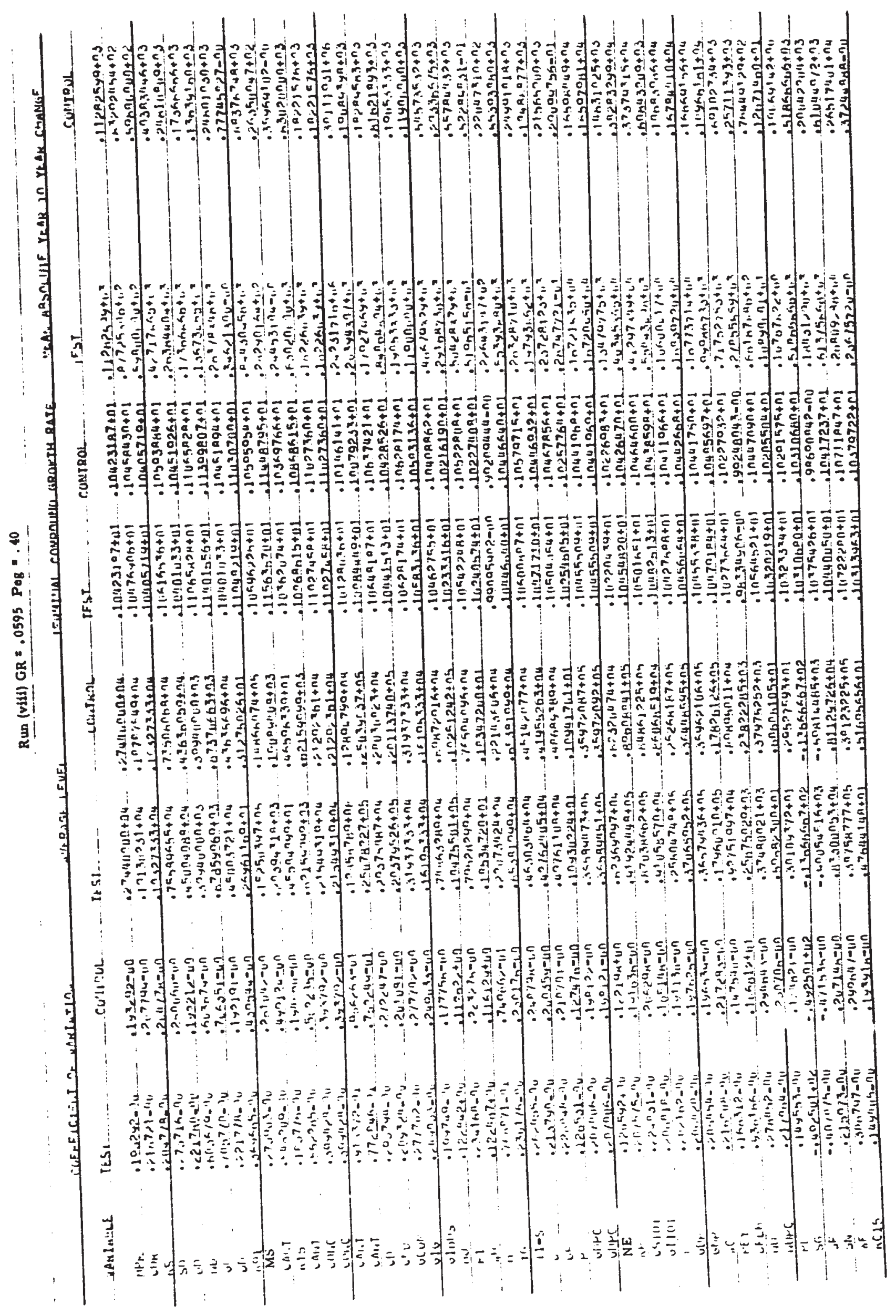




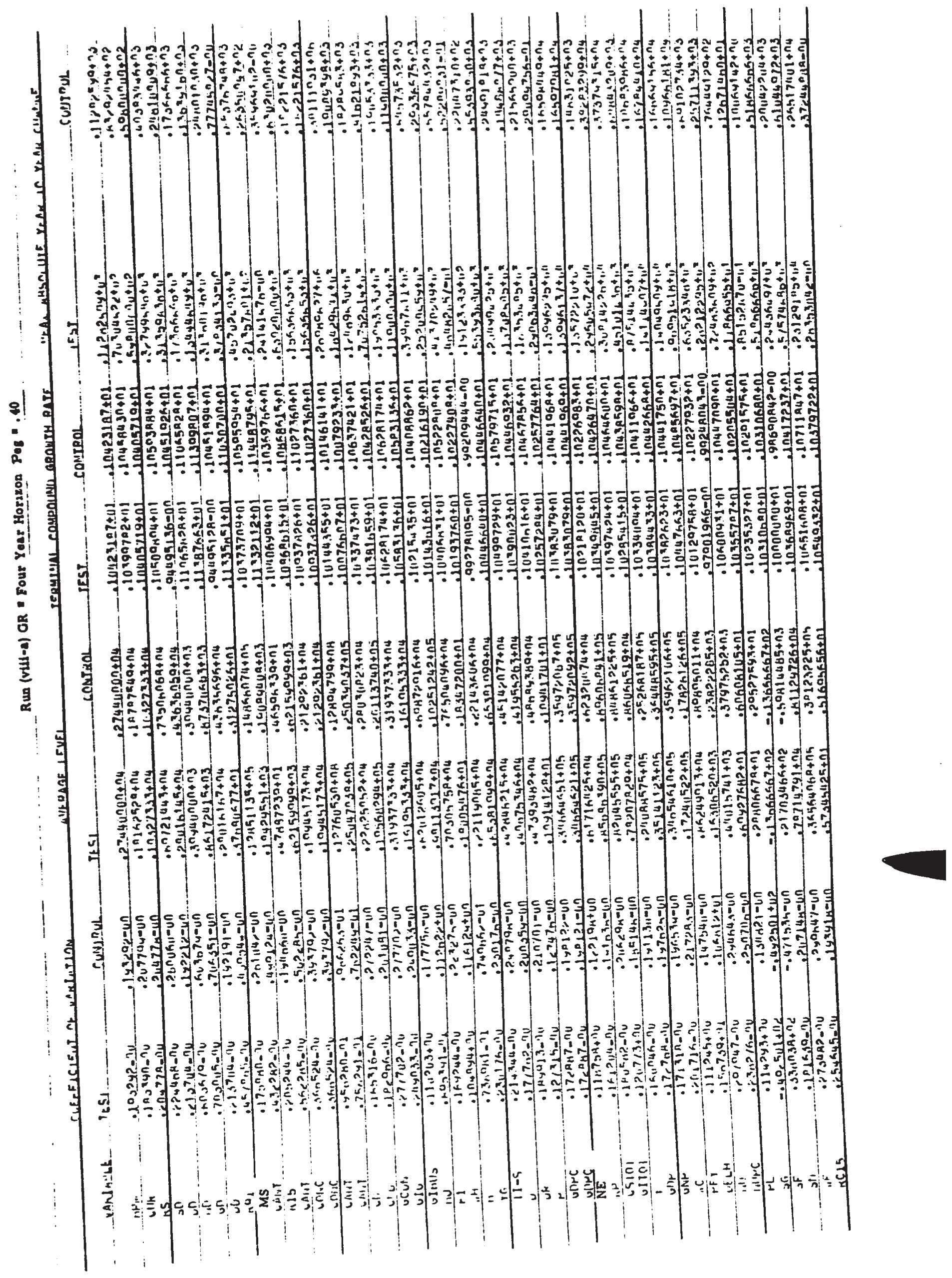




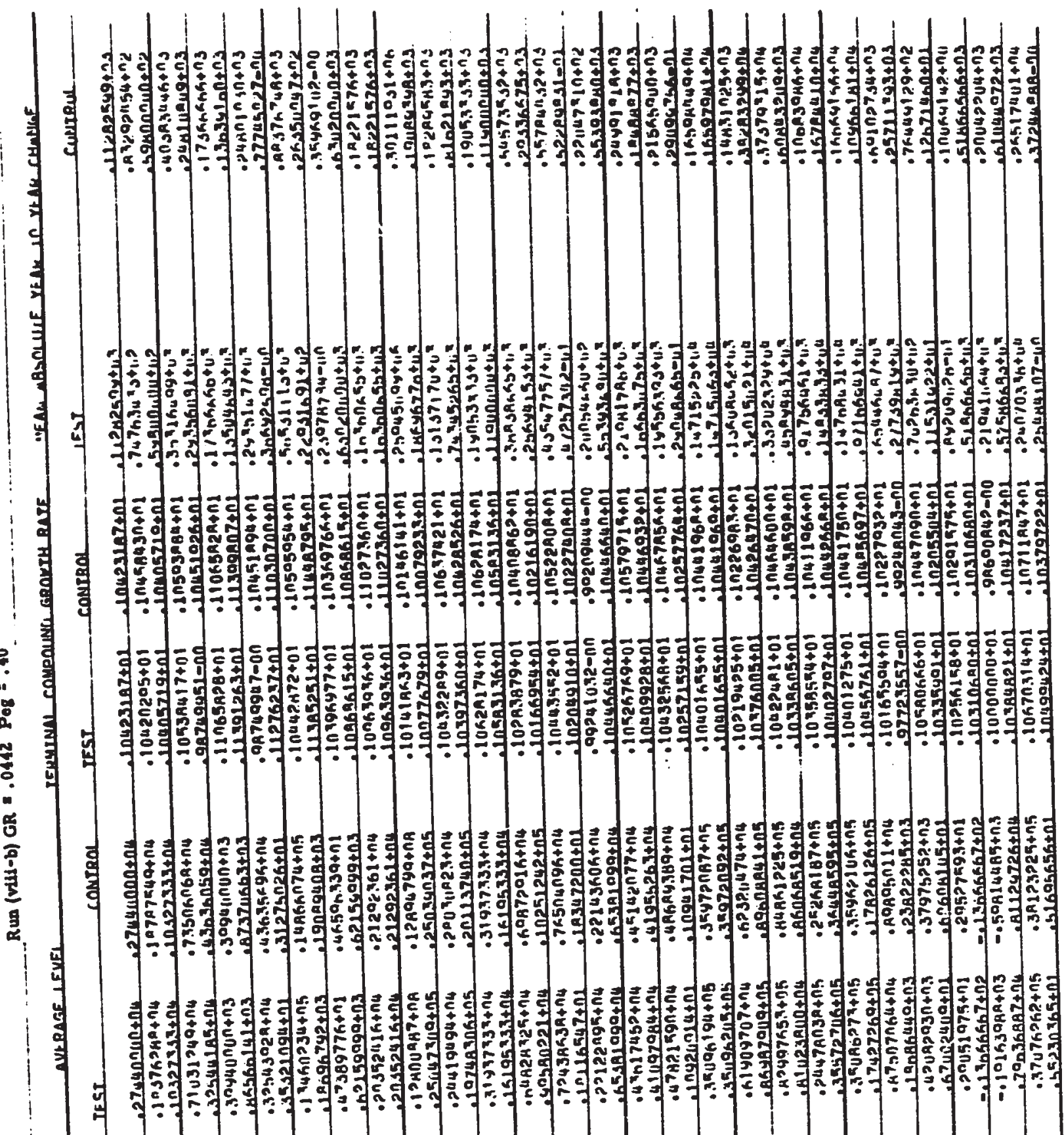

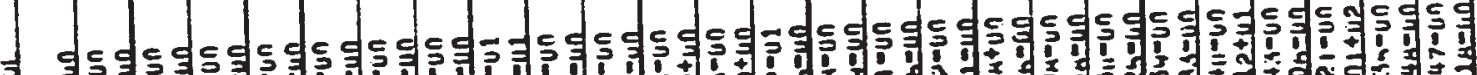

1

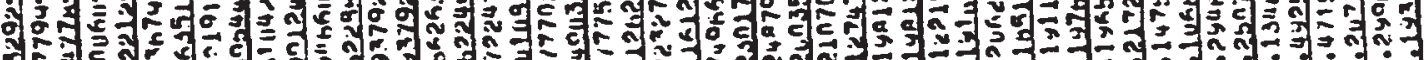
4 .

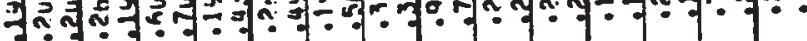

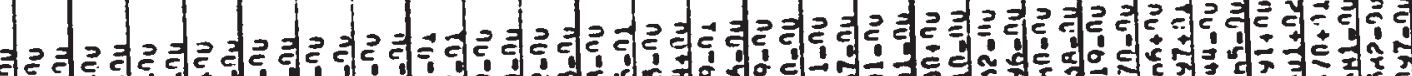
A. -

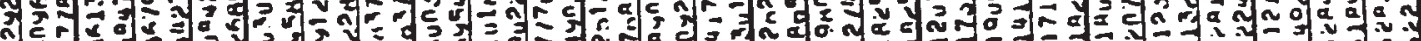

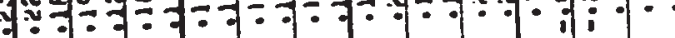

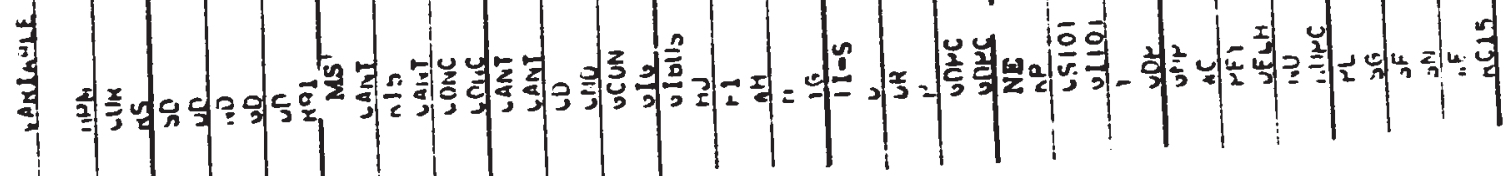




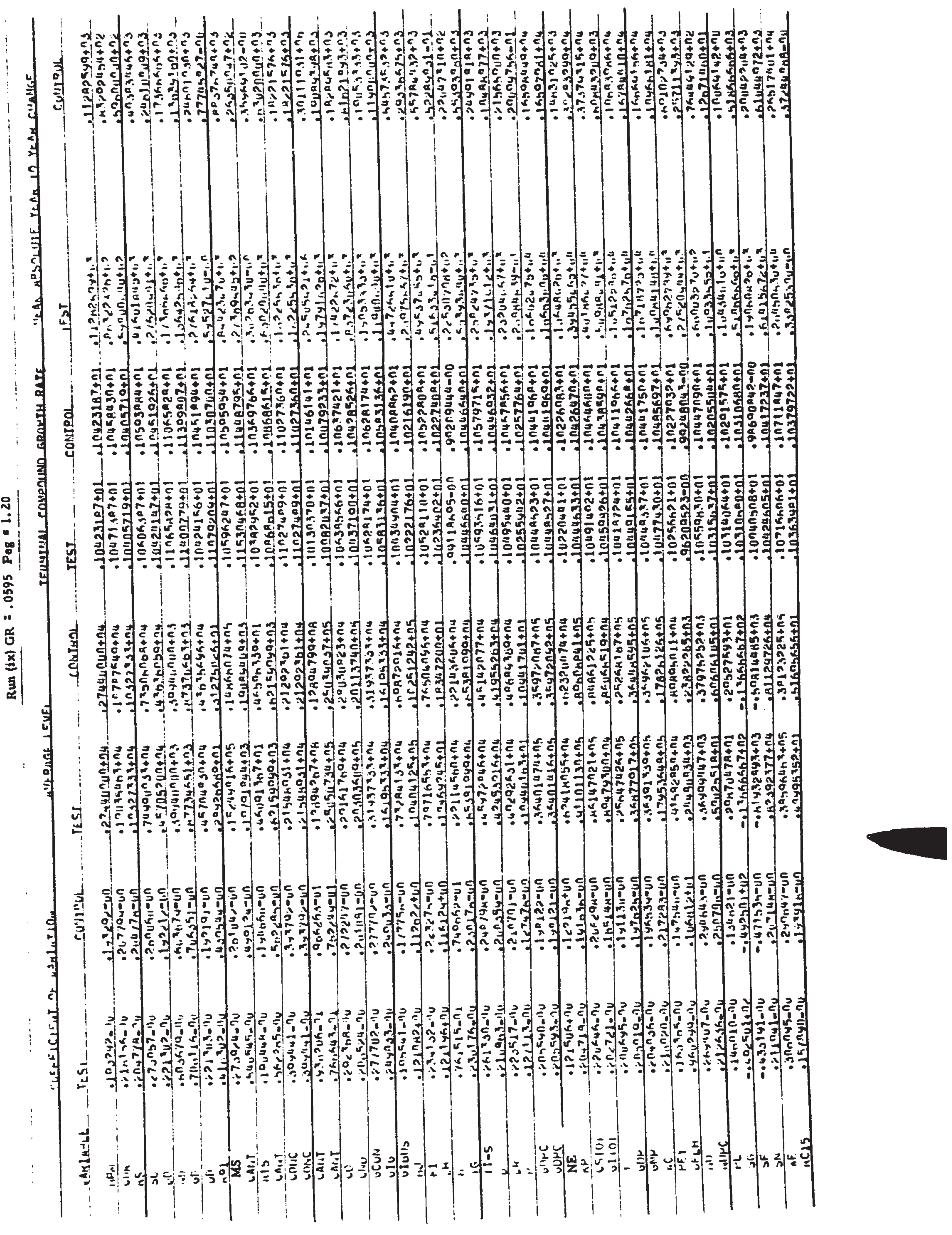




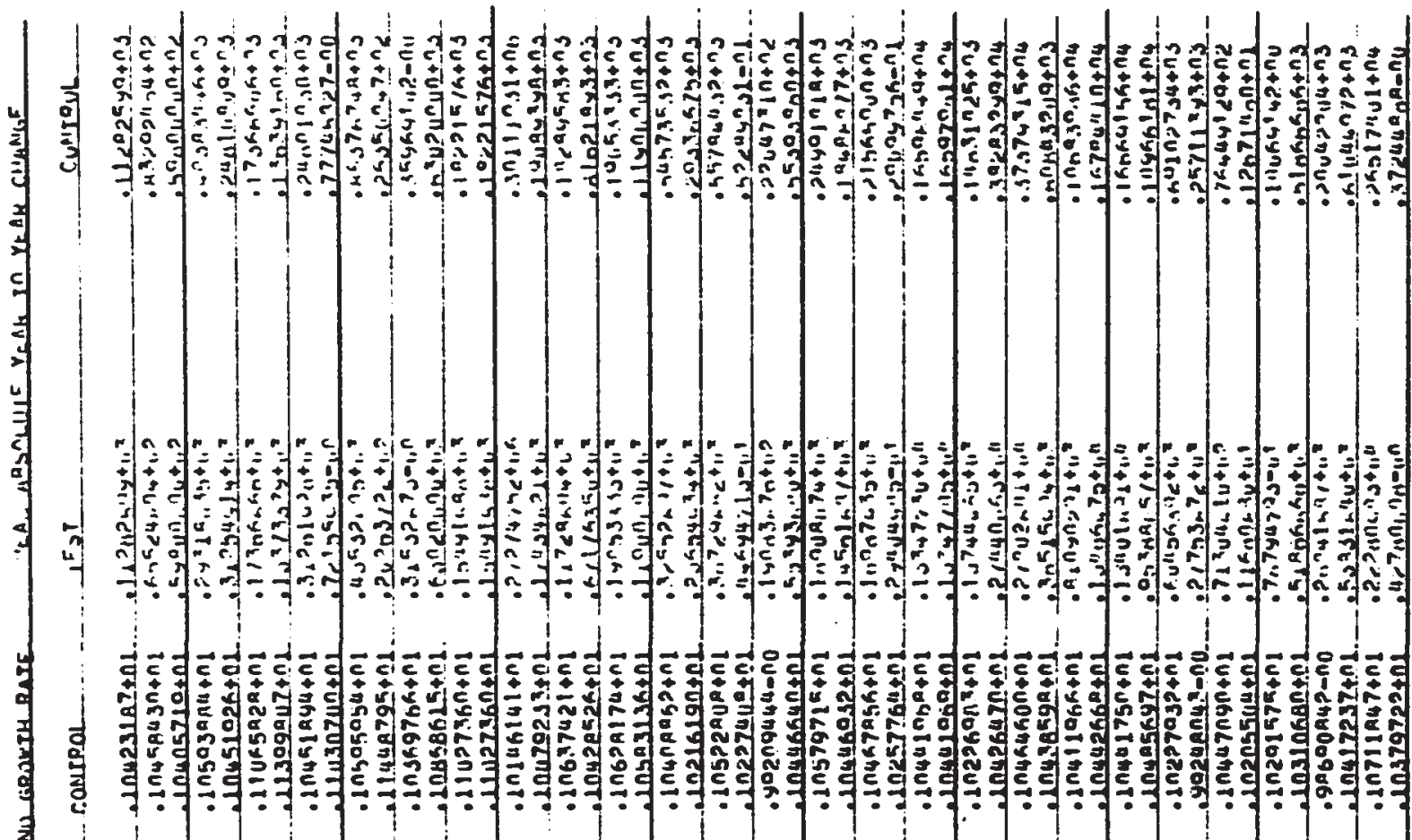

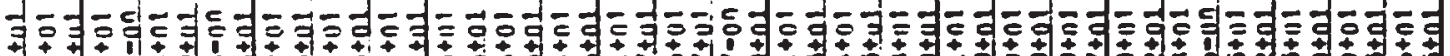

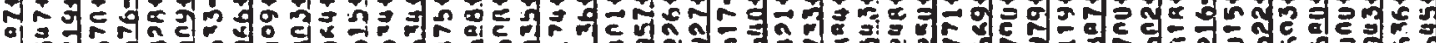

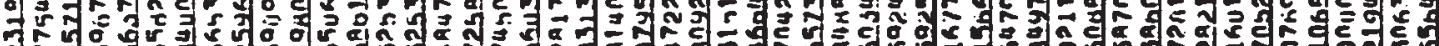

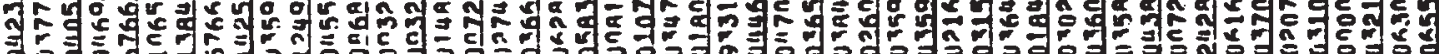

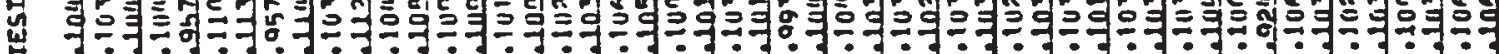

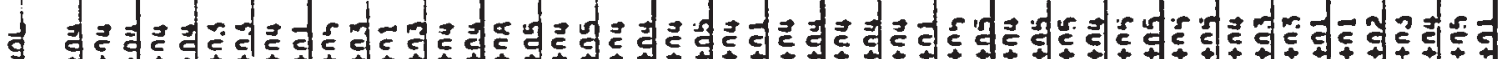

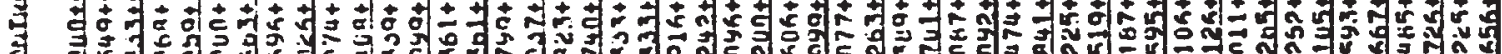

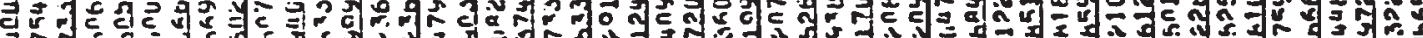

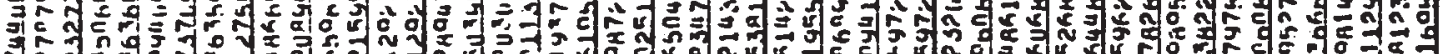

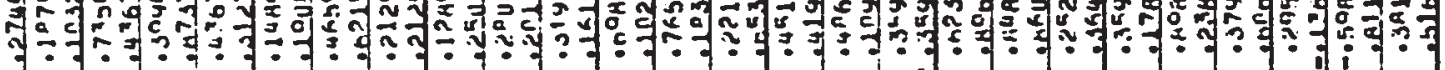

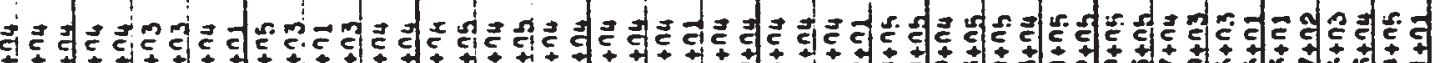

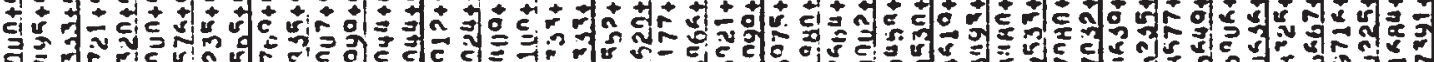

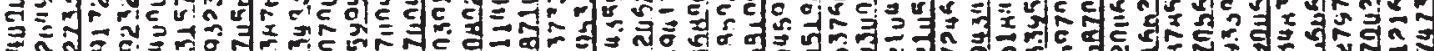
u tra d d

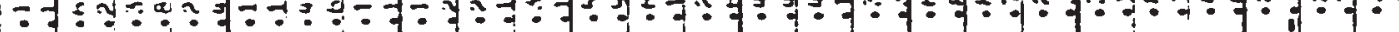

ذ $=$ vid

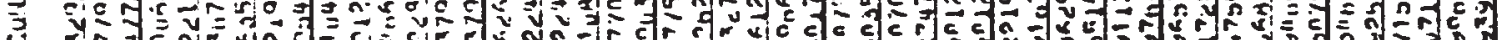

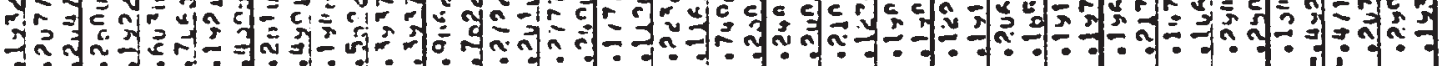

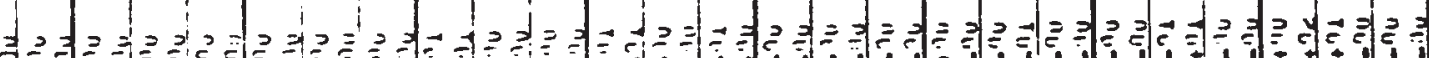
2010 s.

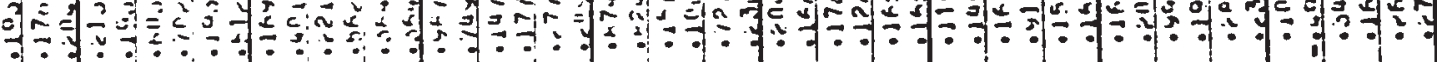




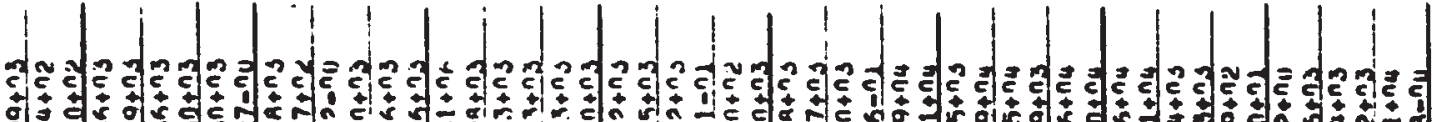

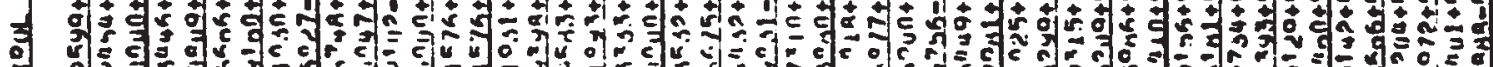

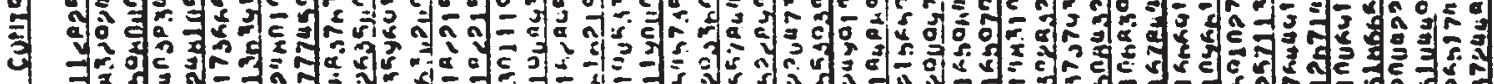

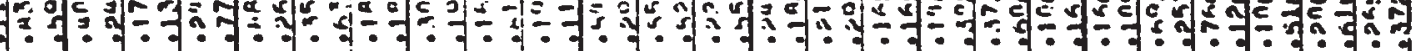

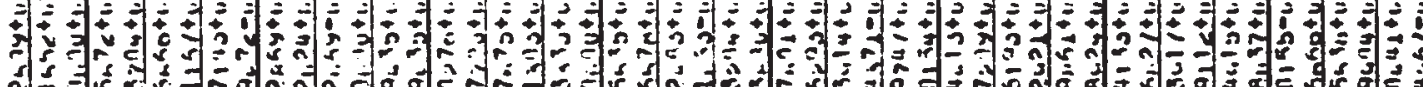

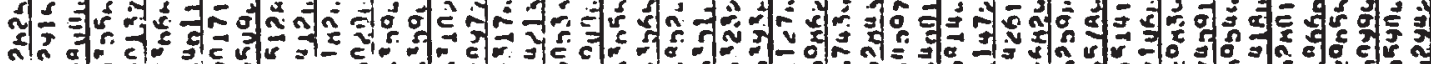

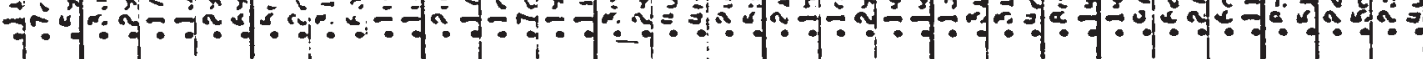

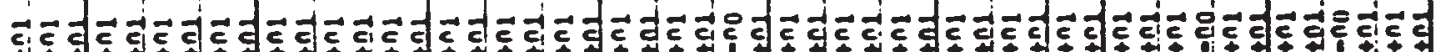

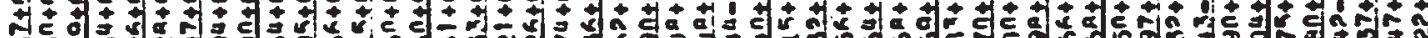

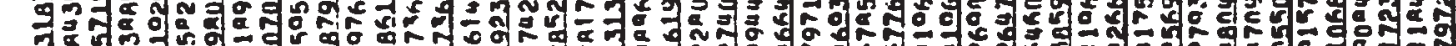

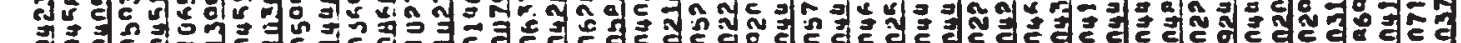

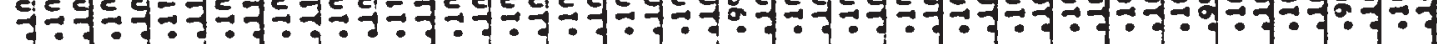

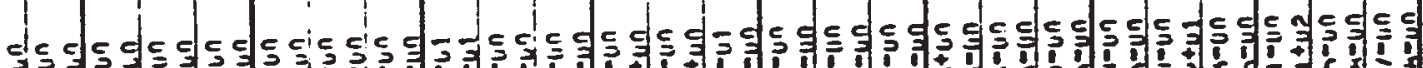

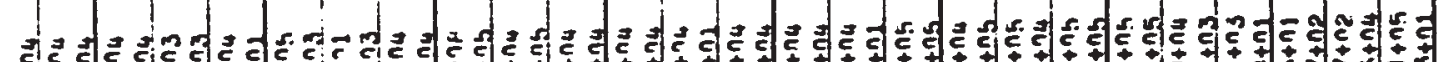

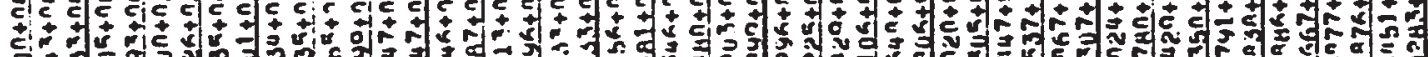

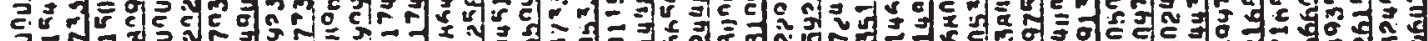

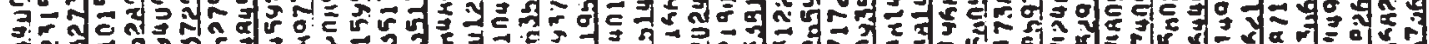

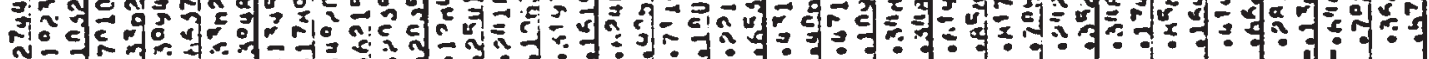

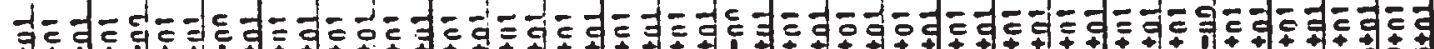

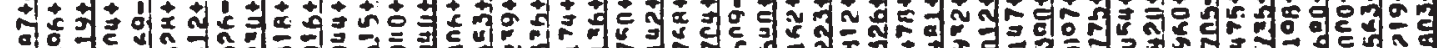

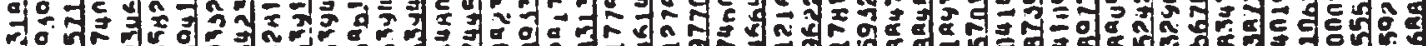

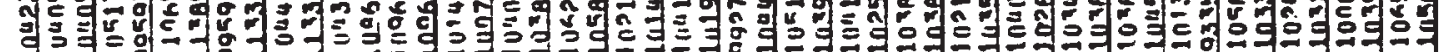

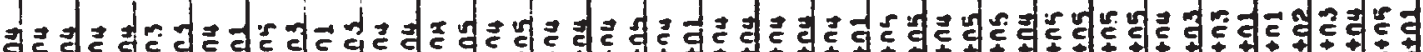

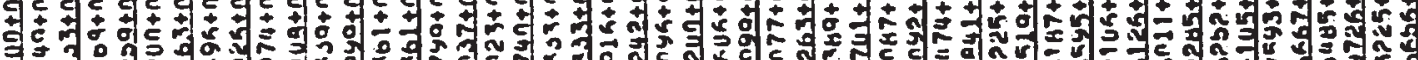
c] 留

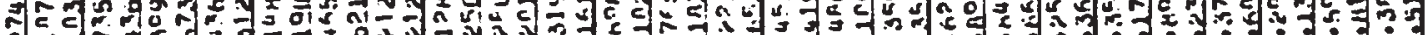
4 通

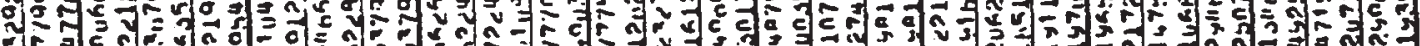

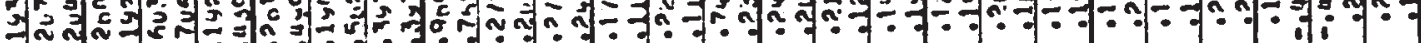
-9.

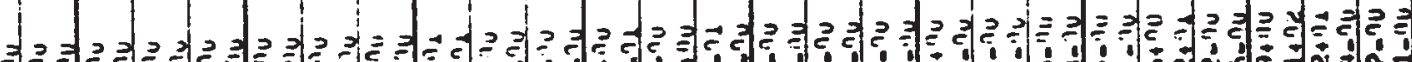

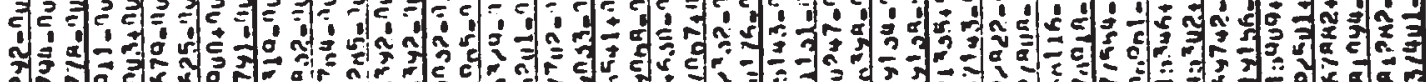

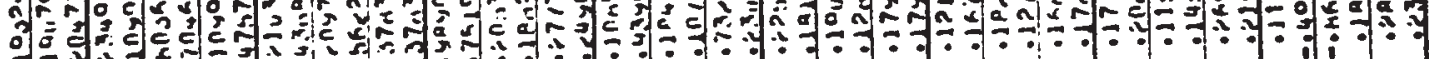

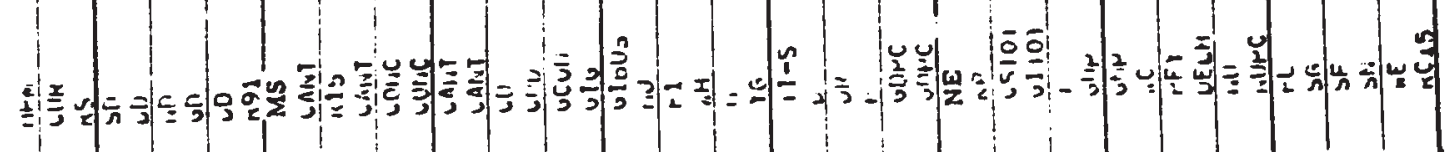




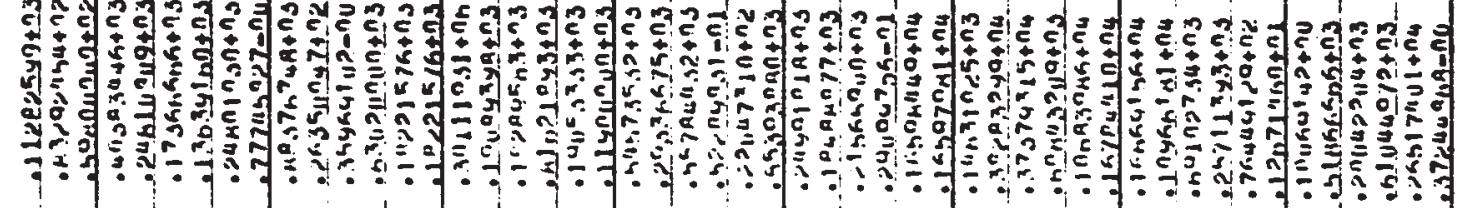

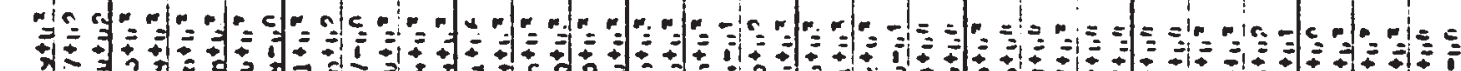

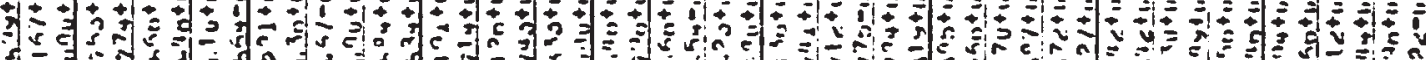

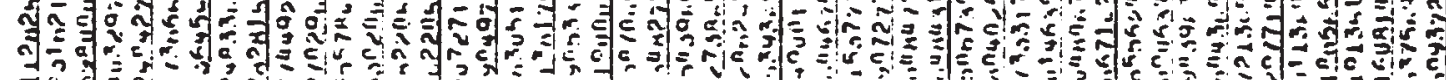
1

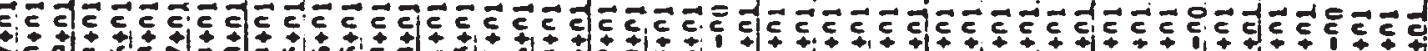

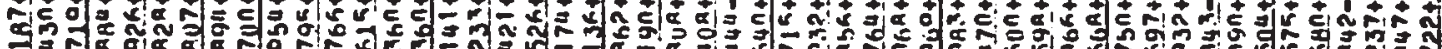

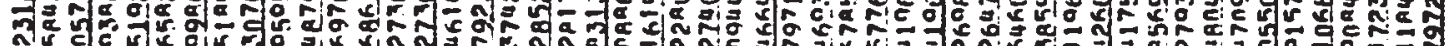

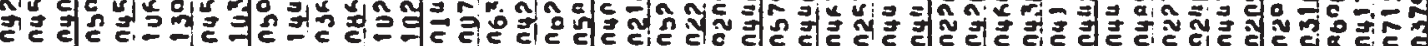

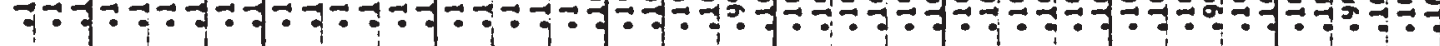

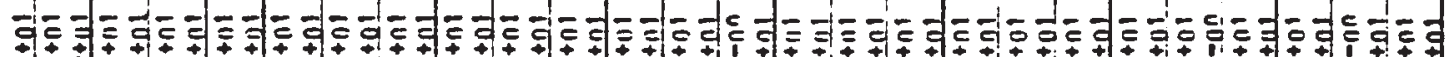

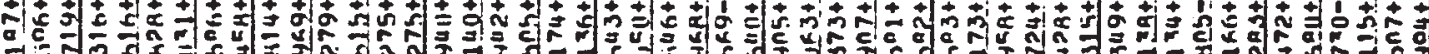

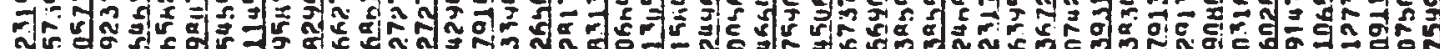

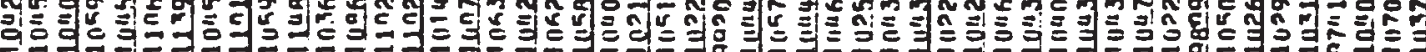

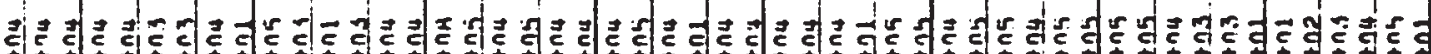

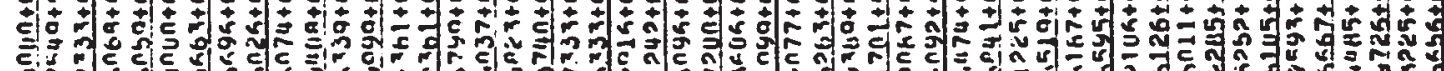

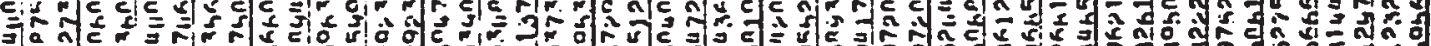

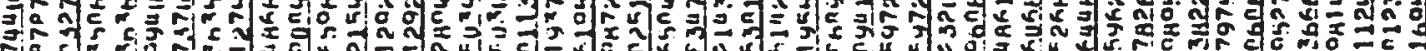

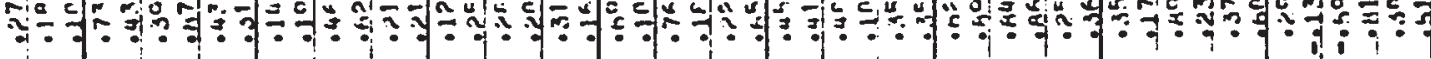

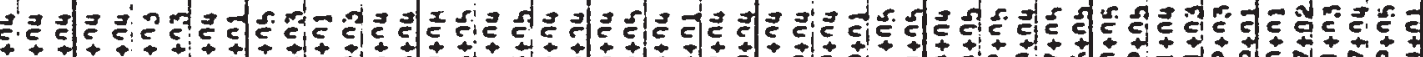

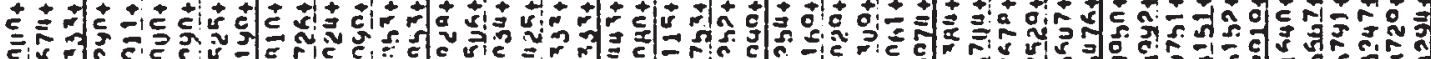

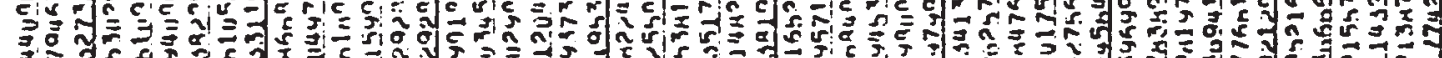

$\overrightarrow{5}$

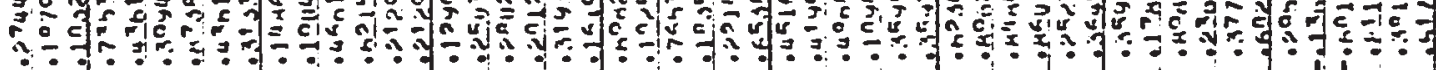

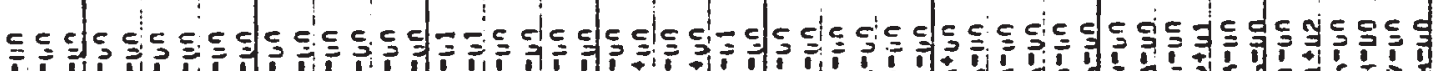

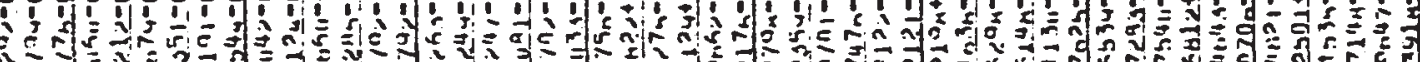
Ar

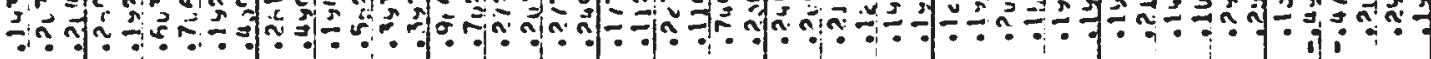

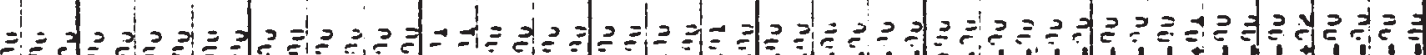

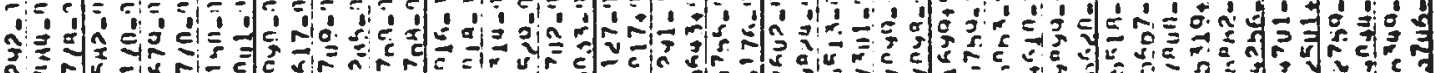
ó

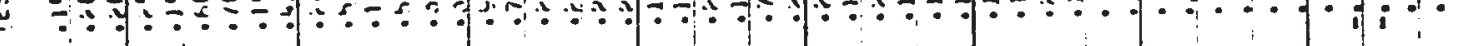

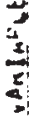

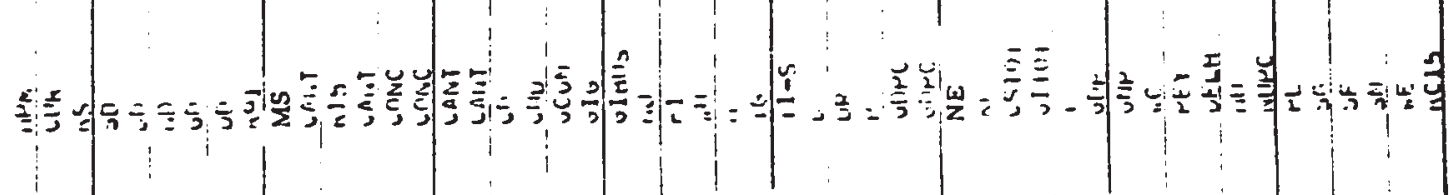




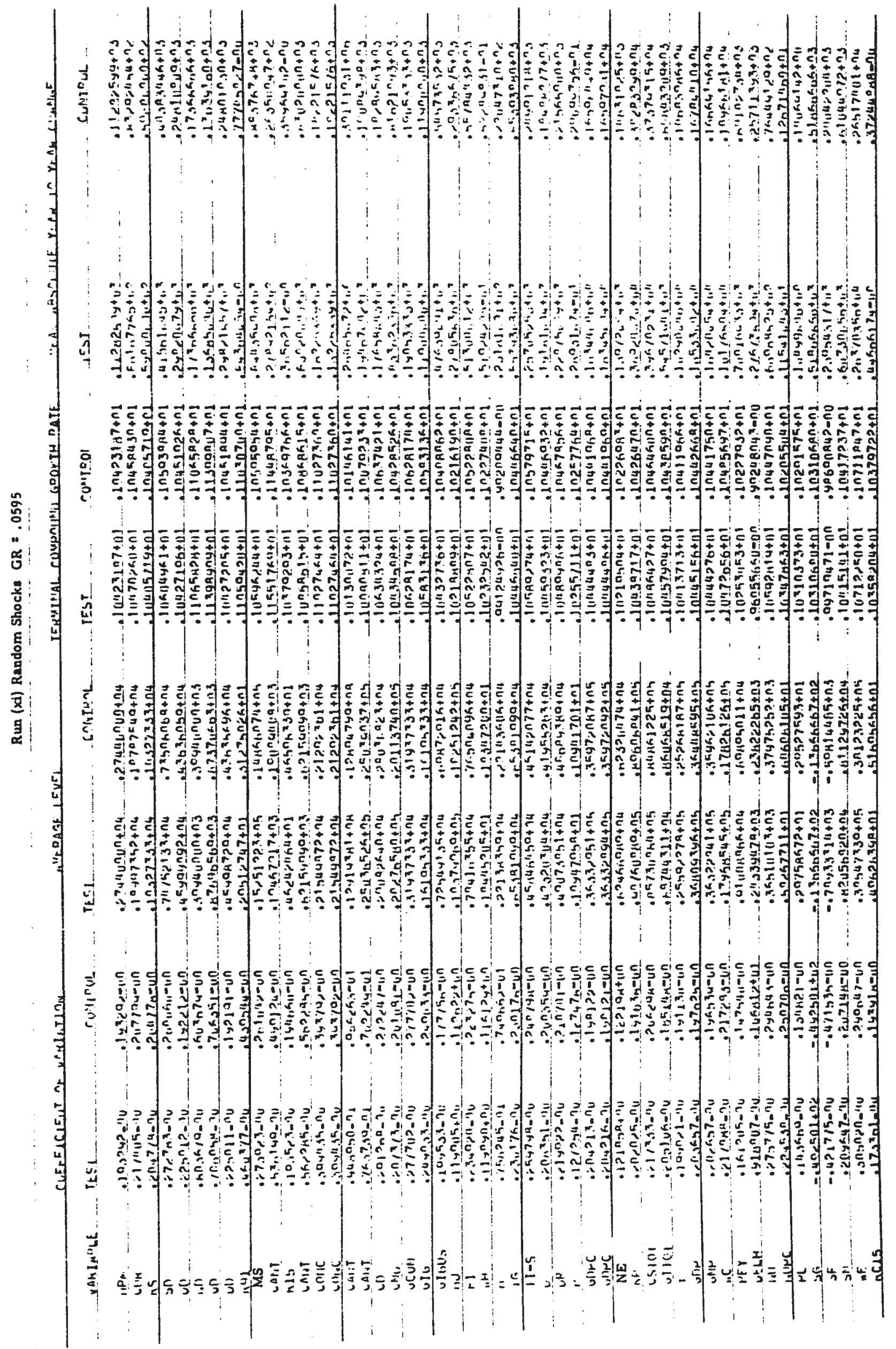




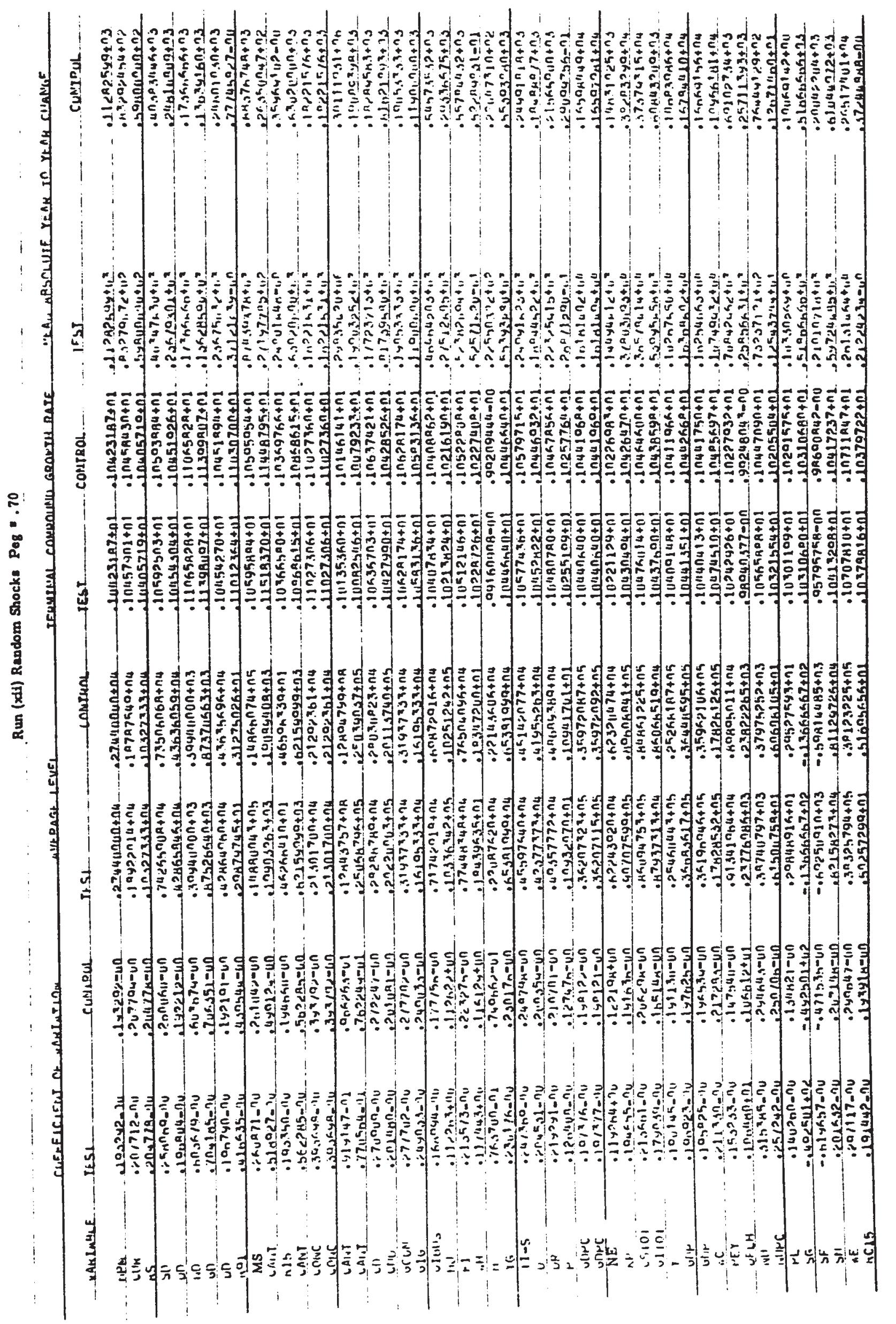




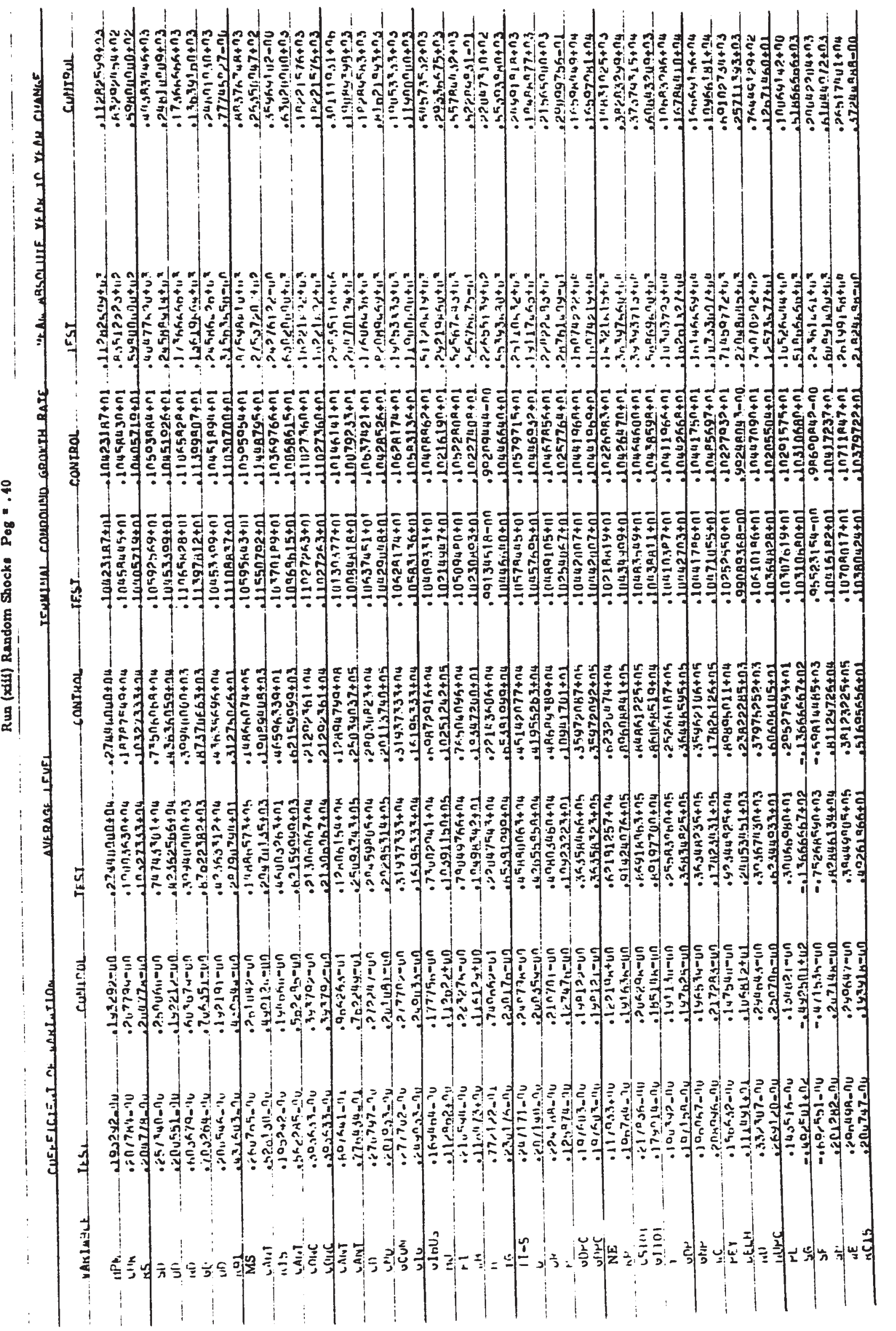




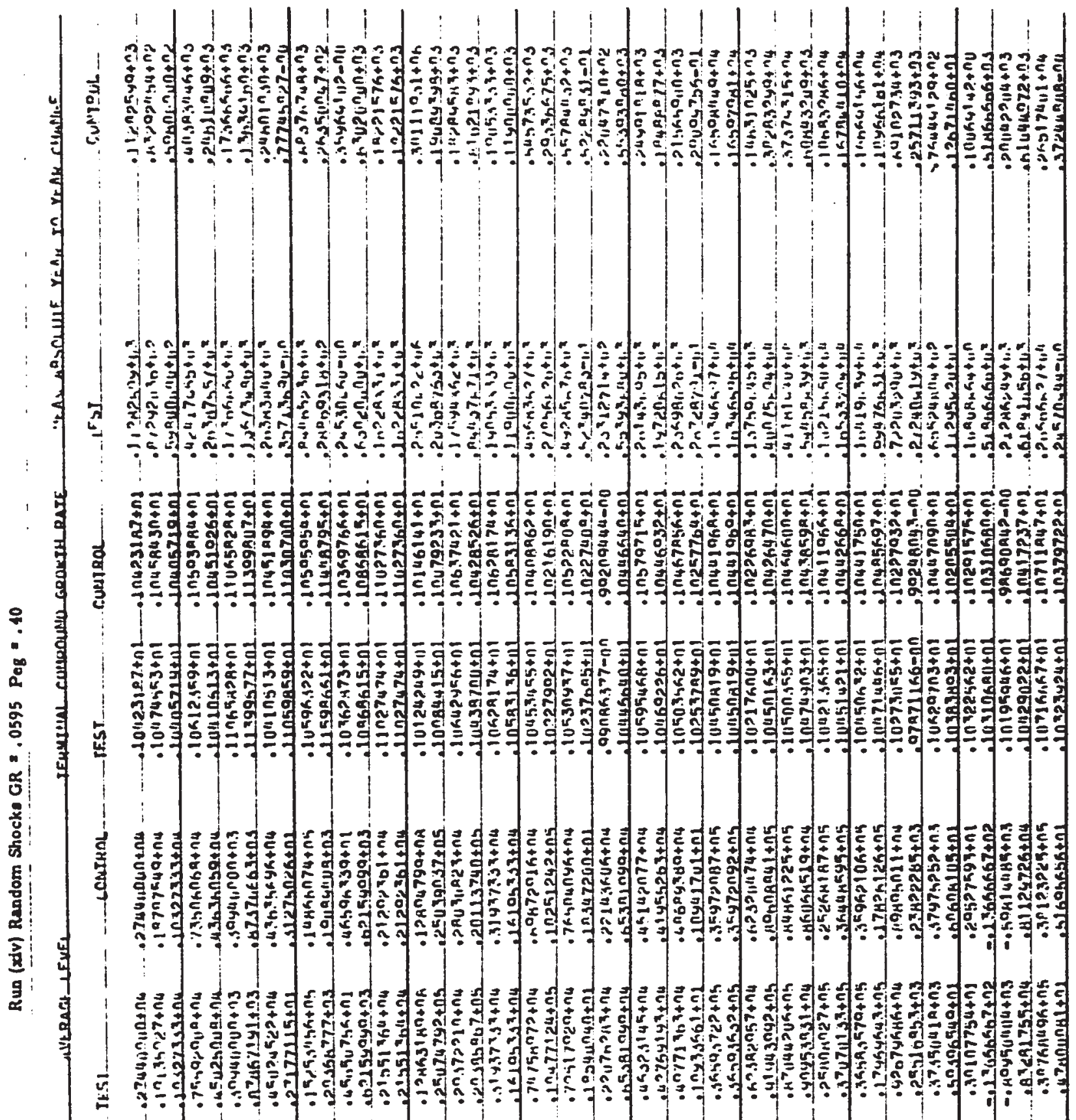

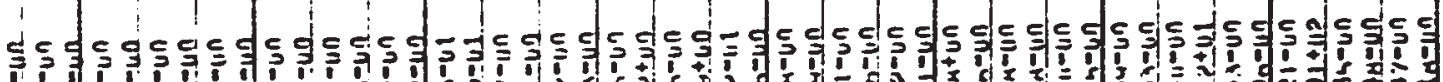

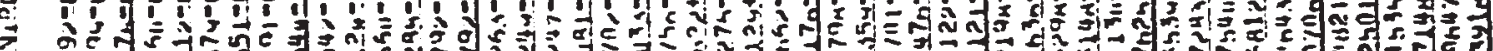
年

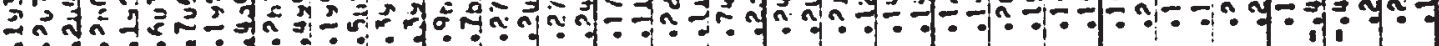
(1)

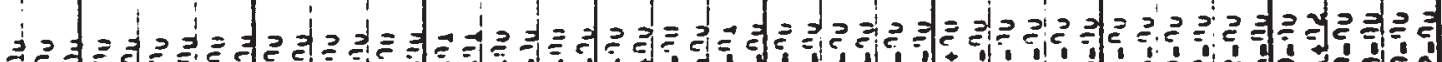
- 10

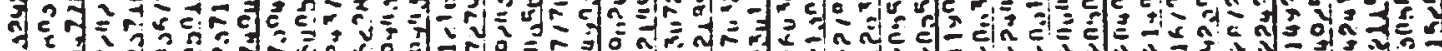

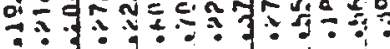

4 


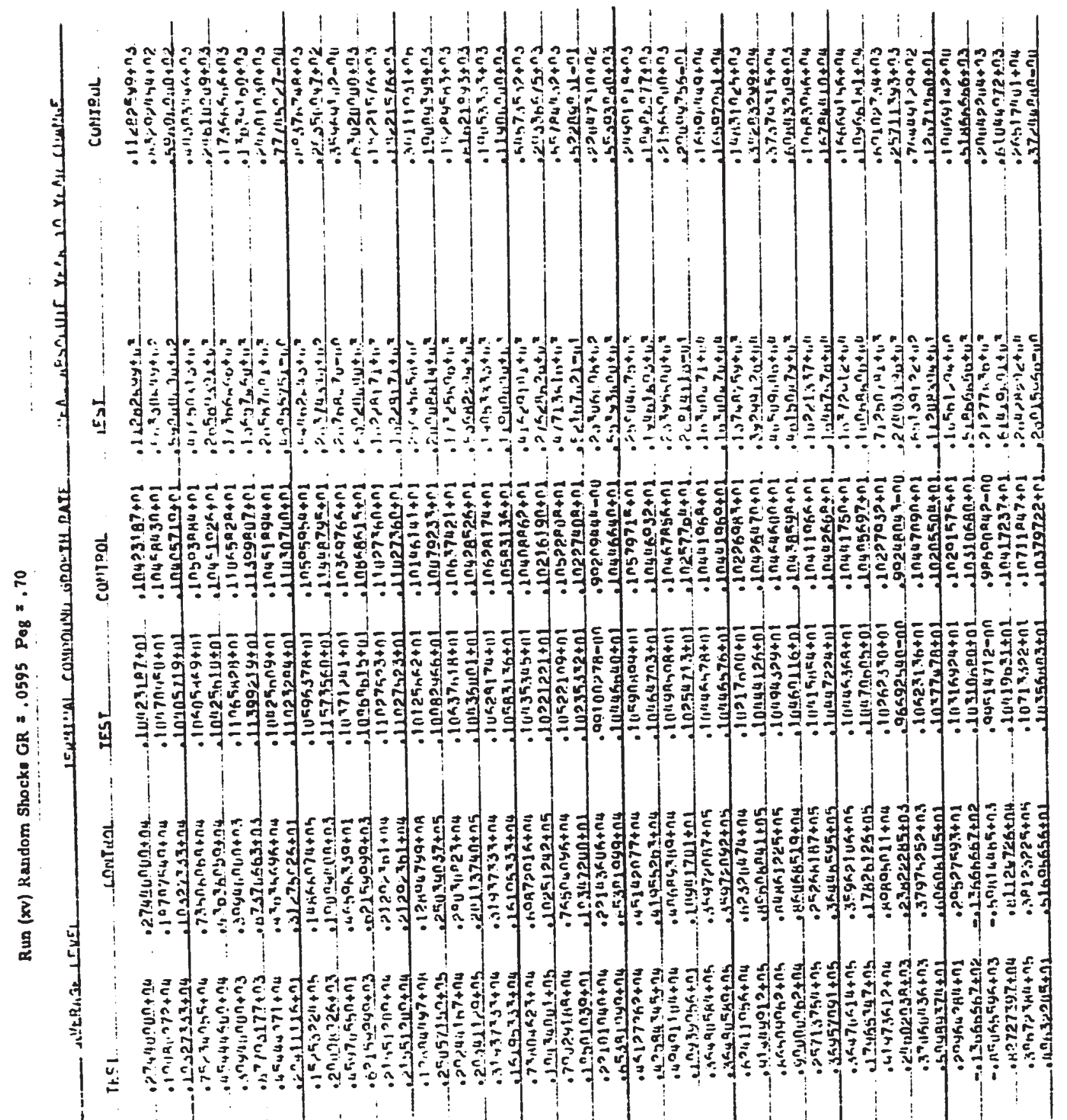

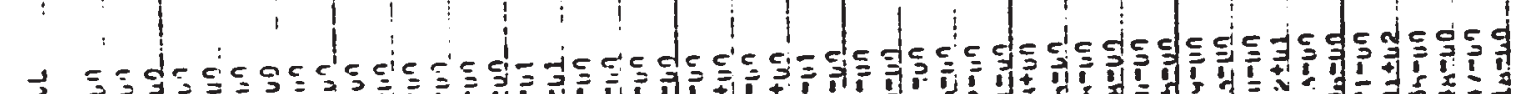

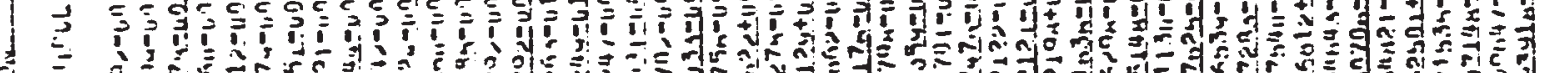
$\rightarrow 2$ v

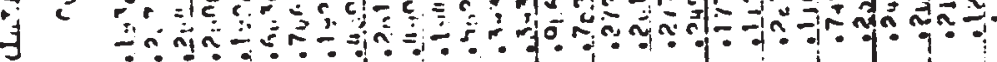

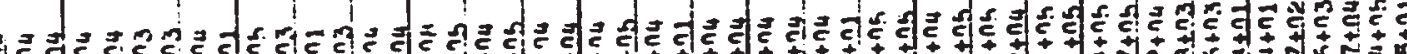

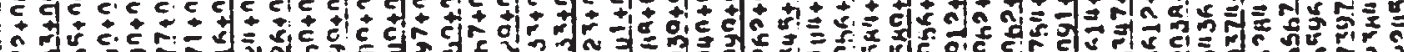

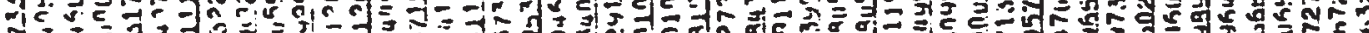

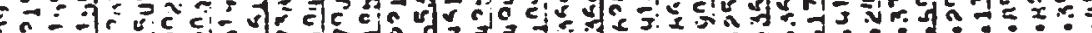

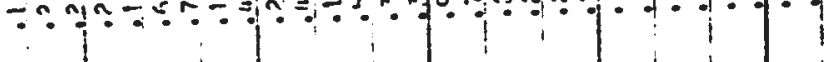
1 190 a 舟 象 


\section{CHAPT ER SEV EN}

\section{Suggestions for Future Research}

\section{Section A - Introduction}

The purpose of this chapter is to use our hindsight to provide foresight for other researchers who pursue lines of research which border on the areas covered by this study. The first two sections (B and C) relate to our obligation to indicate how the structure which we are dealing with has probably altered. Other sections deal with some suggestions for the estimation and solution of large macro-systems.

Section B - Real Rates of Interest

In chapter six we discussed briefly the distinction between real and nominal rates of interest and indicated that as an empirical matter the relationship between nominal rates of interest and the expected rate of inflation did not appear to be important during the sample period which we studied. In this section we attempt to justify that assertion by reporting some of our empirical investigations of the matter.

We started with the hypothesis that $i=I+g$ where $i$ is the nominal interest rate, $r$ is the "real rate" and $g$ is the expected rate of inflation.

(1) For an excellent survey of the problem and some empirical results for the U.S. see William P. Y ohe and Denis S. Karnosky, "Interest Rates and Price Level Changes, 1952-69", Federal Reserve Bank of St. Louis Review, Dec. 1969. For an analysis of some of the consequences of ignoring price expectations where they are important see, Martin $S$. Feldstein, "Inflation, Specification Bias and the Impact of Interest Rates," Unpublished paper, Harvard University. The latter of these papers was completed before the research underlying this study was done while the former appeared after. 
In our empirical estimates Almon distributed lags on the firat differences of the logs of the consumer price index were used to measure price expectation. The procedure was to fit regressions with various interest rates as dependent variables and distributed lags of varied length and degree together with a constant term as explanatory variables. (2) The grid searched was bounded by sixth degree polynomials and 44 mouth lags and the stability of each of the combinations selected from the grid was tested by fitting them to various sub-period samples. Monthly data were used throughout to enable us to use reasonably long lag distributions.

There is a definite evolutionary trend discernable in the equations.

The best equation for the period 1951-1969 explained only $19 \%$ of the variation in interest rates. (3) For that period a fifth degree almon $1 \mathrm{ag}$ pattern extending 44 months into the past proved superior to other distributions

(2) The long term corporate, the long term government and the conventional mortgage rate were each examined.

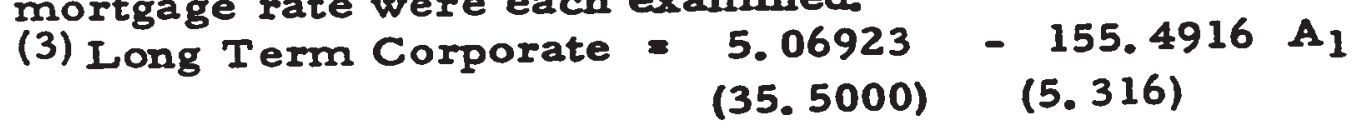

$$
\begin{aligned}
& +882.836 A_{2}-1833.083 A_{3}+1641.476 A_{4}-533.185 A_{5} \\
& \begin{array}{llll}
(4.910) & (4.451) & (4.040) & \text { (3.670) }
\end{array} \\
& \bar{R}^{2}=.191917 \mathrm{Su} / \overline{\mathrm{y}}=13.4438 \quad \text { D. } \mathrm{W} .=.01968
\end{aligned}
$$

The $A_{i}$ are Almon variables where $i$ is the degree. 
involving sixth to first degree polynomials and lag lengths of 12 or 24 months. Advancing the fitting period to 1956-1969 produced a remarkable change in the degree of explanation provided by the equation. In this case a fourth degree polynomial again fitted for a forty-four month lag proved superior to others tried. (4) The percentage of the variation in this sub-period explained by the equation was four times greater than that provided for the 1951-1969 sub-period.

The most recent sub-period tried - 1963-1969 - yielded astonishing results in terms of the degree of explanation provided. A sixth degree polynomial lag distribution extending over 44 months explained $96 \%$ of the variation in the long term corporate rate. (5)

The preceding results indicate a definite evolution of the degree to which expected price movements tend to be reflected in nominal interest rates.
(4) Long Term Corporate $=\begin{gathered}3.666 \\ (46.340)\end{gathered}+\begin{aligned} & 16.721 A_{1} \\ & (11.310)\end{aligned}$
$-51.9859 A_{2}+60.340 A_{3}-23.6756 A_{4}$
(9.221)
(8. 311$)$
(7.690)

$$
\overline{\mathrm{R}}^{2}=.86785 \quad \mathrm{Su} / \overline{\mathrm{y}}=6.942
$$
D. W. $=.10278$
(5) Long Term Corporate $=3.38919+15.568 \mathrm{~A}_{1}-97.6094 \mathrm{~A}_{2}$ (33. $323 \quad$ (3.389) (2.805) $+318.830 A_{3}-517.732 A_{4}+403.3947 A_{5}$ (3. 118) (3. 278) (2. 935$)$
$-120.8845 A_{6}$
(3. 415$)$

$$
\bar{R}^{2}=.96767 \quad S u / y_{y}=3.1079 \quad \text { D. W. }=.2926
$$


The results thus far considered do not, however, give a very good indication of how rapidly the structure which generated the results is changing. In order to get an idea of this structural movement in more recent times, we ran the same regressions over the two. sub-periods 1958-1969 and 1958-1966. The purpose of dropping the three year period 1966- 1969 was to see how radically the structure may have changed in the period outside our sample.

Comparing the results for the two sub-periods makes it quite clear that the inflationary experience of the sixties is becoming an increasingly important factor in peoples' behaviour toward financial assets and that the evolution of financial sophistication suggested by the results has accelerated in more recent times. (6) All of the results taken together suggest that although the expected rate of inflation may not have been accounted for in nominal rates over much of our sample period it certainly is being reflected in current interest rate movements. This observation leads us to suggest that current research should reflect

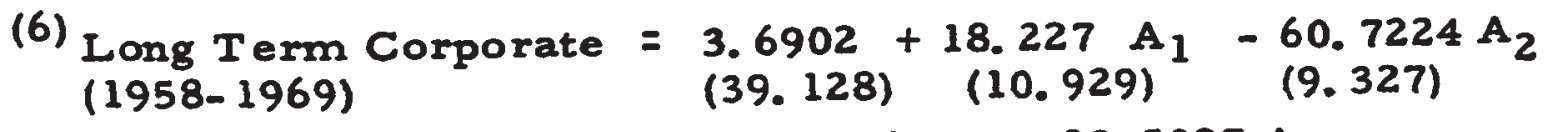

$$
\begin{aligned}
& +73.3946 \mathrm{~A}_{3}-29.5097 \mathrm{~A}_{4} \\
& \text { (8. 5885) (8.041) } \\
& \bar{R}^{2}=.8634 \quad S u / \bar{y}=6.8385 \quad \text { D. } w .=.10453 \\
& \text { Long Term Corporate }=4.76074+12.382 \mathrm{~A}_{1}-44.424 \mathrm{~A}_{2} \\
& (1958-1966) \\
& \text { (46.067) (9.605) } \\
& +54.586 \mathrm{~A}_{3}-21.947 \mathrm{~A}_{4} \\
& \text { (8.530) (7.967) } \\
& \bar{R}^{2}=.5665 \quad \mathrm{Su} / \bar{y}=5.143 \quad \text { D. W. }=.16995
\end{aligned}
$$


the importance of inflationary expectations as a determinant of recent and future economic behaviour. In particular, models currently being constructed should attempt to explicitly encorporate the decline in the strength of money illusion which apparently is occuring. (7) In view of the fact that it is a structural evolution that we are talking about, adequate treatment of it will not be easy. On the other hand, as the above mentioned paper by Feldstein shows, failure to come to grips with the problem where it exists can result in meaningless structural estimates. Section C - Prices and the Money Supply

The preceding section has attempted to show that although inflationary expectations were not of significant importance during the sample period used in the construction of our model this fails to be true in the more recent past. This seeming evolution of economic behaviour suggests a further area of empirical research which is crucial to the understanding of future long term monetary behaviour. That is, the relationship between the growth rate of the money supply and prices.

In our model, changes in the growth rate of the money supply elicited a decrease in the average level of interest rates. This result

(7) In addition to the evidence reported here on the existence of money illusion over our sample period, there is corroborating evidence for a similar sample period on U.S. data. A recent report by William Bronson and Alvin Klevorick presented results that supported the hypothesis that there was "a significant degree of money illusion.. . " over the period 1955-1965. See their paper, "Money Illusion and the Aggregate Consumption Function," American Economic Review, Vol. LIX, Dec., 1969, pp. 832849. 
is in large part attributable to the negligible effect which the money supply has on the absolute price level. A price equation which gave substantial weight to the money supply would probably not produce this result. The net effect in the long run of an increase in the rate of monetary expansion could thus be a rise in interest rates. As was indicated in chapter five, an equation which attempted to reflect this dependence of prices on the money supply was not compatible with the rest of the model in simulation. The failure of this equation to work may reflect the weakness of the linkage or its literal non-existence over our sample period. (8) Whatever, the results on nominal interest rates suggest that structural evolution is occuring at a rapid rate and that because of this the relationship between financial assets and the price level of output that we observed during the last two decades may not be at all indicative of current and future behaviour. In view of these on-going developments and because of the crucial role which they play in the transmission of and the ultimate impact of policy much work needs to be done on the relationship between the money supply and the price level Having determined this linkage and the previously mentioned one between prices and nominal interest rates the profession will be in a much better position to cope with the problems of prescribing policy in an inflationary

(8) In a paper soon to be published in the Journal of Money Credit and Banking, Edward Gramlich demonstrates that the U.S. data also yield the money supply acquires the wrong sign. 
environment. (9)

Section D - Eetimation Procedures

Chapter five dealt with the structural dynamics of the model. As such its principal function was to indicate the equations which preliminary simulations showed to be undependable or unsuitable because of their dynamic properties. That 'cut and try' procedure was necessitated by the fact that there is no eimple way to determine how a given equation will function when it is inserted into a dynamic system. This is due in part to the variance properties of the other endogenous variables in the system and in part to the structural properties of other equations. Limited information fitting procedures attempt to account for the first source of difficulty while full-information estimation methods attempt to take account of both. The purpose of this section is to outline a

(9) We should indicate that it is our belief that the solutions to these problems are not to be found in the use of quasi-reduced forms or simple, highly aggregative models. This is so because both of these methods beg the central question of how the pricing mechanism works and consequently neither can distinguish between various forms of inflationary processes. It is easy to suppose, for example, that the degree of imperfection in the price formation process effectively isolates it from market forces in that sort of environment the relationship between prices and the money supply becomes an academic curiosum. A simple model applied to the data generated by that sort of system would not be capable of discriminating between associative and causal behaviour however and would generate what, from a structural point of view, would be nonsense. Unfortunately, because reduced form equations are promiscuous in this sense and often yield credible results because of the nature of the data employed they have come into wide use in the profession. This is to be regarded, in every sense, as a retrograde movement in the field of empirical research. 
procedure which utilizes only simple limited information estimation procedures directly but which has the properties of full information methods. (10)

The first step in the procedure is to obtain consistent two stage estimates of all structural parameters "zsing either a small number of principal components for the whole exogenous set or a fow of the leading structurally ordered exogenous variables in the manner suggested by Fisher. (11) The choice of variables for the first stage at this point is not crucial since the object is only to acquire consistent estimates. Care should be taken to acquire estimates which are not highly inefficient, however, since the procedure does require a fairly accurate 'first guess'. (12) The second step in the procedure is to solve the model successively for the endogenous variables over the entire fitting period using the values of the lagged endogenous variables which the system

(10) I first outlined this procedure some time ago in conversation with A. Blomqvist. Subsequently I was informed that D. Jorgensen had already suggested a less general procedure while L. R. Klein has developed both in, An Essay on the Theory of Economic Prediction, Sanomaprint, Helsinki, 1968.

(11) Franklin Fisher, Dynamic Structure and Estimation in Economy-wide Econometric Models, chapter 15 in, The Brookings Quarterly Econometric Model of the United States; J.S. Duesenberry et. alia,, editors, Rand McNally, Chicago, 1965.

(12) The use of highly inefficient first estimates may lead to a nonconvergent sequence or one which converges very slowly. 
generates. These solution values provide a further wighted combination of the cogenous variables to be used as inotruments in the second stage of the leat squares procedure. The advantage of uning these variables as instrumente is that they are generated by using all of the dynamic structure of the model as well as the variance properties of the exogenous variables.

This process is iterated until the inotrumento generated in succeseive eolutions are the same.

The method has great intuitive appeal in that the etructural estimates which eventually evolve are directly determined by the exogenous variables in the oy atem, the models dynamic properties and the initial conditions. The method has the unfortunate property that weak variables which we may for a priori reasons want to retain are eliminated in the mechanics of the procedure. The method does however, have the appeal of simplicity and cheapness. (13)

The algorithm which we have just outlined only applies if all equations in the oy otem have the same aample period. A computer program which provides full-information eatimates of a system conforming to that requirement is currently being developed by the author for use on an intermediate-eize monthly model of the Canadian financial sector.

(13) Cheapness is a relative thing. This method is cheap in comparison with other full-information methods. It is, of conrse, much more expensive than iordinary two stage least squares. 
Section E - Solution Aids

The purpose of this section is to outline some suggestions for dealing with the solution of a system of equations where resource allocation is a problem. The ideas contained in this section are less useful for researchers having access to large simulation packages than for those who don't. We have included it in the hope that it might save some resources for someone who undertakes a project of this sort singlehandedly.

As was indicated earlier, the Gauss -Seidel method is very sensitive to normalization and ordering. The optimal situation for the method is for the upper triangular partition in the matrix of the partial derivatives of the system to be empty. In that case the system is perfectly recursive and the ordering sequence is trivial. In systems that are interdependent the object is to normalize and order in such a way as to closely approximate recursivity. That is to say, to make the lower triangular elements dominant.

In the case where all variables are dimensioned the same, the partial derivative matrix of the system is a good guide to the order in which the equations should be solved and indicates where re-normalization is likely to be required. There is a constraint on this procedure, however, when variables are not all dimensioned the same. For example, the ordering procedure may suggest that a given demand equation be normalized on quantity. While this ordering way be optimal from a single period 
solution point of view it may be the case that for certain values of the variables the system will not converge. This difficulty rises from the fact that the partial derivates are derived from an estimation procedure which is not invariant with respect to the dimensionality of the va riables. This problem can usually be overcome in stable systems by weighting the partial derivatives with the ratio of the variances of the dependent and independent variables. This adjustment corrects the derivative for relative variation and hence makes it a better measure of dominance. The use of these weighted partial derivates as a guide should greatly reduce the time required to obtain a convergent sequence and would also indicate how sensitive that sequence is to structural changes which one might like to make after the solution order has been obtained. In addition, it gives one some idea as to how sensitive the system will be to changes in the initial conditions. 